\title{
SIMPLIFIED APPROACH OF SEISMIC ANALYSIS USING A PLANAR LINEAR ELASTIC MODEL FOR AN OFFICE BUILDING WITH NO REGULARITY IN PLAN IN COMPARISON TO A SPATIAL MODEL ACCORDING TO FINITE ELEMENT SOFTWARE
}

by

Timo Schlenker

B.Eng. Karlsruhe University of Applied Sciences, Karlsruhe, Germany, 2017

\author{
A Major Research Project \\ presented to Ryerson University \\ and \\ Karlsruhe University of Applied Sciences \\ in partial fulfillment of the \\ requirements for the degree of \\ Master of Engineering \\ in the program of \\ Civil Engineering
}

Karlsruhe, Germany, 2020

(C) Timo Schlenker, 2020 


\section{AUTHOR'S DECLARATION}

I hereby declare that I am the sole author of this MRP. This is a true copy of the MRP, including any required final revisions.

I authorize Ryerson University and Karlsruhe University of Applied Sciences to lend this MRP to other institutions or individuals for the purpose of scholarly research.

I further authorize Ryerson University and Karlsruhe University of Applied Sciences to reproduce this MRP by photocopying or by other means, in total or in part, at the request of other institutions or individuals for the purpose of scholarly research.

I understand that my MRP may be made electronically available to the public. 


\title{
ABSTRACT
}

SIMPLIFIED APPROACH OF SEISMIC ANALYSIS USING A PLANAR LINEAR ELASTIC MODEL FOR AN OFFICE BUILDING WITH NO REGULARITY IN PLAN IN COMPARISON TO A SPATIAL MODEL ACCORDING TO FINITE ELEMENT SOFTWARE

\author{
by \\ Timo Schlenker \\ Department of Civil Engineering \\ Ryerson University and Karlsruhe University of Applied Sciences \\ Master of Engineering, 2020
}

This master's project introduces a simplified approach to calculate the earthquake resistance of a four-storey office building. Therefore, the moment distribution of each bracing wall according to the approach will be compared to the moment distribution according to the earthquake resistance calculation of a finite element software. Both, the simplified approach and the calculation using a spatial model will be introduced and performed. The comparison then will be investigated to explain the differences and why the approach can not be considered to be a conservative simplification to calculate the investigated building for earthquake resistance.

Furthermore, this masters project is based on the 2018 German National Annex of Eurocode 8 and compares it to the predecessor version of 2011. 


\section{TABLE OF CONTENTS}

Author's Declaration ...........................................................................................................ii

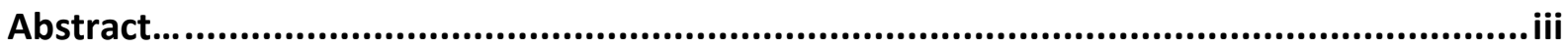

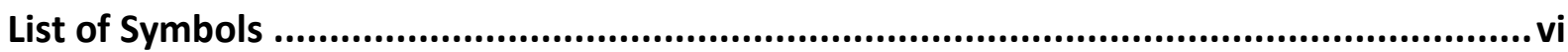

List of Tables ................................................................................................................ viii

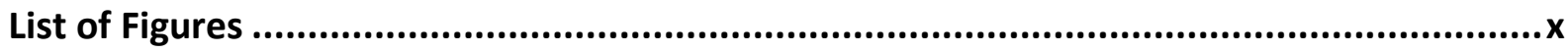

List of Appendices ........................................................................................ xii

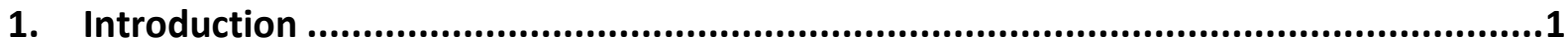

1.1 Introduction of investigated building ................................................................ 1

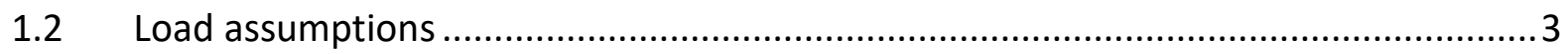

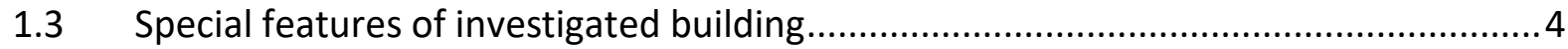

1.4 Eurocode 8: design of structures for earthquake resistance ...............................6

1.4.1 Introduction of the concept of the National Annex....................................

1.4.2 Comparison between the concept of the NA and the current NA ..................10

2. simplified Approach for earthquake resistance ...............................................15

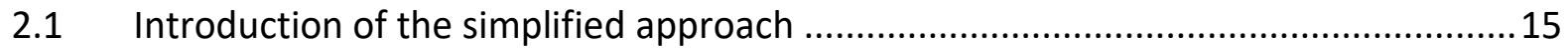

2.2 Horizontal forces according to the concept of the NA ........................................ 16

2.3 Distribution of the horizontal forces on the bracing walls .....................................22

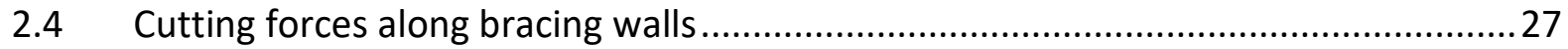

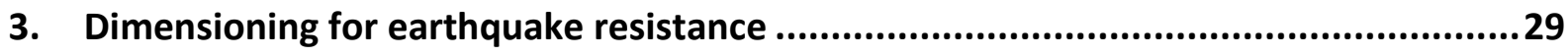

3.1 Background information of fenite element model ..............................................29

3.2 Introduction of finite element software RFEM5 …........................................... 30 
3.3 Creating spatial model of investigated building ............................................... 30

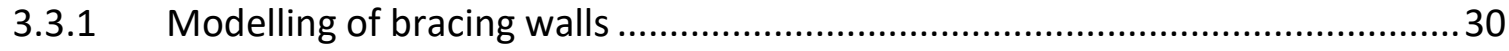

3.3.2 Determination of required vertical reinforcement.......................................33

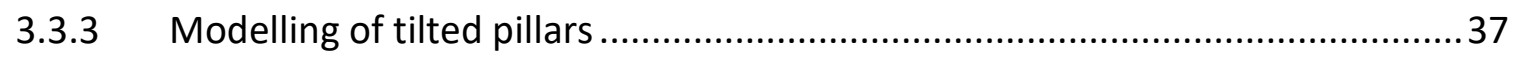

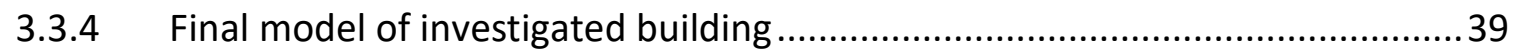

S.4 Seismic analysis of investigated building ..................................................... 40

3.5 Resulting moment distribution on bracing walls........................................... 43

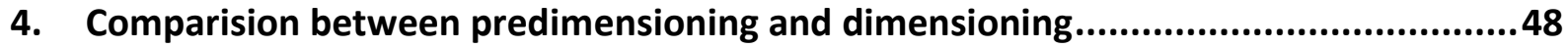

4.1 Comparision of moment distirbution along bracing walls ................................... 48

4.2 distribution of a horizontal force on bracing elements on spatial model.................52

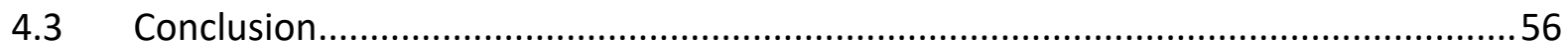

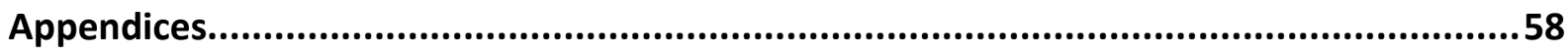

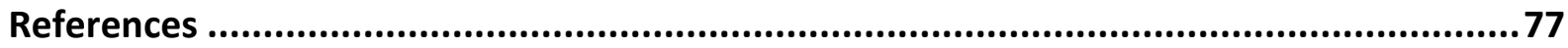




\section{LIST OF SYMBOLS}

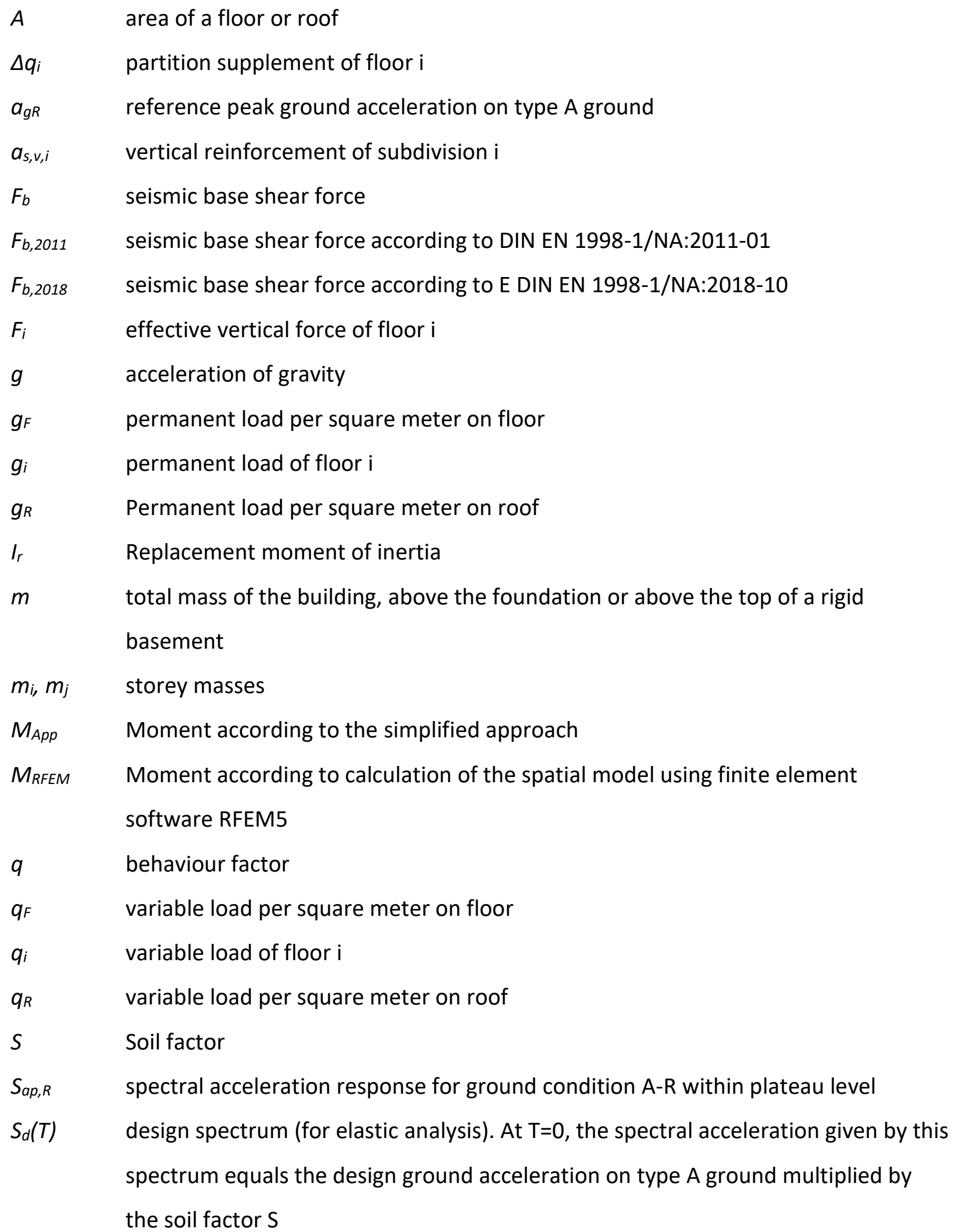


$S_{d, 2011}(T)$ design spectrum (for elastic analysis) according to DIN EN 1998-1/NA:2011-01. At $\mathrm{T}=0$, the spectral acceleration given by this spectrum equals the design ground acceleration on type A ground multiplied by the soil factor $\mathrm{S}$

$S_{d, 2018}(T)$ design spectrum (for elastic analysis) according to E DIN EN 1998-1/NA:2018-10. At $\mathrm{T}=0$, the spectral acceleration given by this spectrum equals the design ground acceleration on type A ground multiplied by the soil factor $S$

$T \quad$ vibration period of linear single degree of freedom system

TBE Technical Building Equipment

$T_{N C R} \quad$ reference return period of the reference seismic action for the no-collapse requirement

$\checkmark \quad$ Shear force

$w_{b} \quad$ bending deformation

$w_{s} \quad$ Shear deformation

$w_{\text {tot }} \quad$ total deformation

$z_{i}, z_{j} \quad$ height of masses $m_{i}, m_{j}$ above the level of application of seismic action (foundation or top of rigid basement)

$\gamma_{1} \quad$ importance factor

$\lambda$ correction factor, the value of which is equal to $\lambda=0,85$ if $\mathrm{T} \leq 2 \mathrm{TC}$ and the building has more than two storeys, or $\lambda=1,0$ otherwise.

$\psi_{2, i} \quad$ combination coefficient for the quasi-permanent value of a variable action $\mathrm{i}$ $\psi_{E, i} \quad$ combination coefficient for a variable action $\mathrm{i}$, to be used when determining the effects of the design seismic action 


\section{LIST OF TABLES}

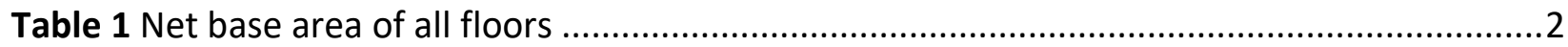

Table 2 Floor heights, permanent and variable loads of the investigated building ......................3

Table 3 List of valid Eurocode 8 parts (Beuth Verlag $\mathrm{GmbH}, 2019)$..........................................6

Table 4 Underground conditions according to the concept of the NA table NA.3...................... 7

Table 5 Soil factor $\mathrm{S}$ according to the concept of the NA table NA.4 ........................................8

Table 6 Importance classes and factors for buildings according to the concept of the NA table NA.7

Table 7 Control periods to describe elastic horizontal response spectrum according to the concept of NA

Table 8 Combination coefficients for service loads according to the concept of NA table

NA.6.

Table 9 Design spectrum at plateau level according to current NA formula NA.11 and concept of NA figure NA.2 and $\mathrm{NCl}$ 3.2.2.5 (3)P

Table 10 Parameters to determine design spectrum according to current NA and concept of NA

Table 11 Determined design spectrum according to current NA and concept of NA.....

Table 12 Calculation of effective masses using simplified loads and building characteristics......12

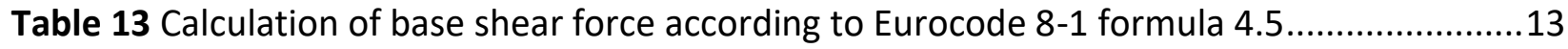

Table 14 Equating design spectrum of current NA and concept of NA ...................................14

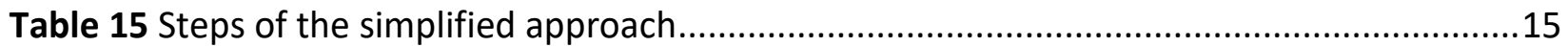

Table 16 building characteristcs and loads to determine effective masses .............................16

Table 17 Parameters to determine effective masses .......................................................16

Table 18 Effective vertical forces of each floor..............................................................17

Table 19 Extract of table 7 to show control periods...........................................................18

Table 20 Distribution of horizontal seismic forces at all floors ...........................................21

Table 21 Investigation of the effect of bending and shear deformation on three investigated walls $A, B$ and $C$ 
Table 22 Summary of appendix $L$ and $M$ : Moment of inertia and replacement moment of inertia for each floor

Table 23 Calculation of required moment of inertia of one tilted pillar .................................25

Table 24 Total moment of inertia of tilted pillars in each floor ..................................................26

Table 25 Distribution of a horizontal force on bracing elements on each floor.........................26

Table 26 Shear force distribution along bracing walls.........................................................2

Table 27 Moment distribution along bracing walls ...........................................................28

Table 28 Calculation of $L^{*}$ for example of vertical reinforcement ........................................36

Table 29 Required vertical reinforcement for Wall A and Wall B of example for vertical

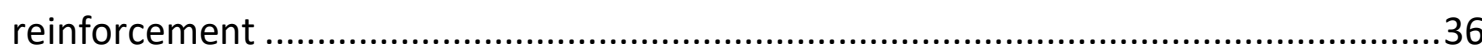

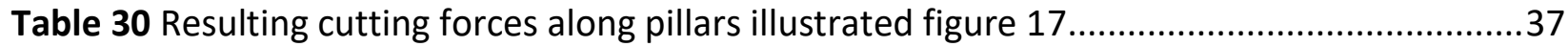

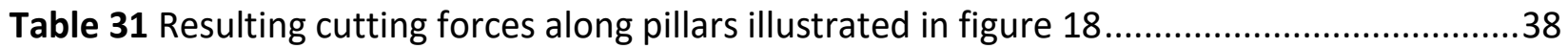

Table 32 Total masses and vertical forces for mass cases of investigated building ....................40

Table 33 Period, acceleration and effective modal mass factor for each mode shape

Table 34 Maximum shear force distribution of each bracing wall according to Appendices $S$ and $\mathrm{T}$

Table 35 Maximum moment distribution of each bracing wall according to Appendices $U$ and $\mathrm{V}$

Table 36 Moment distribution along each bracing wall according to the approach of predimension (same as table 27)

Table 37 Moment distribution along each bracing wall using a spatial model (same as table 33)

Table 38 Comparison factors of approach to actual calculation for earthquake resistance .49

Table 39 Differences between approach and dimensioning calculation.... .50

Table 40 Difference of the moments per $m$ wall length .51

Table 41 Comparison of absorption of a horizontal force of each bracing element of spatial model and approach .53

Table 42 Comparison of spatial model and approach for wall 102 .54 


\section{LIST OF FIGURES}

Figure 1 Illustration of the investigated building and the parking lot .....................................

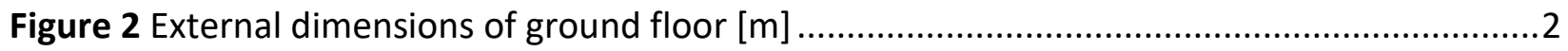

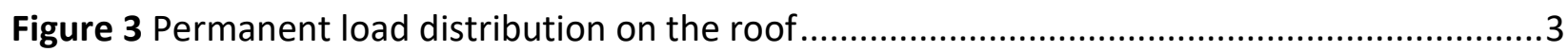

Figure 4 Cut A-A (Appendix J) to illustrate the $X$ shape of the tilted pillars and lowered section

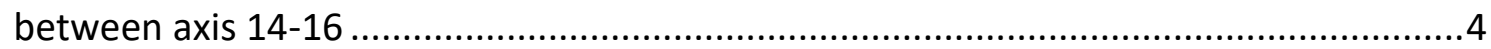

Figure 5 Extract of Appendix $\mathrm{K}$ to illustrate the bracing walls and their designation ....................5

Figure 6 Form and description of the elastic acceleration response spectrum according to the concept of NA figure NA.2

Figure 7 Illustration of the elastic response design spectrum of the investigated building.........19

Figure 8 MDOF System to illustrate horizontal seismic forces .............................................21

Figure 9 Geometrical designations and static system for wall A, B and C ..............................22

Figure 10 Horizontal deformation of tilted pillars due to horizontal force ...............................25

Figure 11 MDOF system, shear and moment distribution of wall 102 ..................................27

Figure 12 Illustration of a wall modelled by a surface (left) and member (right) .......................31

Figure 13 Model for investigation of absorption behaviour of investigated walls.......................32

Figure 14 Static system for conversion of moment into stress distribution .............................33

Figure 15 Static system and shear distribution due to vertical and earthquake loading .............34

Figure 16 Subdivisions to determine the required vertical reinforcement ..............................35

Figure 17 Static system for tilted pillars suspended to a vertical force modelled as a beam

(left) and as a truss (right)

Figure 18 Static system for tilted pillars suspended to a horizontal force modelled as a beam

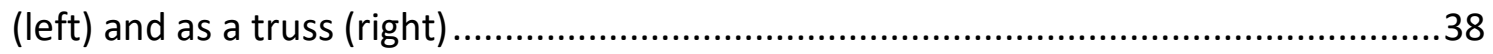

Figure 19 Illustration of RFEM5 model of the investigated building ......................................39

Figure 20 Shear distribution along wall 102 according to RFEM5 ........................................44

Figure 21 Moment distribution along wall 102 according to RFEM5 …................................44

Figure 22 Moment distribution according to horizontal forces of figure 20 .............................45

Figure 23 Deformed spatial model due to $E_{E d x}$ " + " 0,30 $E_{E d y}$................................................47

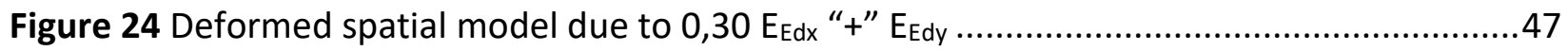


Figure 25 Illustration of spatial model of ground floor suspended to a single load of $1.000 \mathrm{kN}$..52

Figure 26 Shear distribution according to a horizontal force of $1.000 \mathrm{kN}$ in each floor of spatial

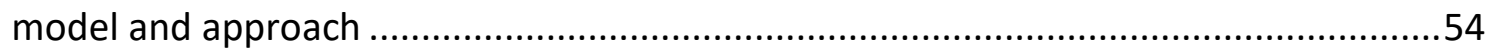

Figure 27 Comparison of shear distribution along wall 102 ....................................................55 


\section{LIST OF APPENDICES}

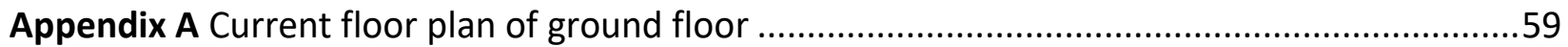

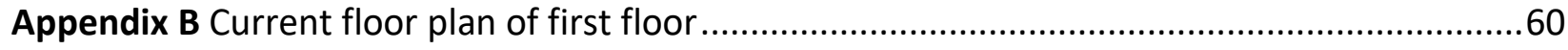

Appendix C Current floor plan of second floor .....................................................................61

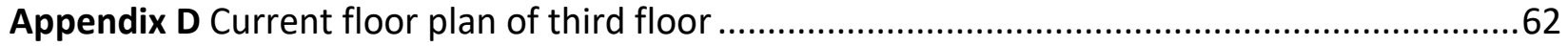

Appendix E Floor plan of ground floor including all openings $[\mathrm{m}]$......................................63

Appendix F Floor plan of first floor including all openings $[\mathrm{m}]$............................................64

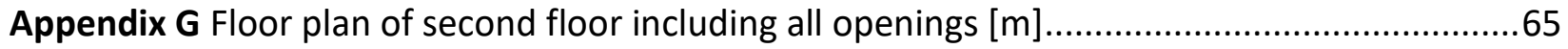

Appendix $\mathbf{H}$ Floor plan of third floor including all openings $[\mathrm{m}]$.........................................66

Appendix I Floor plan of rooftop including all openings [m] ............................................67

Appendix J Visualisation of all Axis and Cuts in investigated building ...................................68

Appendix K Illustration of Cores and distribution of embracing walls ...................................69

Appendix L Calculation of the replacement moment of inertia for bracing walls on ground floor

Appendix M Calculation of the replacement moment of inertia for bracing walls on upper floors

Appendix $\mathbf{N}$ Distribution of a horizontal force on bracing elements on ground floor .72

Appendix $\mathbf{O}$ Distribution of a horizontal force on bracing elements on first floor .72

Appendix P Distribution of a horizontal force on bracing elements on second floor..... .73

Appendix Q Distribution of a horizontal force on bracing elements on third floor .73

Appendix $\mathbf{R}$ Values of the elastic design response spectrum of figure 7 .74

Appendix S Shear force distribution along each bracing wall for combination $100 \% \mathrm{X}$ and $30 \% \mathrm{Y}$

Appendix T Shear force distribution along each bracing wall for combination $30 \% \mathrm{X}$ and $100 \% \mathrm{Y}$

Appendix U Moment distribution along each bracing wall for combination $100 \% \mathrm{X}$ and $30 \% \mathrm{Y}$...76 Appendix V Moment distribution along each bracing wall for combination $30 \% \mathrm{X}$ and $100 \% \mathrm{Y}$...76 


\section{INTRODUCTION}

\subsection{INTRODUCTION OF INVESTIGATED BUILDING}

The building which will be examined in the course of this master's project is a four-storey office building which is connected to a parking lot and next to an existing building as illustrated in figure 1. However, only the office building will be examined throughout this project. The building is located in 77815 Buehl, Germany, close to the French-German border.

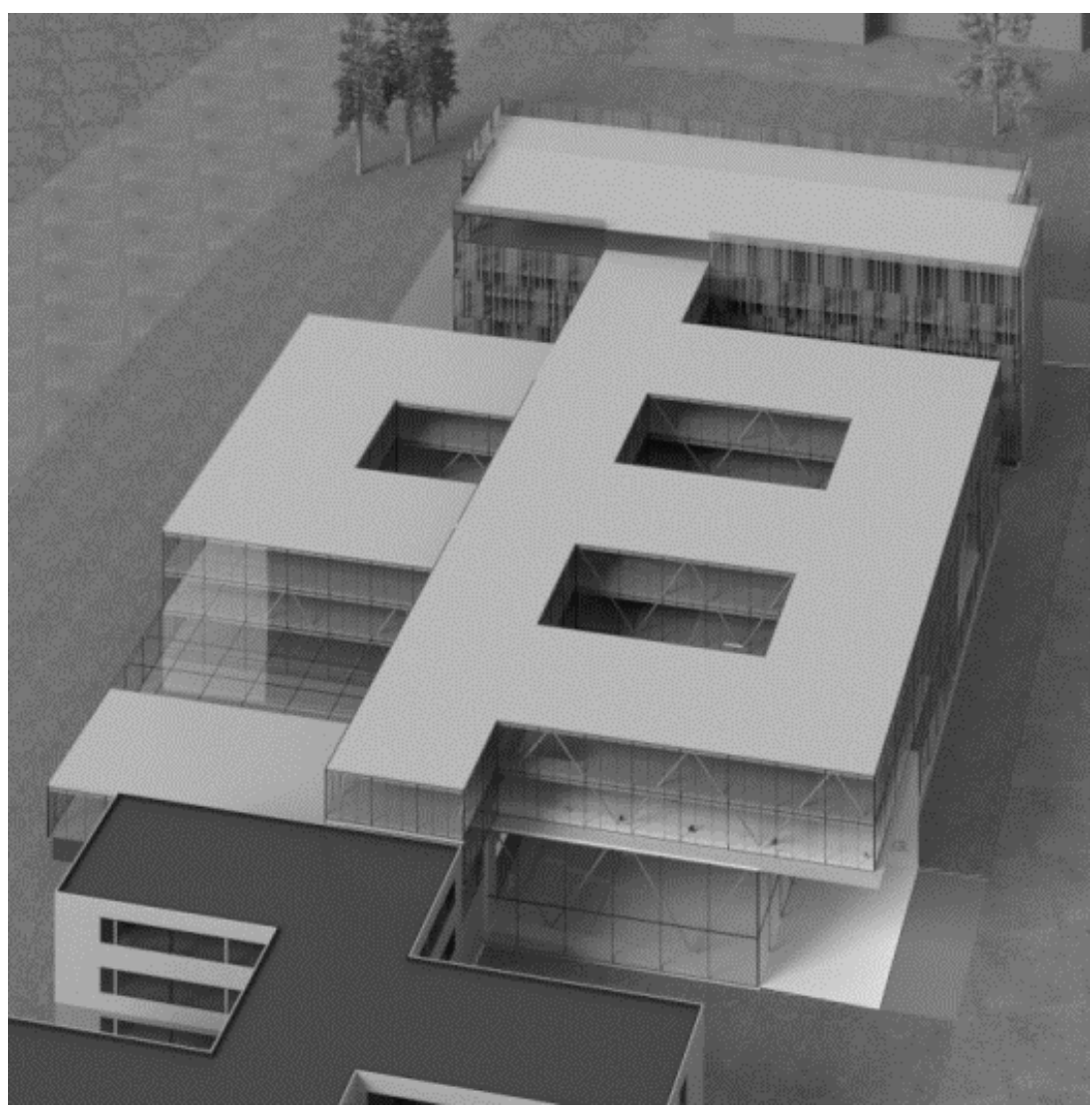

Figure 1 Illustration of the investigated building and the parking lot

The current plan of the building envisages four floors, but not every floor is planned to have the same floor layout. The ground floor, for example, will have a section on which no other floor will be built for the time the building is being constructed. However, the owning company intends to keep their options open by designing the building in such a way that they could add structure afterwards in order to have the same external dimensions for each of the floors. Therefore, the design of the building for earthquake resistance, upon which this project is based, is not 
orientated on the current floor plans (Appendix A-D), but on the option with all floors having the same external dimensions. The external dimensions are illustrated in figure 2 below.

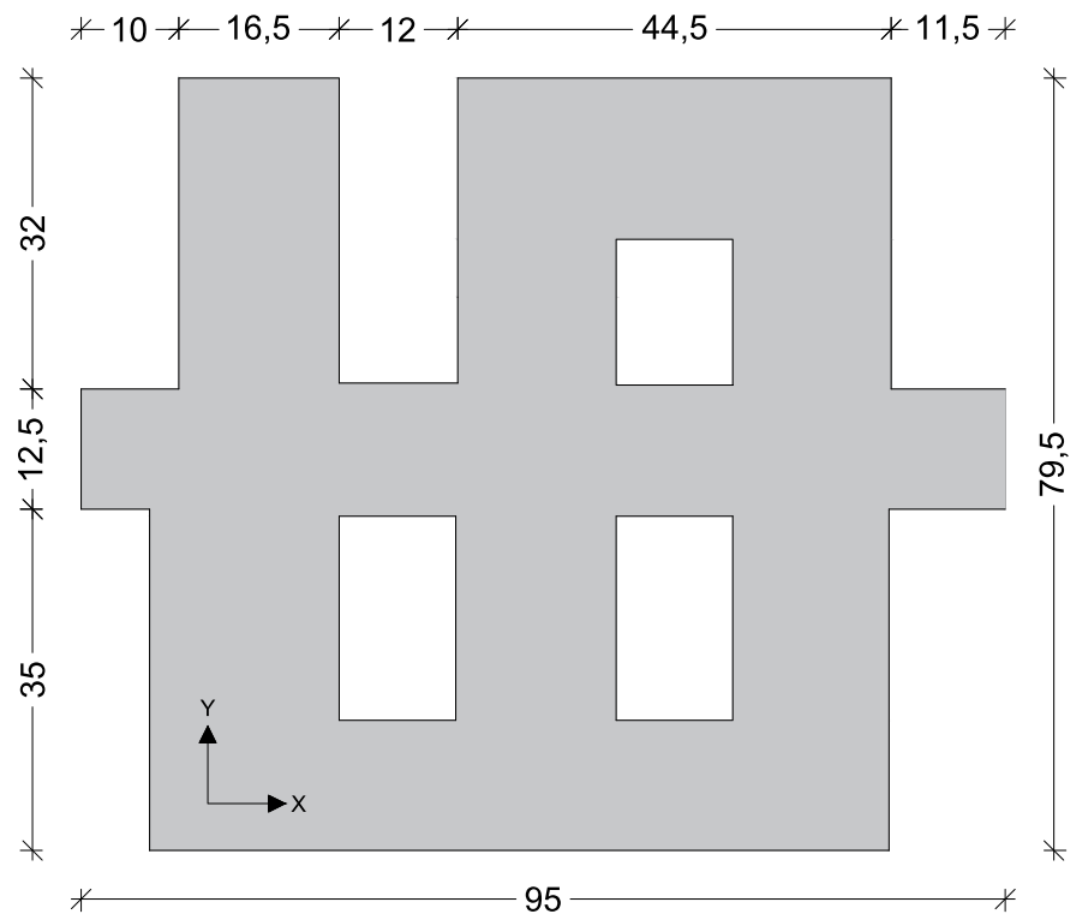

Figure 2 External dimensions of ground floor [m]

In this context, it is relevant to note that not every floor has the same floor plan despite the same external dimensions since every floor has different openings for stairways or technical building equipment. In addition to that, there are various courtyards and patios which reduce the base area of the first, second and third floor compared to the ground floor.

This can be seen in table 1 which depicts the existing net base area of each floor. Appendix E-I shows the floor layout of each floor including all openings for stairways, technical building equipment or elevators.

\begin{tabular}{r|c} 
Floor & Net base area \\
\hline Ground floor & $5.811\left[\mathrm{~m}^{2}\right]$ \\
\hline First floor & $4.672\left[\mathrm{~m}^{2}\right]$ \\
\hline Second floor & $4.557\left[\mathrm{~m}^{2}\right]$ \\
\hline Third floor & $4.724\left[\mathrm{~m}^{2}\right]$ \\
\hline Roof & $4.927\left[\mathrm{~m}^{2}\right]$ \\
\hline
\end{tabular}

Table 1 Net base area of all floors 


\subsection{LOAD ASSUMPTIONS}

The floor heights, permanent loads and variable loads of the investigated building are shown in table 2 below. The dead weight of the structure is not included. However, the partition supplement according to Eurocode (EC) 1-1/National Annex (NA) section 6.3.1.2 needs to be added to the variable load in order to get the total variable load on each floor.

\begin{tabular}{r|cccc} 
Floor & floor height & Permanent load & Variable load & Partition supplement \\
\hline Ground floor & $5,70 \mathrm{~m}$ & $2,00 \mathrm{kN} / \mathrm{m}^{2}$ & $5,00 \mathrm{kN} / \mathrm{m}^{2}$ & - \\
\hline First floor & $4,10 \mathrm{~m}$ & $2,00 \mathrm{kN} / \mathrm{m}^{2}$ & $4,00 \mathrm{kN} / \mathrm{m}^{2}$ & $1,20 \mathrm{kN} / \mathrm{m}^{2}$ \\
\hline Second floor & $4,10 \mathrm{~m}$ & $2,00 \mathrm{kN} / \mathrm{m}^{2}$ & $4,00 \mathrm{kN} / \mathrm{m}^{2}$ & $1,20 \mathrm{kN} / \mathrm{m}^{2}$ \\
\hline Third floor & $4,10 \mathrm{~m}$ & $2,00 \mathrm{kN} / \mathrm{m}^{2}$ & $4,00 \mathrm{kN} / \mathrm{m}^{2}$ & $1,20 \mathrm{kN} / \mathrm{m}^{2}$ \\
\hline Roof & - & $2,00 / 5,00^{1} \mathrm{kN} / \mathrm{m}^{2}$ & $1,00 \mathrm{kN} / \mathrm{m}^{2}$ & - \\
\hline 1 & permanent load in the section of the roof with technical building equipment (see figure 3) & \\
\hline
\end{tabular}

Table 2 Floor heights, permanent and variable loads of the investigated building

All ceilings, including the roof, exist of a $24 \mathrm{~cm}$ thick concrete plate. The permanent load in table 2 is the assumption of the floor construction, including pipes, cables or roof structure. Furthermore, technical building equipment will be installed on a section of the roof leading to $5,00 \mathrm{kN} / \mathrm{m}^{2}$ of permanent load within this section. The variable load of $1,00 \mathrm{kN} / \mathrm{m}^{2}$ on the roof includes snow.

The resulting permanent load distribution on the rooftop is shown in figure 3.

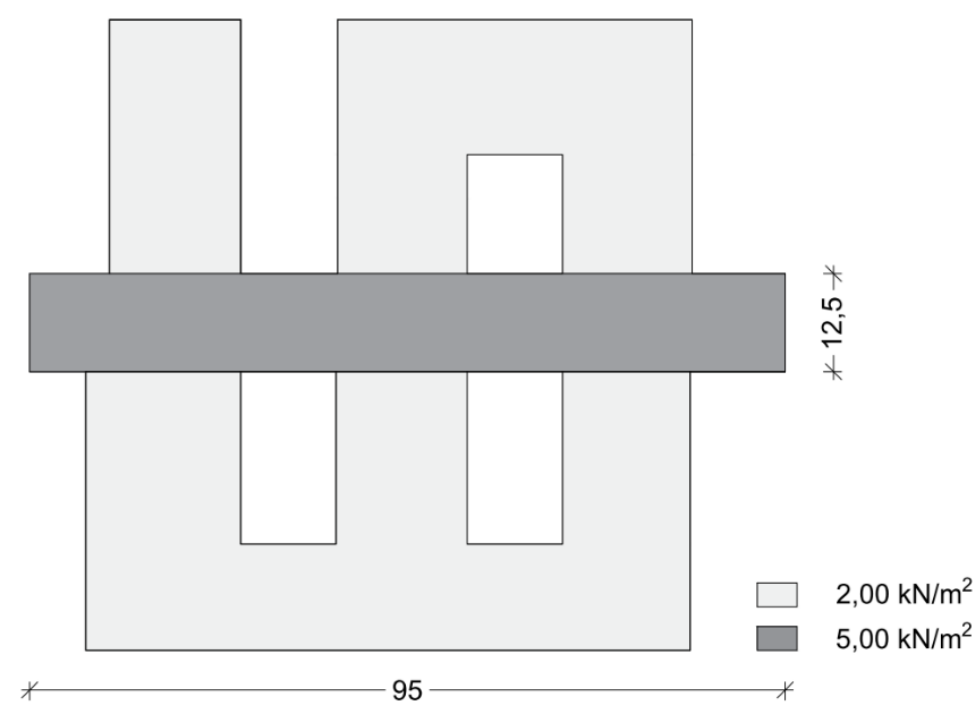

Figure 3 Permanent load distribution on the roof 


\subsection{SPECIAL FEATURES OF INVESTIGATED BUILDING}

The use of tilted pillars by $80^{\circ}$ on ground floor and $77^{\circ}$ on upper floors is a special feature of this building. They are used in almost every section of the facade to create the shape of $X^{\prime}$ s throughout all floors which is illustrated in figure 4 . A characteristic of tilted pillars is that they can absorb horizontal forces. Therefore, they can be used in order to calculate the earthquake resistance.

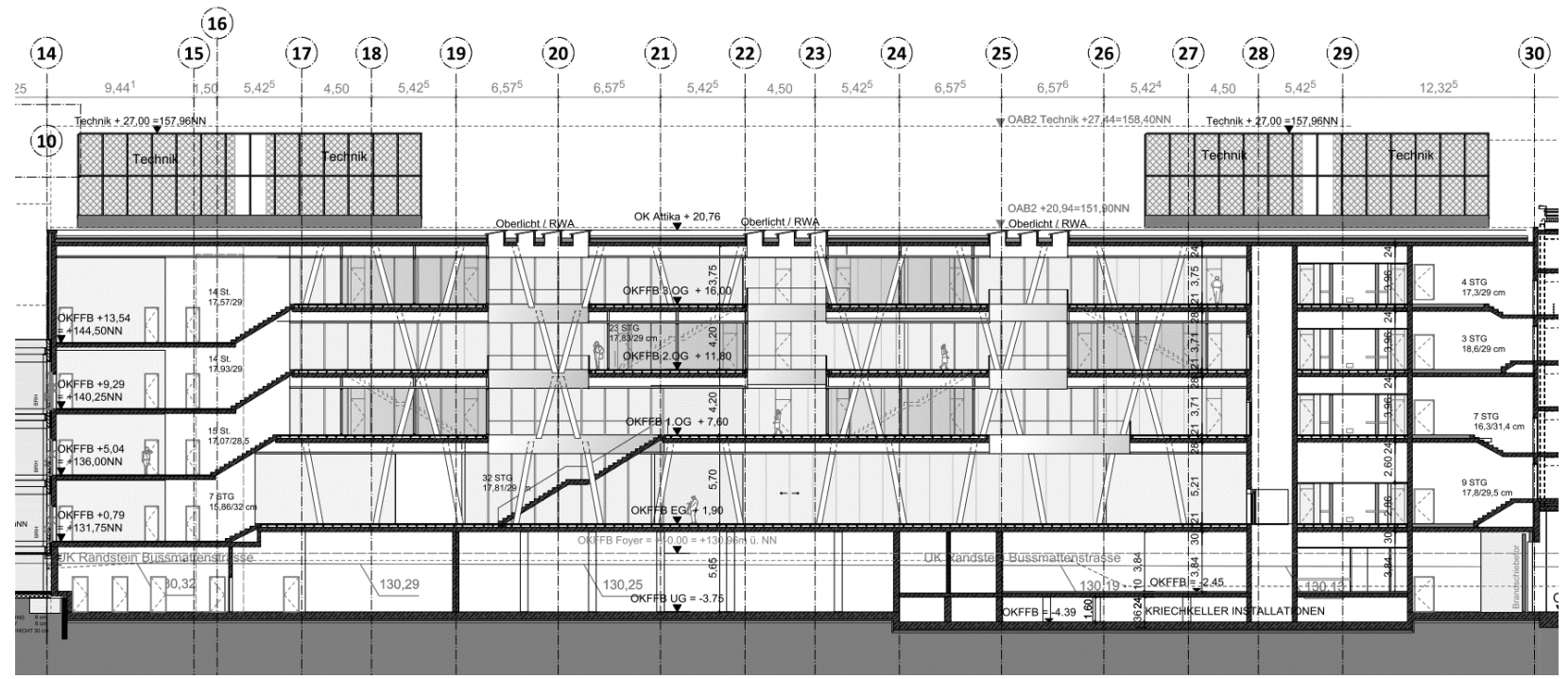

Figure 4 Cut A-A (Appendix J) to illustrate the tilted pillars and lowered section between axis 14-16

Another feature of the tilted pillars is that they do not have a connecting point in the beam between two pillars on top of each other. This results in a pillar being shifted in or against the tilted direction compared to the pillar below or above it. This creates a gap between two pillars on top of each other which leads to vertical forces that need to be transferred into the beam and then into the pillar below. The distance between two pillars is not very long, but due to large vertical forces it results in a moment in the beam.

The resulting moment will not be investigated throughout this master's project. Only the fact that tilted pillars can absorb horizontal forces will be considered.

To calculate the earthquake resistance, the tilted pillars are assumed to absorb horizontal forces of an earthquake. However, the pillars can not be the only bracing element for this building and therefore concrete walls must be taken into account as well. 
Since the investigated building is not planned to have many concrete walls due to the concept of many tilted pillars in sections of the facade, concrete walls are only available in four sections of the building. These areas are called cores and are illustrated in figure 5 .

Within these cores some walls are only build on a certain floor. However, to be used as a bracing wall, the wall needs to be built on every floor to absorb horizontal forces and to transmit the forces into the foundation of the building. Furthermore, it needs to be considered that the bracing walls can absorb horizontal forces from the ceilings. Therefore, the bracing walls can not be fully surrounded by openings used for the technical building equipment or stairways. Moreover, the ceiling must be able to give off the horizontal forces into the walls. This was not the case for some walls in core 1, since the ceiling of all floors between axis 14-16 are lower compared to the rest of the floor as illustrated in figure 4. Therefore, the forces are considered not to be transmitted into this lower area. That's why walls in this area are not regarded to absorb horizontal forces.

The section of the building including all bracing walls and their designation is shown in figure 5 below. Every wall has a three-digit designation which follows two simple rules. The core number determines the first digit of a wall. The two last digits describe the number of the wall within the core. If the last digit is even, it means that the wall is in X-direction, if the digit is uneven, the wall is in Y-direction

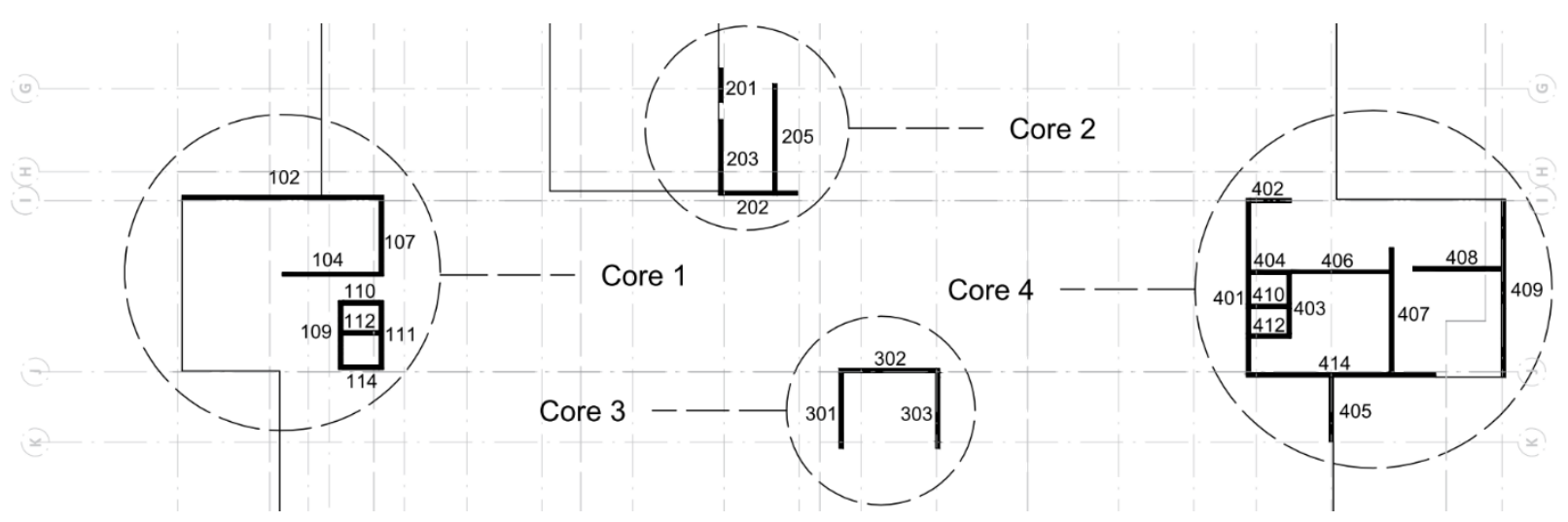

Figure 5 Extract of Appendix $K$ to illustrate the bracing walls and their designation 


\subsection{EUROCODE 8: DESIGN OF STRUCTURES FOR EARTHQUAKE RESISTANCE}

\subsubsection{General information about EC 8}

The European Committee for Standardisation (CEN, French: Comité Européen de Normalisation) is a public organisation that drafts the European Standards (EN) which outline the harmonized technical rules of how structural design should be performed within the European Union. Those European Standards are called Eurocodes (EC). Since March 2010 every European country is required to design public structures according to the Eurocode and replace the national codes which were used before. In addition to the Eurocode every European country is expected to publish a National Annex (NA) which determines national parameters. [6]

In June 2009 the EC 8: "Design of Structures for earthquake resistance" was fully published in German. The National Annex was added in February 2010 which included simplified rules of application for common structural engineering. The current EC 8 consists of six parts, three added National Annex and one modification document $(A)$ which are all listed in table 3 below.

\begin{tabular}{l|llr} 
Eurocode 8 & German designation & Full Name & Published \\
\hline Part 1 & DIN EN 1998-1 & General rules, seismic actions and rules for buildings & $2010-12$ \\
\hline Part 1/NA & DIN EN 1998-1/NA & General rules, seismic actions and rules for buildings & $2011-01$ \\
\hline Part 1/A1 & DIN EN 1998-1/A1 & General rules, seismic actions and rules for buildings & $2013-05$ \\
\hline Part 2 & DIN EN 1998-2 & Bridges & $2011-02$ \\
\hline Part 2/NA & DIN EN 1998-2/NA & Bridges & $2011-03$ \\
\hline Part 3 & DIN EN 1998-3 & Assessment and retrofitting of buildings & $2010-12$ \\
\hline Part 4 & DIN EN 1998-4 & Silos, tanks and pipelines & $2007-01$ \\
\hline Part 5 & DIN EN 1998-5 & Foundations, retaining structures and geotechnical aspects & $2010-12$ \\
\hline Part 5/NA & DIN EN 1998-5/NA & Foundations, retaining structures and geotechnical aspects & $2011-07$ \\
\hline Part 6 & DIN EN 1998-6 & Towers, masts and chimneys & $2006-03$ \\
\hline
\end{tabular}

Table 3 List of valid Eurocode 8 parts (Beuth Verlag GmbH, 2019)

\subsubsection{Introduction of the concept of the National Annex}

In October 2018 a new concept for the NA of EC 8-1 was published. The German designation for the concept is E DIN EN 1998-1/NA:2018-10, which is not an official standard yet, but considered 
to be a valid pre-standard or concept [2]. This concept brought some major changes in designing a structure for earthquake resistance.

Within this chapter, a few sections and innovations of the new concept for the NA will be introduced. Sections that do not influence the simplified approach or the dimensioning calculation will be neglected since these sections do not affect the content of this master's project.

In general, the response of structures to an earthquake mostly depends on the ground conditions. Therefore, EC 8 uses seven ground types, but only three of them are included in the German NA. These three are labeled ground type A (rock or rocklike geological formation), ground type B (deposits of very dense sand, gravel or very stiff clay) and ground type C (deep deposits of dense or medium-dense sand, gravel or stiff clay). However, the German National Annex also contains three types of geological underground classes: R (solid rock), $\mathrm{T}$ (flat sedimentary basins and transition zones) and S (deep sedimentary basins). For any further calculations, the NA uses seven underground conditions which are a combination of the ground types and the underground classes as illustrated in table 4 below.

\begin{tabular}{l|lllllll}
\hline Underground conditions & A-R & B-R & C-R & B-T & C-T & B-S & C-S \\
\hline Table &
\end{tabular}

Table 4 Underground conditions according to the concept of the NA table NA.3

The first part of EC 8 is typically used to get the elastic response spectrum of a structure resulting from an earthquake. To get this response spectrum a new map was implemented in the concept of the German NA to illustrate the distribution of the spectral acceleration response for the ground condition $A-R$ within the plateau area $S_{a p, R}$ for a reference return period of $T_{N C R}=475$ years. Since $S_{a p, R}$ depends on the precise location of the structure, the possibility to get the value of $\mathrm{S}_{\mathrm{ap}, \mathrm{R}}$ online using a digital map [4] has been provided.

Another renewal in the concept of the German NA of EC 8 is the connection of the spectral acceleration response $S_{a p, R}$ to the reference peak ground acceleration $a_{g R}$ and the soil factor $S$. The reference peak ground acceleration $\mathrm{agR}_{\mathrm{g}}$ only depends on the spectral acceleration response $\mathrm{S}_{\mathrm{ap}, \mathrm{R}}$ and therefore has a linear relationship according to the concept of the NA formula NA.1 which is shown below. 


$$
a_{g R}=\frac{s_{a p, R}}{2,5}
$$

The soil factor S, however, depends on the underground condition but also on the spectral acceleration response $S_{a p, R}$. This relation is shown in table 5 .

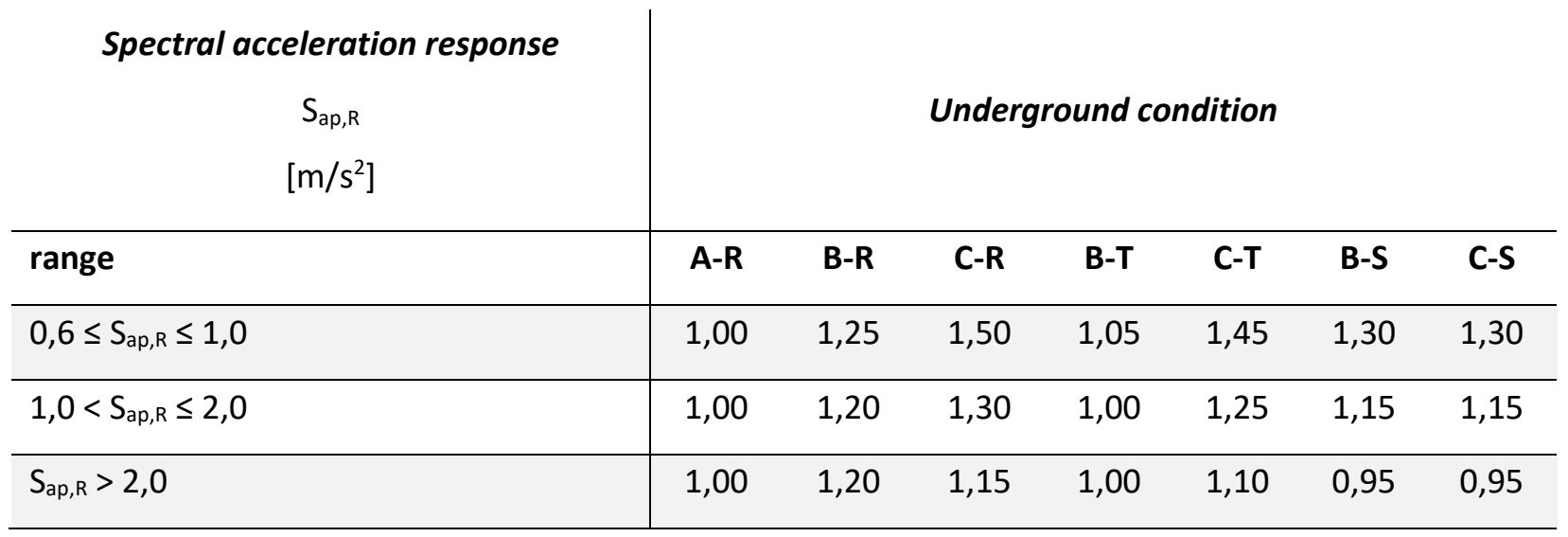

Table 5 Soil factor S according to the concept of the NA table NA.4

To get the elastic horizontal response spectrum, all three parameters, spectral acceleration response $S_{a p, R}$, reference peak ground acceleration $a_{g R}$ and soil factor $S$ are needed.

Another parameter that influences the spectral acceleration, is the importance class and therefore the importance factor $\gamma_{1}$. EC 8-1 defines the importance class for each building, but each National Annex determines the according importance factor which is illustrated in table 6 for the concept of the NA.

\begin{tabular}{c|lc} 
Importance class & Buildings & Importance factor $\mathbf{V}_{\mathbf{1}}$ \\
\hline I & $\begin{array}{l}\text { Buildings of minor importance for public safety, e.g. agricultural } \\
\text { buildings etc. }\end{array}$ & 0,80 \\
\hline II & Ordinary buildings, not belonging in the other categories & 1,00 \\
\hline III & $\begin{array}{l}\text { Buildings whose seismic resistance is of importance in view of the } \\
\text { consequences associated with a collapse, e.g. schools, assembly } \\
\text { halls, cultural institutions etc. }\end{array}$ \\
\hline IV & $\begin{array}{l}\text { Buildings whose integrity during earthquakes is of vital importance } \\
\text { for civil protection, e.g. hospitals, fire stations, power plants, etc. }\end{array}$ & 1,40 \\
\hline
\end{tabular}

Table 6 Importance classes and factors for buildings according to the concept of the NA table NA.7

The Period T of the spectral acceleration has given sections by the NA depending on the ground condition which are shown in table 7. 


\begin{tabular}{c|cccc} 
Underground condition & $T_{A}[s]$ & $T_{B}[s]$ & $T_{C}[s]$ & $T_{D}[s]$ \\
\hline$A-R$ & 0,01 & 0,10 & 0,20 & 2,00 \\
\hline$B-R$ & 0,01 & 0,10 & 0,25 & 2,00 \\
\hline$C-R$ & 0,01 & 0,10 & 0,30 & 2,00 \\
\hline$B-T$ & 0,01 & 0,10 & 0,25 & 2,00 \\
\hline$C-T$ & 0,01 & 0,10 & 0,40 & 2,00 \\
\hline$B-S$ & 0,01 & 0,10 & 0,40 & 2,00 \\
\hline$C-S$ & 0,01 & 0,10 & 0,50 & 2,00 \\
\hline
\end{tabular}

Table 7 Control periods to describe elastic horizontal response spectrum according to the concept of NA

To illustrate the total frequency range according to the concept of the NA, the spectral acceleration which can be assumed to be constant from $T=0 \mathrm{~s}$ to $T_{A}=0,01 \mathrm{~s}$, has its highest value in the section from $T_{B}$ to $T_{C}$ which is called the plateau value. The total form and description of the spectral acceleration response spectrum can be retrieved from figure 6 .

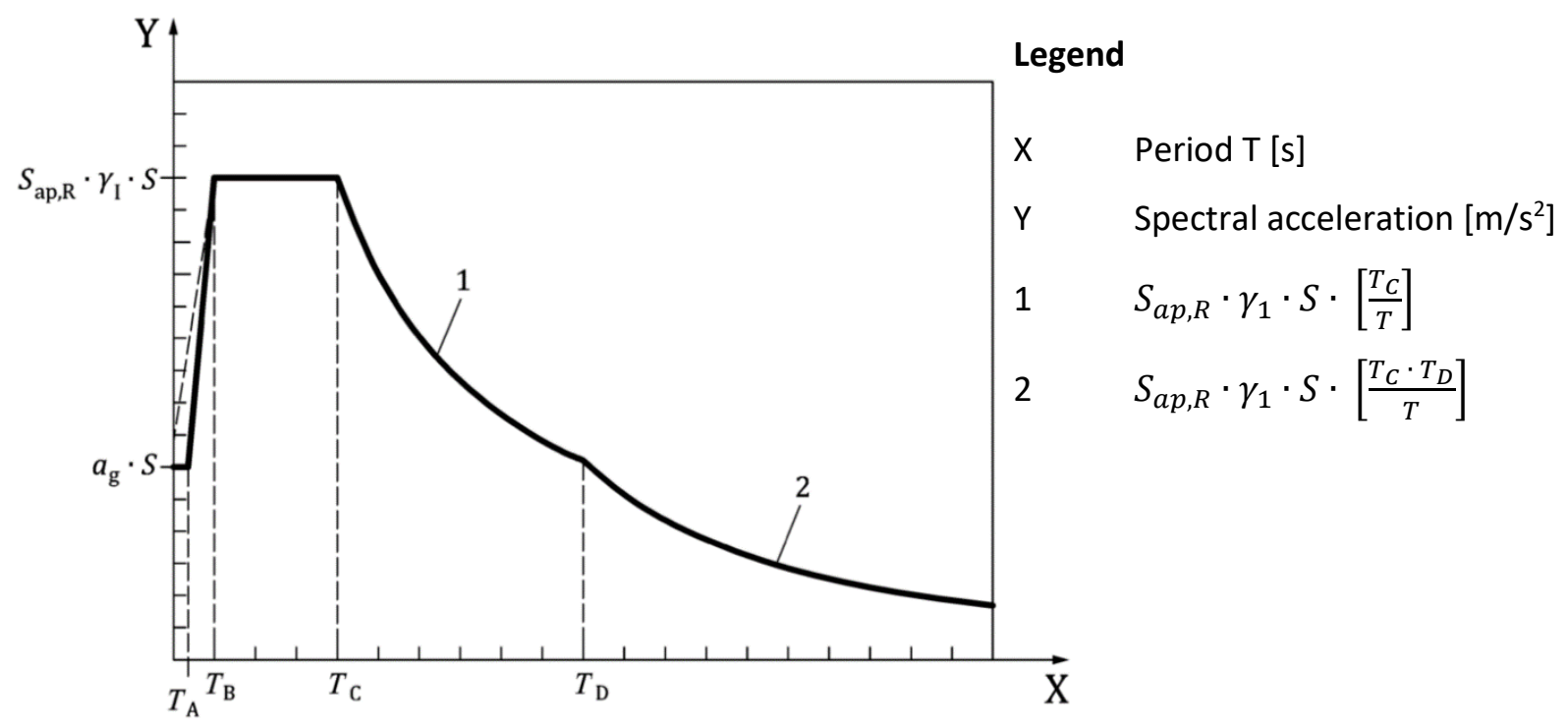

Figure 6 Form and description of the elastic acceleration response spectrum according to the concept of NA figure NA.2

To calculate the earthquake resistance of a building, the effective masses must be determined. Therefore, permanent loads must be applied fully. However, the variable loads are not applied 
fully. The general EC 8 suggests combinations coefficients depending on the location within the building and on the category of the variable loads. The concept of the NA defines the value of the combination coefficients as table 8 shows.

\begin{tabular}{l|ll}
\multicolumn{1}{c|}{$\begin{array}{c}\text { Type of variable action according to DIN } \\
\text { EN 1991-1-1/NA }\end{array}$} & \multicolumn{1}{|c}{ Location within building } & $\boldsymbol{\varphi}$ \\
\hline \multirow{2}{*}{ Service loads of category A-C, T and Z } & Top floor including roof & 1,00 \\
\cline { 2 - 3 } & Other floors & 0,70 \\
\hline Service loads of category D-F, T and Z & All floors & 1,00 \\
\hline
\end{tabular}

Table 8 Combination coefficients for service loads according to the concept of NA table NA.6

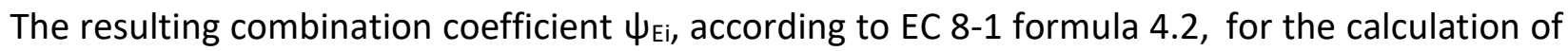
the effects of an earthquake should be determined by multiplying $\varphi$ with the combination coefficient $\psi_{2 i}$ for the quasi-permanent value of service load $q_{i}$.

$$
\psi_{\mathrm{Ei}}=\varphi \cdot \psi_{2 \mathrm{i}}
$$

The sum of the effective masses of permanent and of service loads combined with the elastic acceleration response spectrum are the foundation of any earthquake resistance dimensioning according to EC 8 and the National Annex.

\subsubsection{Comparison between the concept of the NA and the current NA}

To compare the concept of the NA with the current NA, the seismic base shear force will be calculated according both NA. As per EC 8-1 section 4.3.3.2.2, the seismic base shear force $F_{b}$ for both horizontal directions can be determined by the following expression:

$$
F_{b}=S_{d}\left(T_{1}\right) \cdot m \cdot \lambda \cdot \frac{1}{g}
$$

To compare the concept of the NA with the current NA, the ordinate of the design spectrum will be determined at $T_{B} \leq T \leq T_{C}$ which constitutes the plateau level.

The design spectrum at plateau level is calculated differently for the concept and the current NA.

\begin{tabular}{c|cc} 
& Current NA & Concept of NA \\
\hline$T_{B} \leq T \leq T_{C}:$ & $S_{d, 2011}(T)=a_{g R} \cdot \gamma_{1} \cdot S_{2011} \cdot \frac{2,5}{q}$ & $S_{d, 2018}(T)=S_{a p, R} \cdot \gamma_{1} \cdot S_{2018} \cdot \frac{1}{q}$ \\
\hline
\end{tabular}


Table 9 Design spectrum at plateau level according to current NA formula NA.11 and concept of NA figure NA.2 and $N C l$ 3.2.2.5 (3)P

All parameters in table 7 depend on the location of the investigated building and its function. Since the assessed structure is a large office building, located in 77815 Buehl, Germany, all parameters can be determined as table 8 shows.

\begin{tabular}{|c|c|c|c|c|c|}
\hline \multirow{3}{*}{\begin{tabular}{|l|} 
Underground class $^{1}$ \\
Ground type $^{1}$
\end{tabular}} & \multicolumn{2}{|r|}{ Current NA } & \multicolumn{3}{|c|}{ Concept of NA } \\
\hline & $\mathrm{S}$ & \multirow{2}{*}{$S_{2011}^{2}=0,75$} & & $\mathrm{~S}$ & \multirow{3}{*}{$\mathrm{S}_{2018^{8}}=1,15$} \\
\hline & $\mathrm{C}$ & & & C & \\
\hline $\begin{array}{l}\text { Spectral acceleration } \\
\text { response }\end{array}$ & & - & \multicolumn{2}{|c|}{$\mathrm{S}_{\mathrm{ap}, \mathrm{R}^{7}}=1,725 \mathrm{~m} / \mathrm{s}^{2}$} & \\
\hline Seismic zone & $1^{3}$ & $a_{g R}{ }^{4}=0,40 m / s^{2}$ & \multicolumn{3}{|c|}{-} \\
\hline Importance category & III & $\gamma_{1}{ }^{5}=1,20$ & III & \multicolumn{2}{|c|}{$V_{1}{ }^{9}=1,20$} \\
\hline Behaviour factor & \multicolumn{2}{|r|}{$q^{6}=1,50$} & \multicolumn{3}{|c|}{$q^{10}=1,50$} \\
\hline \multicolumn{6}{|c|}{$1 \quad$ A soil survey was used to determine ground type and underground class } \\
\hline \multicolumn{6}{|c|}{2 DIN EN 1998-1/NA:2011-01 table NA.4 } \\
\hline \multicolumn{6}{|c|}{3 DIN EN 1998-1/NA:2011-01 figure NA.1 } \\
\hline \multicolumn{6}{|c|}{$4 \quad$ DIN EN 1998-1/NA:2011-01 table NA.3 } \\
\hline \multicolumn{6}{|c|}{5 DIN EN 1998-1/NA:2011-01 table NA.6 } \\
\hline \multicolumn{6}{|c|}{$6 \quad$ DIN EN 1998-1/NA:2011-01 table NA.7 } \\
\hline \multicolumn{6}{|c|}{7 E DIN EN 1998-1/NA:2018-10 figure NA.1 and online tool GFZ } \\
\hline \multicolumn{6}{|c|}{$8 \quad$ E DIN EN 1998-1/NA:2018-10 table NA.4 } \\
\hline \multicolumn{6}{|c|}{$9 \quad$ E DIN EN 1998-1/NA:2018-10 table NA.7 } \\
\hline \multicolumn{6}{|c|}{10 E DIN EN 1998-1/NA:2018-10 table NA.8 } \\
\hline
\end{tabular}

Table 10 Parameters to determine design spectrum according to current NA and concept of NA

The resulting design spectrum at plateau level according to table 7 can now be calculated using the parameters determined in table 8 .

\begin{tabular}{c|c|c} 
& Current NA & Concept of NA \\
\hline$T_{B} \leq T \leq T_{C}:$ & $S_{d, 2011}(T)=a_{g R} \cdot \gamma_{1} \cdot S_{2011} \cdot \frac{2,5}{q}$ & $S_{d, 2018}(T)=S_{a p, R} \cdot \gamma_{1} \cdot S_{2018} \cdot \frac{1}{q}$ \\
& $S_{d, 2011}(T)=0,40 \mathrm{~m} / \mathrm{s}^{2} \cdot 1,2 \cdot 0,75 \cdot \frac{2,5}{1,5}$ & $S_{d, 2018}(T)=1,725 \mathrm{~m} / \mathrm{s}^{2} \cdot 1,2 \cdot 1,15 \cdot \frac{1}{1,5}$ \\
& $S_{d, 2011}(T)=0,60 \mathrm{~m} / \mathrm{s}^{2}$ & $S_{d, 2018}(T)=1,587 \mathrm{~m} / \mathrm{s}^{2}$
\end{tabular}

Table 11 Determined design spectrum according to current NA and concept of NA 
To calculate the base shear force according to EC 8-1 the effective masses need to be determined. The masses of the investigated building shown in table 12 are simplified and only used for the comparison of the concept and the current National Annex.

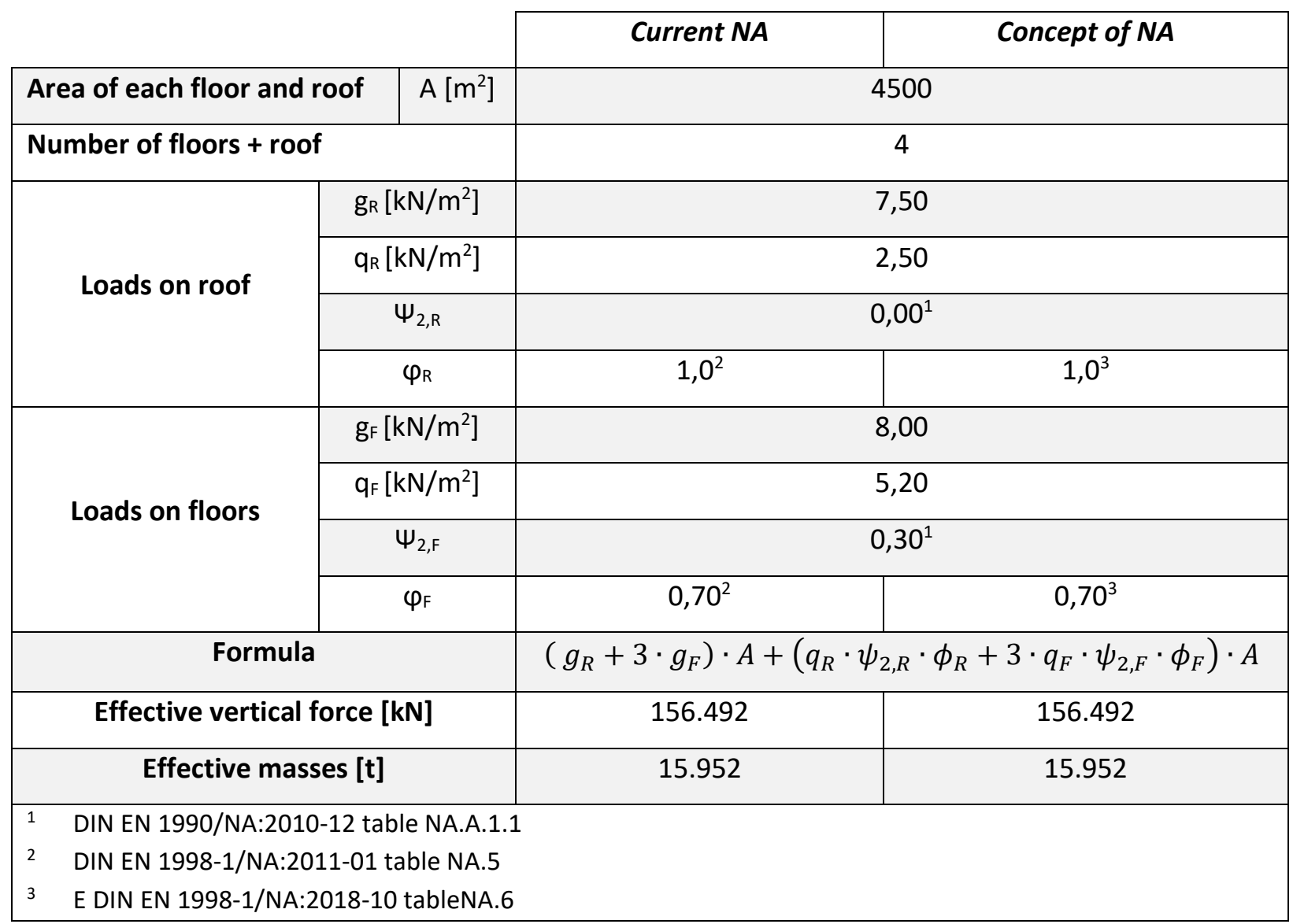

Table 12 Calculation of effective masses using simplified loads and building characteristics

The result of the effective masses show that the concept did not change the way of calculating the effective masses in comparison to the current NA. Since the masses itself do not influence the concept and the current National Annex differently, only the coefficients of the masses could have influenced the result. But since table NA.5 of the current NA and table NA.6 of the concept of NA are the same, both NA have the same effect on the effective masses.

The last parameter that could affect the result of the base shear force is the correction factor $\lambda$. Since the correction factor is determined by the general Eurocode and not the National Annex it does not have influence on the result for the comparison of the concept and the current National Annex. 
The correction factor $\lambda$ is 0,85 for a building with more than two floors and the period $T_{1} \leq 2 \cdot T_{C}$. Otherwise the correction factor $\lambda$ is 1,0 .

Knowing all parameters and coefficients, the base shear force can now be calculated as described in formula 1.3 .

\begin{tabular}{c|c} 
Current NA & Concept of NA \\
\hline $\boldsymbol{F}_{\boldsymbol{b}, \mathbf{2 0 1 1}}=\boldsymbol{S}_{\boldsymbol{d}}\left(\boldsymbol{T}_{\mathbf{1}}\right) \cdot \boldsymbol{m} \cdot \boldsymbol{\lambda} \cdot \frac{\mathbf{1}}{\boldsymbol{g}}$ & $F_{b, 2018}=S_{d}\left(T_{1}\right) \cdot \mathrm{m} \cdot \lambda \cdot \frac{1}{g}$ \\
$\mathbf{F}_{\mathbf{b}, \mathbf{2 0 1 1}}=\mathbf{0 , 6 0} \mathbf{m} / \mathbf{s}^{2} \cdot \mathbf{1 5 6 . 4 9 2} \mathbf{k N} \cdot \mathbf{1}$ & $\mathrm{F}_{\mathrm{b}, 2018}=1,587 \mathrm{~m} / \mathrm{s}^{2} \cdot 156.492 \mathrm{kN} \cdot 1 \cdot \frac{1}{9,81 \mathrm{~m} / \mathrm{s}^{2}}$ \\
$\cdot \frac{\mathbf{1}}{\mathbf{9 , 8 1} \mathbf{m} / \mathbf{s}^{2}}$ & $\mathrm{~F}_{\mathrm{b}, 2018}=25.316,30 \mathrm{kN}$ \\
\hline $\mathbf{F}_{\mathbf{b}, 2011}=\mathbf{9 . 5 7 1 , 4 0} \boldsymbol{k N}$ &
\end{tabular}

Table 13 Calculation of base shear force according to Eurocode 8-1 formula 4.5

As the results show, the seismic base shear force calculated according to the concept of the NA, is larger than the seismic base shear force according to the current NA. Since the effective masses $m$, the correction factor $\lambda$ and the acceleration of gravity g are not influenced by the two NA in different ways, only the design spectrum has changed its value. Therefore, the seismic base shear force increased by $265 \%$ using the concept of the NA of EC 8-1 in comparison to the current NA.

The mathematical background of the changed value of the design spectrum can be investigated by equating the formulas of the design spectrum according to the current and the concept of the NA as table 14 shows.

\begin{tabular}{clcl} 
Current NA & $=$ & Concept of NA & \\
\hline$a_{g R, 2011} \cdot \gamma_{1} \cdot S_{2011} \cdot \frac{2,5}{q}$ & $=$ & $S_{a p, R} \cdot \gamma_{1} \cdot S_{2018} \cdot \frac{1}{q}$ & $\mid \cdot q$ \\
$a_{g R, 2011} \cdot \gamma_{1} \cdot S_{2011} \cdot 2,5$ & $=$ & $S_{a p, R} \cdot \gamma_{1} \cdot S_{2018}$ & $\mid: \gamma_{1}$ \\
$a_{g R, 2011} \cdot S_{2011} \cdot 2,5$ & $=$ & $S_{a p, R} \cdot S_{2018}$ & $\mid: 2,5$ \\
$a_{g R, 2011} \cdot S_{2011}$ & & $\frac{S_{a p, R}}{2,5} \cdot S_{2018}$ & \\
$a_{g R, 2011} \cdot S_{2011}$ & & $a_{g R, 2018} \cdot S_{2018}$ & \\
$0,40 \mathrm{~m} / \mathrm{s}^{2} \cdot 0,75$ & & $0,69 \mathrm{~m} / \mathrm{s}^{2} \cdot 1,15$ & $\mid$ applying values \\
$0,30 \mathrm{~m} / \mathrm{s}^{2}$ & $=$ & $0,794 \mathrm{~m} / \mathrm{s}^{2}$ & $\mid: 0,30 \mathrm{~m} / \mathrm{s}^{2}$
\end{tabular}




$1 \quad 2,65$

Table 14 Equating design spectrum of current NA and concept of NA

By comparing the calculation of the design spectrum of both, the concept and the current National Annex, the same increasing factor of the design spectrum and the seismic base shear force appear. Furthermore, it illustrates that the current and the concept of the NA use the same formula to determine the design spectrum. The difference between the current and the concept of the NA is, that while the reference peak ground acceleration agR within the current NA only depends on the seismic zone but within the concept of the NA it depends on the distribution of the spectral acceleration response $S_{a p, R}$ which is used instead of the seismic zones.

The comparison of the investigated building in this example only determines the factor for this building and is not a general factor since the current and the concept of the NA are not connected linear. It just gives an idea of the increasing factor for the concept of the NA of EC 8. 


\section{SIMPLIFIED APPROACH FOR EARTHQUAKE RESISTANCE}

\subsection{INTRODUCTION OF THE SIMPLIFIED APPROACH}

Calculating the earthquake resistance of a structure with no regularity in plan or elevation must be determined using a spatial model according to EC 8-1 table 4.1. For this approach of predimensioning a structure for earthquake resistance with these characteristics, table 4.1 of EC 8-1 will be neglected.

The reason for the simplified approach is not to change the way of calculating the earthquake resistance for a structure with no regularity in plan or elevation, but to give an engineer the possibility to estimate the earthquake resistance of such a building without using a spatial model which is a time-consuming process to create. This project investigates how close the approach gets to the calculation of a finite element software.

EC 8-1 and its NA determine the horizontal seismic forces on each floor. Afterwards, basically only concepts of technical mechanics are used to determine the resulting moment for each embracing element. The approach of predimensioning is carried out in three steps as table 15 shows.

\begin{tabular}{r|lc} 
Step & Description & Considered Standard \\
\hline $\mathbf{1}$ & Determination of the horizontal seismic forces on each floor & $\begin{array}{c}\text { Eurocode 8-1 } \\
\text { Eurocode 8-1/NA }\end{array}$ \\
\hline $\mathbf{2}$ & Distribution of horizontal forces in each floor on bracing elements & - \\
\hline $\mathbf{3}$ & $\begin{array}{l}\text { Determination of the Moment distribution along total building height } \\
\text { of embracing walls }\end{array}$ & - \\
\hline
\end{tabular}

Table 15 Steps of the simplified approach

In the following chapter, the approach will be performed using the concept of the NA of EC 8-1, for the structure described in chapter 1.2. 


\subsection{HORIZONTAL FORCES ACCORDING TO THE CONCEPT OF THE NA}

The first step of the simplified approach requires the calculation of the horizontal seismic forces on each floor. Therefore, the elastic response spectrum is needed to determine the base shear force. The base shear force is then distributed to horizontal forces on each floor. To illustrate the horizontal forces, the effective masses must be determined first, since these masses are the foundation for any horizontal forces due to an earthquake. Table 16 and 17 summarize the parameters, building characteristics and loads listed in chapter 1 that are required to calculate the effective masses.

\begin{tabular}{|c|c|c|c|c|c|}
\hline Floor $i$ & $\begin{array}{c}\text { Floor height: } \\
h\end{array}$ & $\begin{array}{l}\text { Permanent + } \\
\text { dead load: } g\end{array}$ & $\begin{array}{l}\text { Variable } \\
\text { load: } q\end{array}$ & $\begin{array}{c}\text { Partition } \\
\text { supplement: } \Delta q\end{array}$ & $\begin{array}{c}\text { Net base } \\
\text { area: } A\end{array}$ \\
\hline Ground floor & $5,70 \mathrm{~m}$ & $8,00 \mathrm{kN} / \mathrm{m}^{2}$ & $5,00 \mathrm{kN} / \mathrm{m}^{2}$ & - & $5.811\left[\mathrm{~m}^{2}\right]$ \\
\hline First floor & $4,10 \mathrm{~m}$ & $8,00 \mathrm{kN} / \mathrm{m}^{2}$ & $4,00 \mathrm{kN} / \mathrm{m}^{2}$ & $1,20 \mathrm{kN} / \mathrm{m}^{2}$ & $4.672\left[\mathrm{~m}^{2}\right]$ \\
\hline Second floor & $4,10 m$ & $8,00 \mathrm{kN} / \mathrm{m}^{2}$ & $4,00 \mathrm{kN} / \mathrm{m}^{2}$ & $1,20 \mathrm{kN} / \mathrm{m}^{2}$ & $4.557\left[\mathrm{~m}^{2}\right]$ \\
\hline Third floor & $4,10 \mathrm{~m}$ & $8,00 \mathrm{kN} / \mathrm{m}^{2}$ & $4,00 \mathrm{kN} / \mathrm{m}^{2}$ & $1,20 \mathrm{kN} / \mathrm{m}^{2}$ & $4.724\left[\mathrm{~m}^{2}\right]$ \\
\hline Roof & - & $8,0 / 11,0^{1} \mathrm{kN} / \mathrm{m}^{2}$ & $1,00 \mathrm{kN} / \mathrm{m}^{2}$ & - & $4.927\left[\mathrm{~m}^{2}\right]$ \\
\hline
\end{tabular}

Table 16 building characteristcs and loads to determine effective masses

\begin{tabular}{l|lc} 
Parameter & & value \\
\hline \multirow{2}{*}{$\phi$} & Top floor including roof & 1,00 \\
\cline { 2 - 3 } & All other floors & 0,70 \\
\hline$\psi_{2}$ & & 0,30 \\
\hline
\end{tabular}

Table 17 Parameters to determine effective masses

The following equation shows how the effective vertical force of each floor must be calculated:

$$
F_{i}=A_{i} \cdot\left(g_{i}+\psi_{2} \cdot \phi \cdot\left(q_{i}+\Delta q_{i}\right)\right)
$$

The result of the effective vertical forces for each floor are shown in table 18. 


\begin{tabular}{r|c|c} 
Floor & Designation & Effective vertical force \\
\hline First floor & $\mathrm{m}_{1}$ & $42.482[\mathrm{kN}]$ \\
\hline Second floor & $\mathrm{m}_{2}$ & $41.428[\mathrm{kN}]$ \\
\hline Third floor & $\mathrm{m}_{3}$ & $42.951[\mathrm{kN}]$ \\
\hline Roof & $\mathrm{m}_{4}$ & $44.457^{1}[\mathrm{kN}]$ \\
\hline \multicolumn{2}{|r|}{ Total } & $171.318[\mathrm{kN}]$ \\
\hline $1 \quad$ including TBE according to figure 3 \\
\hline
\end{tabular}

Table 18 Effective vertical forces of each floor

After the effective vertical forces of the investigated building have been defined, the elastic response spectrum must be determined to get the horizontal forces on each floor. Therefore, some parameters are required which are based on the location, size and use of the building.

By using the online tool [4] provided by "GFZ Helmholtz Centre Potsdam", the spectral acceleration response is defined based on the exact location of the structure as shown below.

$$
S_{a p, R}=1,725 \mathrm{~m} / \mathrm{s}^{2}
$$

Since the spectral acceleration response $S_{a p, R}$ and the reference peak ground acceleration $a_{g R}$ have a linear relation, $\mathrm{agR}_{\mathrm{g}}$ can be calculated according to formula 1.1 as presented below.

$$
a_{g R}=\frac{S_{a p, R}}{2,5}=0,69 \mathrm{~m} / \mathrm{s}^{2}
$$

According to the soil survey, the ground type is described as type $C$ and the underground class as class S, which results in an underground condition C-S. Therefore, the soil factor S, which depends on the underground condition and the spectral acceleration response $S_{a p, R}$, can be retrieved from table 5 on page 8 as shown below.

$$
S=1,15
$$

Other parameters that affect the elastic response spectrum are the importance factor $\gamma_{1}$ and the behaviour factor q. Since the investigated building is a large office building, importance class III can be assumed from table 6 . Furthermore, the behaviour factor can be assumed for a low capacity to dissipate energy according to EC 8-1: table 8.1. This is a conservative but usual simplified approach. The selected importance factor $\gamma_{1}$ and behaviour factor $q$ are shown below. 


$$
\begin{aligned}
& \gamma_{1}=1,20 \\
& q=1,50
\end{aligned}
$$

The underground condition defines the given sections of the elastic response spectrum. These sections can be retrieved from table 7 and are presented in table 19 below.

\begin{tabular}{c|cccc} 
Underground condition & $T_{A}[s]$ & $T_{B}[s]$ & $T_{C}[s]$ & $T_{D}[s]$ \\
\hline$C-S$ & 0,01 & 0,10 & 0,50 & 2,00 \\
\hline
\end{tabular}

Table 19 Extract of table 7 to show control periods

Knowing all parameters, the elastic response spectrum can now be illustrated by the following formulas for all four sections. Since these formulas include the behaviour factor $q$, the resulting spectrum is called design spectrum. According to EC 8-1: 3.2.2.5 the design spectrum is introduced to consider that the capacity of structural systems resist seismic actions in the nonlinear range permits their design for resistance to seismic forces smaller than those corresponding to a linear elastic response. That means that the design spectrum is to avoid explicit inelastic structural analysis in design by considering the capacity of a building to dissipate energy through mainly ductile behaviour of its elements and/or other mechanisms. Therefore, the behaviour factor reduces the spectrum.

As stated in EC 8-1: 3.2.2.5 (3)P "the behaviour factor $\mathrm{q}$ is an approximation of the ratio of the seismic forces that the structure would experience if its response was completely elastic with $5 \%$ viscous damping, to the seismic forces that may be used in the design, with a conventional elastic analysis model, still ensuring a satisfactory response of the structure." 
Below, the formulas describing the form of the design spectrum according to the concept of the NA are presented for each section.

$$
\begin{array}{ll}
0 \leq \mathrm{T} \leq \mathrm{T}_{\mathrm{A}}: & S_{d}(T)=a_{g r} \cdot S \cdot \gamma_{1} \cdot \frac{1}{q} \\
\mathrm{~T}_{\mathrm{B}} \leq \mathrm{T} \leq \mathrm{T}_{\mathrm{C}}: & S_{d}(T)=S_{a p, R} \cdot S \cdot \gamma_{1} \cdot \frac{1}{q} \\
\mathrm{~T}_{\mathrm{C}} \leq \mathrm{T} \leq \mathrm{T}_{\mathrm{D}}: & \mathrm{S}_{\mathrm{ap}, \mathrm{R}} \cdot \gamma_{1} \cdot \mathrm{S} \cdot\left[\frac{\mathrm{T}_{\mathrm{C}}}{\mathrm{T}}\right] \cdot \frac{1}{q} \\
\mathrm{~T}_{\mathrm{D}} \leq \mathrm{T}: & \mathrm{S}_{\mathrm{ap}, \mathrm{R}} \cdot \gamma_{1} \cdot \mathrm{S} \cdot\left[\frac{\mathrm{T}_{\mathrm{C}} \cdot \mathrm{T}_{\mathrm{D}}}{\mathrm{T}}\right] \cdot \frac{1}{q}
\end{array}
$$

The design spectrum is constant for $0 \leq T \leq T_{A}$ and for $T_{B} \leq T \leq T_{C}$. However, the design spectrum increases linearly for $T_{A} \leq T \leq T_{B}$ and is not described by a formula listed above.

The elastic response design spectrum is illustrated for a total period of 7 seconds in figure 7 .

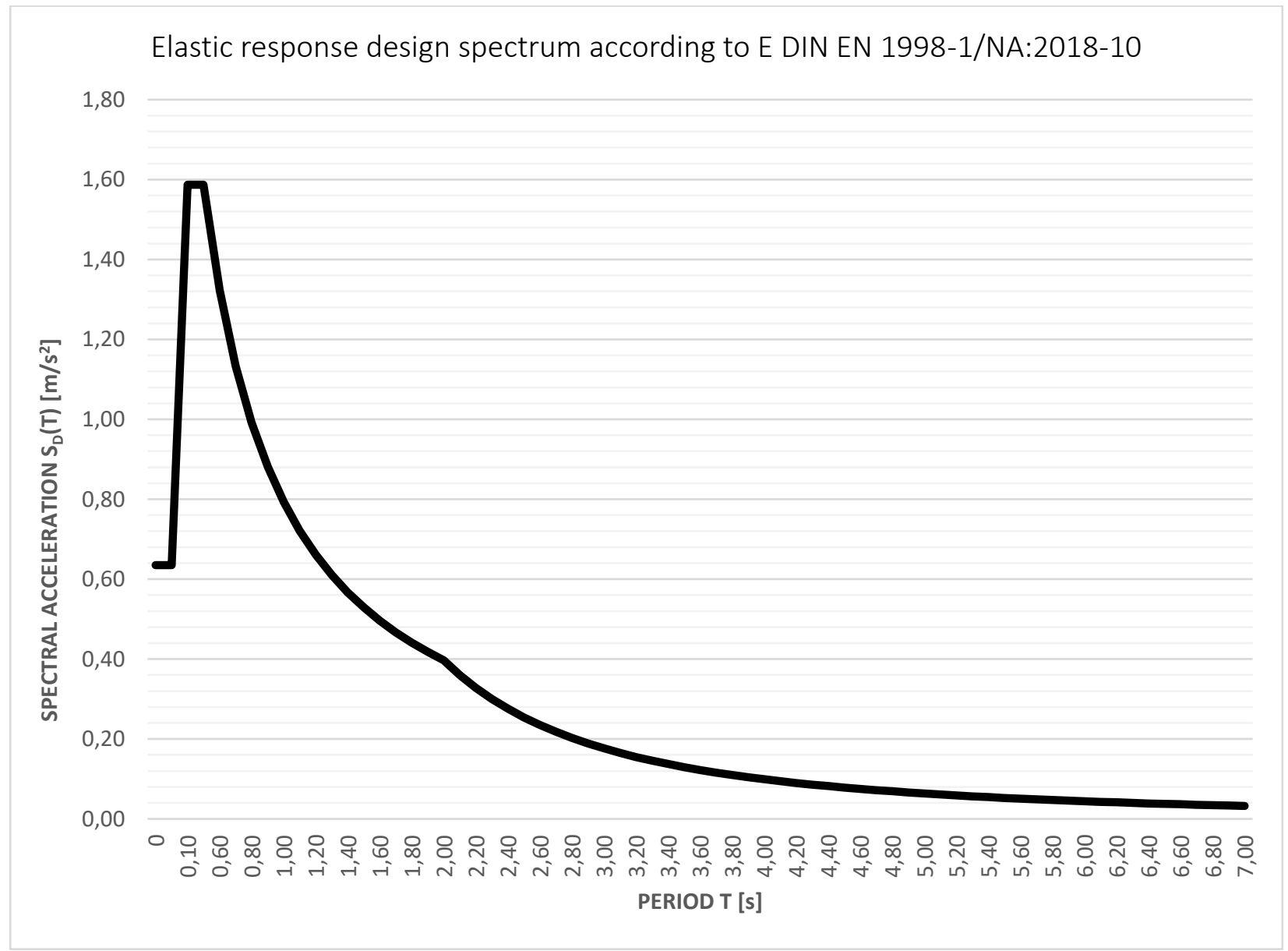

Figure 7 Illustration of the elastic response design spectrum of the investigated building 
The form of the elastic response design spectrum shows the plateau level which is constant for $T_{B} \leq T \leq T_{C}$. The value of the plateau level for the investigated building is shown below.

$$
\mathrm{T}_{\mathrm{B}} \leq \mathrm{T} \leq \mathrm{T}_{\mathrm{C}}: \quad S_{d}(T)=1,587 \mathrm{~m} / \mathrm{s}^{2}
$$

The plateau level is used for this simplified approach of pre-dimensioning to determine the horizontal forces on each floor. However, the total elastic response design spectrum would not have been needed, but since the comparison calculation using finite element software requires the total form of the design spectrum, it is introduced within the simplified approach.

Knowing the design spectrum and the vertical effective masses, the seismic base shear force can now be calculated using formula 1.3 .

$$
F_{b}=S_{d}\left(T_{1}\right) \cdot m \cdot \lambda \cdot \frac{1}{g}
$$

Since $T_{1}$ is assumed to be larger than $2 \cdot T_{c}$, the correction factor $\lambda$ is 1,0 . Furthermore, the value of the acceleration of gravity is assumed to be $\mathrm{g}=9,81 \mathrm{~m} / \mathrm{s}^{2}$, while the total vertical effective mass retrieved from table 18 is $171.318 \mathrm{kN}$. Therefore, the base shear force of the investigated building according to the concept of the NA is calculated as shown below.

$$
\begin{aligned}
& F_{b}=1,587 \mathrm{~m} / \mathrm{s}^{2} \cdot 171.318 \mathrm{kN} \cdot 1,0 \cdot \frac{1}{9,81 \mathrm{~m} / \mathrm{s}^{2}} \\
& F_{b}=27.715 \mathrm{kN}
\end{aligned}
$$

Now that the base shear force is determined, EC 8-1 can be used to get the distribution of the horizontal seismic forces for each floor. Since the fundamental mode shape is approximated by horizontal displacements increasing linearly along the building height, the horizontal forces of each floor should be calculated according to EC 8-1: 4.3.3.2.3 as shown below.

$$
F_{i}=F_{b} \cdot \frac{z_{i} \cdot m_{i}}{\sum z_{j} \cdot m_{j}}
$$

Since all parameters of formula 2.6 are known, the horizontal forces of each flor can be determined as shown in table 20 below. The vertical forces of each storey $m_{i}$ can be retrieved 
from table 18 and the heights of the floor masses $z_{i}$ can be retrieved by adding the floor heights from table 17.

\begin{tabular}{r|c|c|c} 
Floor & $\mathbf{m}_{\mathbf{i}}[\mathbf{k N}]$ & $\mathbf{z}_{\mathbf{i}}[\mathbf{m}]$ & $\mathbf{F}_{\mathrm{i}}[\mathbf{k N}]$ \\
\hline First Floor & 42.482 & 5,70 & 3.281 \\
\hline Second Floor & 41.428 & 9,80 & 5.501 \\
\hline Third Floor & 42.951 & 13,90 & 8.090 \\
\hline Roof & 44.457 & 18,00 & 10.843 \\
\hline
\end{tabular}

Table 20 Distribution of horizontal seismic forces at all floors

All seismic forces calculated in table 20, need to add up to the same value as the base shear force. If that is the case, the horizontal forces are calculated correctly. After the seismic horizontal forces of each floor are known, a Multi Degree of Freedom (MDOF) System can be used to illustrate the horizontal forces on the investigated building as illustrated in figure 8 below.

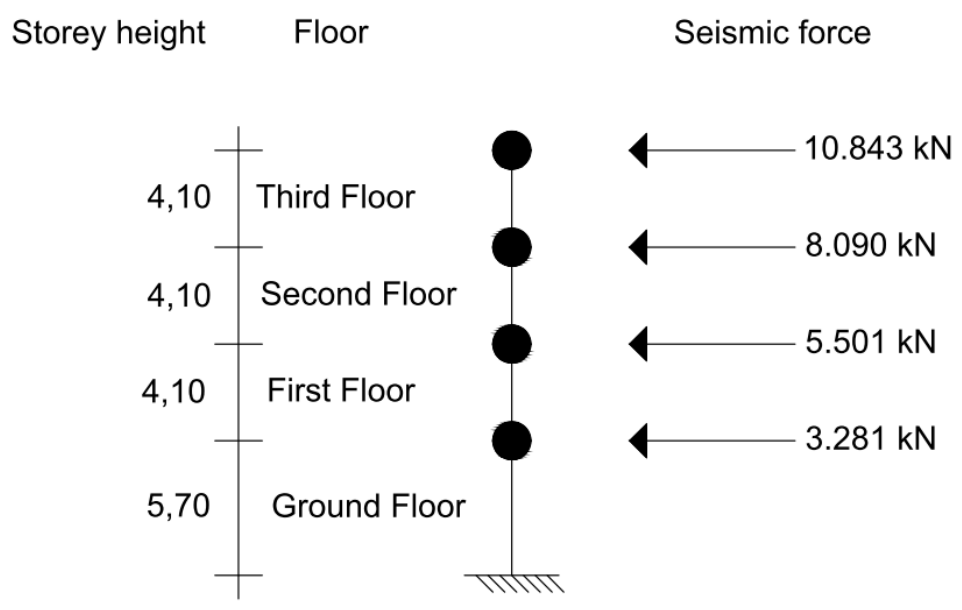

Figure 8 MDOF System to illustrate horizontal seismic forces

Figure 8 summarizes the results of the first step of the simplified approach. The distribution of the horizontal seismic forces is the base for this simplified approach for earthquake resistance. 


\subsection{DISTRIBUTION OF THE HORIZONTAL FORCES ON THE BRACING WALLS}

To calculate the earthquake resistance for the investigated building, the horizontal seismic forces of the MDOF System need to be distributed on the bracing elements for each floor. Normally, it is assumed that forces are being attracted by stiffness which means that a bracing element with larger moment of inertia absorbs a larger force. In these cases, only the bending deformation is considered since the bending deformation is affected by the moment of inertia. However, this assumption would lead to an overestimation of the stiffness of the bracing elements. Besides the bending deformation, there is also the shear deformation which is not affected by the moment of inertia. The simplification that only the bending deformation is considered, is true for elements like beams or short walls. To illustrate the effect of the bending and shear deformation, three walls with a different length will be investigated in table 21. Figure 9 shows the geometrical designations of the investigated walls, as well as the static system which is the base for the bending moment calculation.

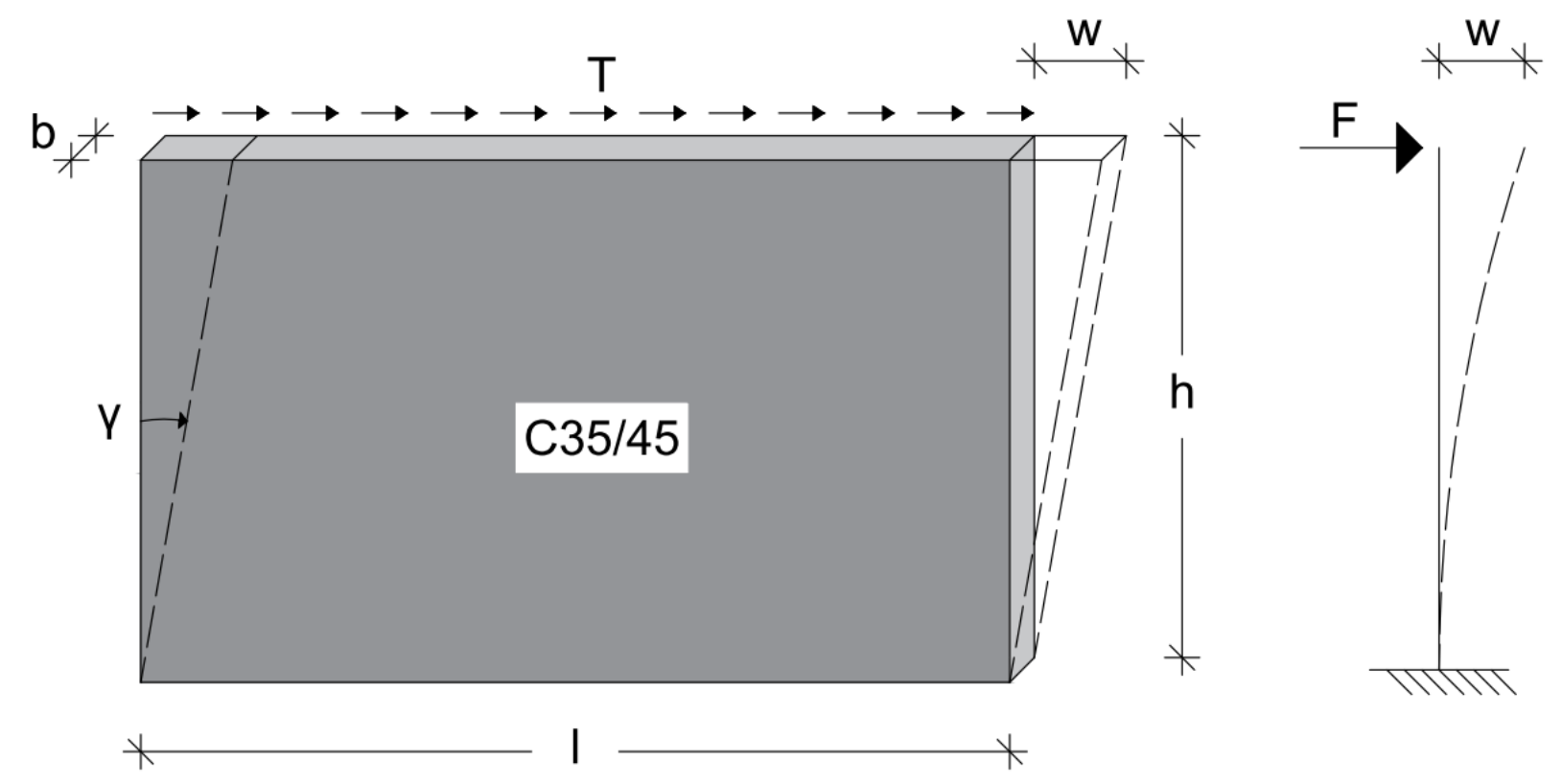

Figure 9 Geometrical designations and static system for wall A, B and C

All the investigated walls have the same height, width and are designed with the same concrete C35/45. The goal of this investigation is to illustrate the increasing proportion of the shear deformation that comes with an increasing length of the wall. The calculation of the bending and shear deformation as well as the comparison are shown in table 21 below. 


\begin{tabular}{l|ccc} 
& Wall A & Wall B & Wall C \\
\hline Height $h$ & $5,00 \mathrm{~m}$ & $5,00 \mathrm{~m}$ & $5,00 \mathrm{~m}$ \\
\hline Width $b$ & $0,30 \mathrm{~m}$ & $0,30 \mathrm{~m}$ & $0,30 \mathrm{~m}$ \\
\hline Length I & $0,50 \mathrm{~m}$ & $2,00 \mathrm{~m}$ & $5,00 \mathrm{~m}$ \\
\hline Modulus of elasticity $E$ & $34.000 \mathrm{MN} / \mathrm{m}^{2}$ & $34.000 \mathrm{MN} / \mathrm{m}^{2}$ & $34.000 \mathrm{MN} / \mathrm{m}^{2}$ \\
\hline Force F & $100 \mathrm{kN}$ & $100 \mathrm{kN}$ & $100 \mathrm{kN}$ \\
\hline
\end{tabular}

\begin{tabular}{|c|c|c|c|}
\hline Moment of Inertia $\quad I=\frac{b \cdot l^{3}}{12}$ & $0,00313 \mathrm{~m}^{4}$ & $0,20 \mathrm{~m}^{4}$ & $3,13 \mathrm{~m}^{4}$ \\
\hline Bending deformation $\quad w_{b}=\frac{F \cdot h^{3}}{3 \cdot E I}$ & $39,22 \mathrm{~mm}$ & $0,61 \mathrm{~mm}$ & $0,039 \mathrm{~mm}$ \\
\hline \multicolumn{4}{|c|}{ Shear deformation } \\
\hline$G=\frac{E}{2 \cdot(1+v)}$ & $14.167 \mathrm{MN} / \mathrm{m}^{2}$ & 14.167 MN/m² & $14.167 \mathrm{MN} / \mathrm{m}^{2}$ \\
\hline$T=\frac{F}{b \cdot l}$ & $0,67 \mathrm{kN} / \mathrm{m}^{2}$ & $0,17 \mathrm{kN} / \mathrm{m}^{2}$ & $0,07 \mathrm{kN} / \mathrm{m}^{2}$ \\
\hline$\gamma=\frac{T}{G}$ & $4,71 \cdot 10^{-5}$ & $1,18 \cdot 10^{-5}$ & $4,71 \cdot 10^{-6}$ \\
\hline Shear deformation & $0,24 \mathrm{~mm}$ & $0,06 \mathrm{~mm}$ & $0,02 \mathrm{~mm}$ \\
\hline \multicolumn{4}{|c|}{ Result } \\
\hline Total deformation & $39,46 \mathrm{~mm}$ & $0,67 \mathrm{~mm}$ & $0,059 \mathrm{~mm}$ \\
\hline Proportion of $w_{s}$ in $w_{t}$ & $0,61 \%$ & $8,96 \%$ & $33,90 \%$ \\
\hline
\end{tabular}

Table 21 Investigation of the effect of bending and shear deformation on three investigated walls $A, B$ and $C$

The result of the investigation of the influence of the shear deformation to the total deformation confirms the theory above. All investigated walls have the same dimensions except for the length and the same load. The results show that the influence of the shear deformation to the total deformation is almost nonexistent for the short wall $\mathrm{A}$, but has a big influence on the long wall $\mathrm{C}$. This influence increases to which the bending deformation has almost no influence on the total deformation.

This effect shows, that if the horizontal seismic forces are distributed on the bracing elements based on the stiffness without including the influence of the shear deformation, the distribution of the forces is not correct. Therefore, a replacement moment of inertia, which considers the influence of the shear deformation, will be used to distribute the horizontal seismic force on the 
bracing walls. The replacement moment of inertia $\mathrm{l}_{\mathrm{e}}$ was introduced by F. P. Mueller and E. Keintzel in their book "Erdbebensicherung von Hochbauten" in 1978 and is calculated according to formula 2.7 below.

$$
I_{r}=\frac{I}{1+\frac{3,64 \cdot I}{h^{2} \cdot A} \cdot \frac{E}{G}}
$$

This formula is used to determine the replacement moment of inertia for all bracing walls. The proportion of each replacement moment of inertia to the sum of them all, determines how much of the horizontal seismic forces of each floor is absorbed of each bracing element. Appendix $L$ and $\mathrm{M}$ illustrate the calculation of the replacement moment of inertia for each bracing wall. Appendix $\mathrm{L}$ shows the calculation for the ground floor and appendix $\mathrm{M}$ for the upper floors. Table 22 below summarizes the results of appendix $L$ and $M$.

\begin{tabular}{r|c|c|c|c}
\multirow{2}{*}{} & \multicolumn{2}{|c|}{ Moment of inertia } & \multicolumn{2}{c}{ Replacement moment of inertia } \\
& $\mathbf{I}_{\mathbf{x}}\left[\mathbf{m}^{4}\right]$ & $I_{\mathbf{y}}\left[\mathbf{m}^{4}\right]$ & $I_{\mathbf{r}, \mathbf{x}}\left[\mathbf{m}^{4}\right]$ & $I_{\mathbf{r}, \mathbf{y}}\left[\mathbf{m}^{4}\right]$ \\
\hline Ground floor & 169,29 & 132,18 & 45,85 & 44,99 \\
\hline Upper floors & 169,29 & 132,18 & 29,16 & 29,52 \\
\hline
\end{tabular}

Table 22 Summary of appendix $L$ and M: Moment of inertia and replacement moment of inertia for each floor

However, the investigated building also contains tilted pillars that can absorb horizontal forces. This can be considered by calculating the required moment of inertia of a wall that has the same horizontal deformation as one tilted pillar due to the same load. Afterwards, the total moment of inertia of all tilted pillars can be determined.

The software RFEM5 by Dlubal is used to determine the horizontal deformation of a tilted pillar. Since the ground floor is higher than the upper floors, two pillars will be implemented because the floor height has an influence on the resulting horizontal deformation. Figure 10 shows the tilted pillars and their horizontal deformation due to a horizontal load of $1.000 \mathrm{kN}$. Since the upper floors have a higher floor height than the ground floor, the horizontal deformation of a pillar from the ground floor must be larger than the horizontal deformation of the upper floors due to the same horizontal force. 


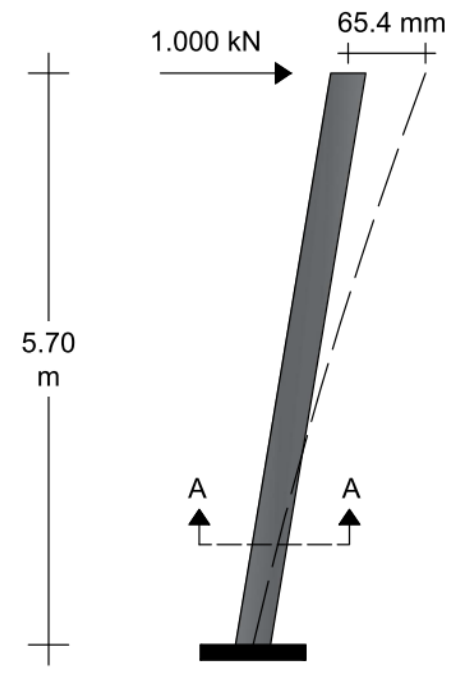

Ground floor

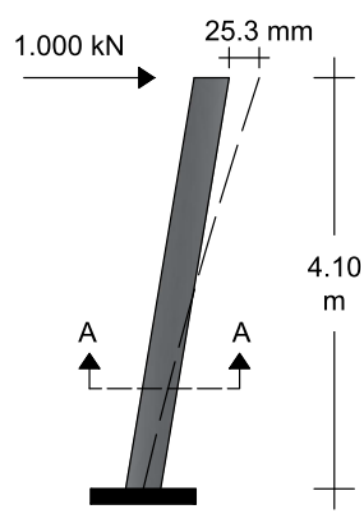

Upper floors

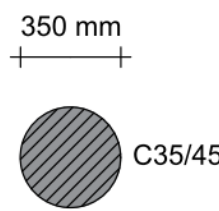

Cross section A-A

Figure 10 Horizontal deformation of tilted pillars due to horizontal force according to RFEM

To determine the required moment of inertia of a wall with the same horizontal deformation as a tilted pillar, the same formula as for the bending deformation from table 21 will be used. The shear deformation will be neglected, since the wall represents a pillar which is not affected by shear deformation due to its small cross section.

$$
I_{\text {req }}=\frac{F \cdot h^{3}}{3 \cdot E \cdot w_{b}}
$$

Now that all parameters are known, the required moment of inertia can be determined for a tilted pillar on the ground floor as wells as on the upper floors as table 22 shows below.

\begin{tabular}{r|cc} 
& Ground floor & Upper floors \\
\hline Force $F$ & $1.000 \mathrm{kN}$ & $1.000 \mathrm{kN}$ \\
\hline Wall height $h$ & $5,70 \mathrm{~m}$ & $4,10 \mathrm{~m}$ \\
\hline Modulus of elasticity $E$ & $34.000 \mathrm{MN} / \mathrm{m}^{2}$ & $34.000 \mathrm{MN} / \mathrm{m}^{2}$ \\
\hline Bending deformation $w_{b}$ & $65,4 \mathrm{~mm}$ & $25,3 \mathrm{~mm}$ \\
\hline Required moment of inertia I $I_{\text {rea }}$ & $0.02776 \mathrm{~m}^{4}$ & $0.02671 \mathrm{~m}^{4}$ \\
\hline
\end{tabular}

Table 23 Calculation of required moment of inertia of one tilted pillar

The required moment of inertia can now be used to determine how much of the horizontal seismic forces of each floor will be absorbed by the pillars. Since the tilted pillars can only absorb a horizontal force in the direction in which they are tilted, table 24 shows the number of tilted 
pillars and the total moment of inertia of each floor in $X$ and $Y$ direction considering only the tilted pillars. The calculation of the total moment of inertia of each floor follows a simple multiplication of the number of pillars with the moment of inertia of one pillar from table 23.

\begin{tabular}{r|cc|cc} 
& $\begin{array}{c}\text { Number of pillars } \\
\text { in X direction }\end{array}$ & $\begin{array}{c}\text { Total moment of } \\
\text { inertia } \mathbf{I}_{\mathbf{x}}\end{array}$ & $\begin{array}{c}\text { Number of pillars } \\
\text { in Y direction }\end{array}$ & $\begin{array}{c}\text { Total moment of } \\
\text { inertia } \mathbf{I}_{\mathbf{y}}\end{array}$ \\
\hline Ground floor & 54 & $1,50 \mathrm{~m}^{4}$ & 57 & $1,58 \mathrm{~m}^{4}$ \\
\hline First floor & 43 & $1,15 \mathrm{~m}^{4}$ & 70 & $1,87 \mathrm{~m}^{4}$ \\
\hline Second floor & 47 & $1,26 \mathrm{~m}^{4}$ & 72 & $1,92 \mathrm{~m}^{4}$ \\
\hline Third floor & 53 & $1,42 \mathrm{~m}^{4}$ & 67 & $1,79 \mathrm{~m}^{4}$ \\
\hline
\end{tabular}

Table 24 Total moment of inertia of tilted pillars in each floor

Now all parameters are known to determine the proportion which will be absorbed of each bracing element in each floor. Therefore, the total moment of inertia of all bracing elements in $\mathrm{X}$ and $\mathrm{Y}$ direction will be determined. Then, the relation of the individual moment of inertia of the bracing element to the total moment of inertia determines the percentage that the bracing element absorbs. Table 25 shows the proportion that each bracing element absorbs in each floor which is a summary of appendix $\mathrm{N}$ to $\mathrm{Q}$.

\begin{tabular}{|c|c|c|c|c|c|c|c|c|c|}
\hline \multirow{2}{*}{$\begin{array}{r}\text { Bracing } \\
\text { element }\end{array}$} & \multicolumn{4}{|c|}{ Walls in $\mathrm{X}$ direction: $\mathrm{I}_{\mathrm{e}} / \Sigma \mathrm{I}_{\mathrm{e}}[\%]$} & \multirow{2}{*}{$\begin{array}{l}\text { Bracing } \\
\text { element }\end{array}$} & \multicolumn{4}{|c|}{ Walls in $Y$ direction: $I_{\mathrm{e}} / \sum \mathrm{I}_{\mathrm{e}}[\%]$} \\
\hline & Floor 0 & Floor 1 & Floor 2 & Floor 3 & & Floor 0 & Floor 1 & Floor 2 & Floor 3 \\
\hline 102 & 27,07 & 23,84 & 23,76 & 23,63 & 107 & 5,88 & 6,19 & 6,18 & 6,20 \\
\hline 104 & 9,23 & 9,49 & 9,46 & 9,41 & 109 & 3,83 & 4,29 & 4,28 & 4,30 \\
\hline 110 & 0,97 & 1,33 & 1,32 & 1,31 & 111 & 3,83 & 4,29 & 4,28 & 4,30 \\
\hline 112 & 0,84 & 1,15 & 1,15 & 1,14 & 201 & 0,69 & 0,92 & 0,92 & 0,92 \\
\hline 114 & 0,97 & 1,33 & 1,32 & 1,31 & 203 & 4,79 & 5,19 & 5,18 & 5,21 \\
\hline 202 & 6,36 & 6,94 & 6,91 & 6,88 & 205 & 6,52 & 6,75 & 6,74 & 6,77 \\
\hline 302 & 7,41 & 7,90 & 7,87 & 7,83 & 301 & 5,49 & 5,83 & 5,82 & 5,85 \\
\hline 402 & 2,42 & 3,02 & 3,01 & 2,99 & 303 & 5,49 & 5,83 & 5,82 & 5,85 \\
\hline 404 & 1,12 & 1,51 & 1,50 & 1,49 & 401 & 24,11 & 20,48 & 20,45 & 20,54 \\
\hline 406 & 8,68 & 9,02 & 8,98 & 8,94 & 403 & 2,98 & 3,45 & 3,45 & 3,46 \\
\hline 408 & 7,08 & 7,59 & 7,56 & 7,53 & 405 & 3,61 & 4,08 & 4,07 & 4,09 \\
\hline 410 & 0,84 & 1,15 & 1,15 & 1,14 & 407 & 13,54 & 12,48 & 12,46 & 12,51 \\
\hline 412 & 1,12 & 1,51 & 1,50 & 1,49 & 409 & 15,84 & 14,26 & 14,23 & 14,29 \\
\hline 414 & 22,73 & 20,44 & 20,36 & 20,26 & - & - & - & - & - \\
\hline Pillars & 3,17 & 3,79 & 4,14 & 4,64 & Pillars & 3,39 & 5,96 & 6,11 & 5,72 \\
\hline Total & 100,00 & 100,00 & 100,00 & 100,00 & Total & 100,00 & 100,00 & 100,00 & 100,00 \\
\hline
\end{tabular}

Table 25 Distribution of a horizontal force on bracing elements on each floor 


\subsection{CUTTING FORCES ALONG BRACING WALLS}

Since the proportions that each bracing element absorbs of a horizontal force in each floor, the cutting forces along each bracing element can now be determined. Therefore, the horizontal seismic forces of figure 8 will be distributed on each bracing element in each floor according to table 25. The result is a MDOF system for each bracing element which can be used to determine the shear and moment distribution.

Figure 11 shows the MDOF system, shear and moment distribution for wall 102.
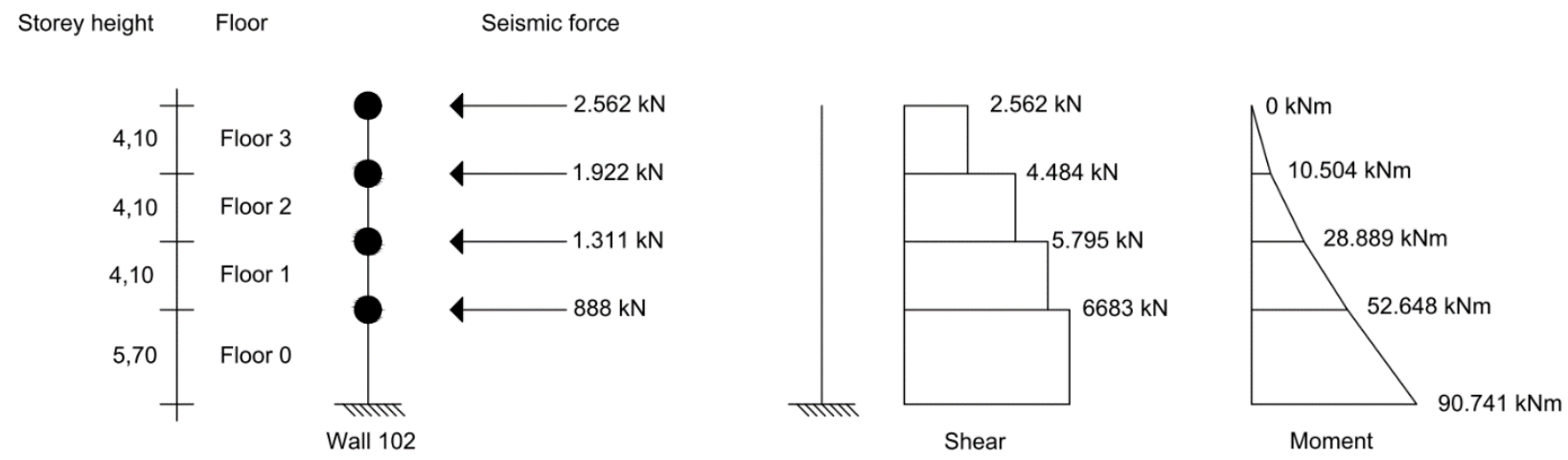

Figure 11 MDOF system, shear and moment distribution of wall 102

Following the same way, table 26 shows the results of the shear distribution for each bracing wall. It needs to be mentioned that the shear force is constant for each bracing wall in each floor.

\begin{tabular}{r|cccc|r|cccc}
$\begin{array}{r}\text { Bracing } \\
\text { element }\end{array}$ & \multicolumn{3}{|c|}{ Walls in X direction: V [kN] } & Bracing & \multicolumn{4}{c}{ Walls in Y direction: V [kN] } \\
\hline $\mathbf{1 0 2}$ & 6.683 & 5.795 & 4.484 & 2.562 & $\mathbf{1 0 7}$ & 1.706 & 1.513 & 1.172 & 672 \\
\hline $\mathbf{1 0 4}$ & 2.610 & 2.308 & 1.786 & 1.020 & $\mathbf{1 0 9}$ & 1.174 & 1.048 & 812 & 466 \\
\hline $\mathbf{1 1 0}$ & 354 & 322 & 249 & 142 & $\mathbf{1 1 1}$ & 1.174 & 1.048 & 812 & 466 \\
\hline $\mathbf{1 1 2}$ & 307 & 280 & 217 & 124 & $\mathbf{2 0 1}$ & 247 & 225 & 174 & 100 \\
\hline $\mathbf{1 1 4}$ & 354 & 322 & 249 & 142 & $\mathbf{2 0 3}$ & 1.427 & 1.269 & 984 & 565 \\
\hline $\mathbf{2 0 2}$ & 1.895 & 1.687 & 1.305 & $\mathbf{7 4 6}$ & $\mathbf{2 0 5}$ & 1.865 & 1.651 & 1.279 & 734 \\
\hline $\mathbf{3 0 2}$ & 2.163 & 1.920 & 1.486 & 849 & $\mathbf{3 0 1}$ & 1.606 & 1.426 & 1.105 & 634 \\
\hline $\mathbf{4 0 2}$ & 813 & 734 & 568 & 324 & $\mathbf{3 0 3}$ & 1.606 & 1.426 & 1.105 & 634 \\
\hline $\mathbf{4 0 4}$ & 403 & 366 & 283 & 162 & $\mathbf{4 0 1}$ & 5.799 & 5.008 & 3.881 & 2.227 \\
\hline $\mathbf{4 0 6}$ & 2.477 & 2.192 & 1.696 & 969 & $\mathbf{4 0 3}$ & 942 & 844 & 654 & 375 \\
\hline $\mathbf{4 0 8}$ & 2.078 & 1.846 & 1.428 & 816 & $\mathbf{4 0 5}$ & 1.116 & 997 & 773 & 443 \\
\hline $\mathbf{4 1 0}$ & 307 & 280 & 217 & 124 & $\mathbf{4 0 7}$ & 3.495 & 3.051 & 2.364 & 1.356 \\
\hline $\mathbf{4 1 2}$ & 403 & 366 & 283 & 162 & $\mathbf{4 0 9}$ & 4.005 & 3.485 & 2.701 & 1.549 \\
\hline $\mathbf{4 1 4}$ & 5.714 & 4.968 & 3.844 & 2.197 & - & - & - & - & - \\
\hline $\mathbf{2 6 5}$ & Floor & eloor 2 & Floor 3 & elenent & Floor 0 & Floor 1 & Floor 2 & Floor 3 \\
\hline
\end{tabular}

Table 26 Shear force distribution along bracing walls 
Next, table 27 shows the moment distribution along each bracing element. The values of the moment distribution shown in table 27 of each floor are located at the foot of the floor.

\begin{tabular}{r|cccc|r|cccc} 
Bracing & \multicolumn{3}{|c|}{ Walls in X direction: M [kNm] } & Bracing & \multicolumn{3}{c}{ Walls in Y direction: M [kNm] } \\
element & Floor 0 & Floor 1 & Floor 2 & Floor 3 & element & Floor 0 & Floor 1 & Floor 2 & Floor 3 \\
\hline $\mathbf{1 0 2}$ & 90.741 & 52.648 & 28.889 & 10.504 & $\mathbf{1 0 7}$ & 23.487 & 13.764 & 7.562 & 2.756 \\
\hline $\mathbf{1 0 4}$ & 35.846 & 20.966 & 11.504 & 4.183 & $\mathbf{1 0 9}$ & 16.234 & 9.542 & 5.243 & 1.912 \\
\hline $\mathbf{1 1 0}$ & 4.939 & 2.923 & 1.603 & 582 & $\mathbf{1 1 1}$ & 16.234 & 9.542 & 5.243 & 1.912 \\
\hline $\mathbf{1 1 2}$ & 4.295 & 2.543 & 1.395 & 507 & $\mathbf{2 0 1}$ & 3.455 & 2.045 & 1.123 & 409 \\
\hline $\mathbf{1 1 4}$ & 4.939 & 2.923 & 1.603 & 582 & $\mathbf{2 0 3}$ & 19.687 & 11.555 & 6.350 & 2.316 \\
\hline $\mathbf{2 0 2}$ & 26.129 & 15.325 & 8.409 & 3.059 & $\mathbf{2 0 5}$ & 25.650 & 15.022 & 8.255 & 3.010 \\
\hline $\mathbf{3 0 2}$ & 29.776 & 17.445 & 9.572 & 3.481 & $\mathbf{3 0 1}$ & 22.132 & 12.978 & 7.132 & 26.01 \\
\hline $\mathbf{4 0 2}$ & 11.301 & 6.666 & 3.657 & 1.329 & $\mathbf{3 0 3}$ & 22.132 & 12.978 & 7.132 & 2.601 \\
\hline $\mathbf{4 0 4}$ & 5.618 & 3.323 & 1.822 & 662 & $\mathbf{4 0 1}$ & 78.634 & 45.579 & 25.045 & 9.131 \\
\hline $\mathbf{4 0 6}$ & 34.032 & 19.914 & 10.927 & 3.974 & $\mathbf{4 0 3}$ & 13.050 & 7.681 & 4.221 & 1.538 \\
\hline $\mathbf{4 0 8}$ & 28.613 & 16.769 & 9.203 & 3.348 & $\mathbf{4 0 5}$ & 15.434 & 9.075 & 4.986 & 1.818 \\
\hline $\mathbf{4 1 0}$ & 4.295 & 2.543 & 1.395 & 507 & $\mathbf{4 0 7}$ & 47.687 & 27.765 & 15.256 & 5.561 \\
\hline $\mathbf{4 1 2}$ & 5.618 & 3.323 & 1.822 & 662 & $\mathbf{4 0 9}$ & 54.541 & 31.714 & 17.425 & 6.353 \\
\hline $\mathbf{4 1 4}$ & 77.706 & 45.136 & 24.767 & 9.007 & - & - & - & - & - \\
\hline
\end{tabular}

Table 27 Moment distribution along bracing walls

Table 26 and 27 constitute the result of this simplified approach for shear and moment distribution for predimensioning a structure for earthquake resistance.

In the following chapter, the dimensioning calculation will be performed using a finite element software. Afterwards the moment distribution of this simplified approach will be compared to moment distribution of the dimensioning calculation according to the finite element software. 


\section{DIMENSIONING FOR EARTHQUAKE RESISTANCE}

\subsection{BACKGROUND INFORMATION OF FENITE ELEMENT MODEL}

After the simplified approach of pre-dimensioning for earthquake resistance in chapter 2 , this chapter describes a way to dimension the investigated building for earthquake resistance. According to EC 8-1 table 4.1, a spatial model is required to perform the earthquake calculation since the criteria for regularity in plan and in elevation of the investigated building are not fulfilled.

To match the criteria of a building with regularity in plan, the building must be symmetric in two directions according to EC 8-1: 4.2.3.2 (2). Since the investigated is not symmetric in two directions it has no regularity in plan.

Furthermore, the criteria for regularity in elevation of a building is that all bracing elements must connect between the top of the building and their foundation without any interruptions according to EC 8-1: 4.2.3.3 (2). Furthermore, the lateral stiffness and the mass of the individual floors are constant and therefore the second criteria for regularity in elevation according to EC 8-1: 4.2.3.3 (3) is met. This means that the investigated building has regularity in elevation.

According to table 4.1 of EC8, the linear-elastic analysis uses a lateral force method of analysis if the fundamental period of vibration period $T_{1}$ meets the following criteria according to EC 8-1: 4.3.3.2.1 (2)a):

$$
T_{1} \leq\left\{\begin{array}{c}
4 \cdot T_{C} \\
2,0 \mathrm{~s}
\end{array}\right.
$$

According to EC 8-1: 4.3.3.2.2 (3), $\mathrm{T}_{1}$ can be determined for buildings with heights of up to $40 \mathrm{~m}$ by the following equation.

$$
T_{1}=C_{t} \cdot H^{3 / 4}
$$

In this equation $C_{t}$ can be assumed to be 0,050 and $H$ is the building height which is $18 \mathrm{~m}$. This results in a period of $T_{1}=0,437 \mathrm{~s}$. According to the concept of the NA table NA.3 for underground condition $C-S, T_{c}$ is $0,50 \mathrm{~s}$ and therefore the requirement for the linear-elastic analysis to use the lateral force method of analysis is met. 
Furthermore, table 4.1 of EC 8-1 determines the behaviour factor, which is in the case of the investigated building the reference value of $q=1.50$ according to the concept of the NA table NA.8. The value of $q$ is chosen to be a conservative solution since it is the smallest value and it affects the calculation of the design elastic response spectrum $S_{d}(T)$ as illustrated in table 9.

To implement a spatial model of the investigated building, the software RFEM5 by Dlubal will be used. The following chapter introduces the software and describes the process of developing the model.

\subsection{INTRODUCTION OF FINITE ELEMENT SOFTWARE RFEM5}

The finite element software RFEM5 by Dlubal can be used to implement 2D or 3D models of buildings. Therefore plates, walls, shells, solids and frame structures can be implemented into a model.

In case of the investigated building, only members and surfaces are needed. Surfaces are used to constitute each floor or roof while the members present beams, tilted pillars and walls. The software allows to change the settings of members so that the tilted pillars for example only carry normal forces in the direction of the member and no shear force. Those members are called trusses.

Moreover, RFEM5 has an add-on module which is called DYNAM Pro. This module can be used to calculate the earthquake resistance. The module will be introduced in detail in chapter 3.4.

\subsection{CREATING SPATIAL MODEL OF INVESTIGATED BUILDING}

\subsubsection{Modelling of bracing walls}

For the creation of a 3D model there is not only one way or possibility to get the result. There are many possibilities to model different structures. This is also the case for modelling the bracing walls of the investigated building. In the following, two different ways will be performed and investigated. The option that fits better to the needs of a model will be used in the main model.

One way is to model a bracing wall as a surface. The second possibility is to model the bracing wall as a member. The first attempt will be performed for a surface and a member with outer 
dimensions of 5,0 $\mathrm{m} \times 0,30 \mathrm{~m} \times 5,0 \mathrm{~m}$ (length $\mathrm{x}$ width $\mathrm{x}$ height). Both walls will be exposed to a horizontal load of $100 \mathrm{kN}$.

Figure 12 shows two walls. One of which is modelled by a surface on the left and the other wall modelled by a member on the right.
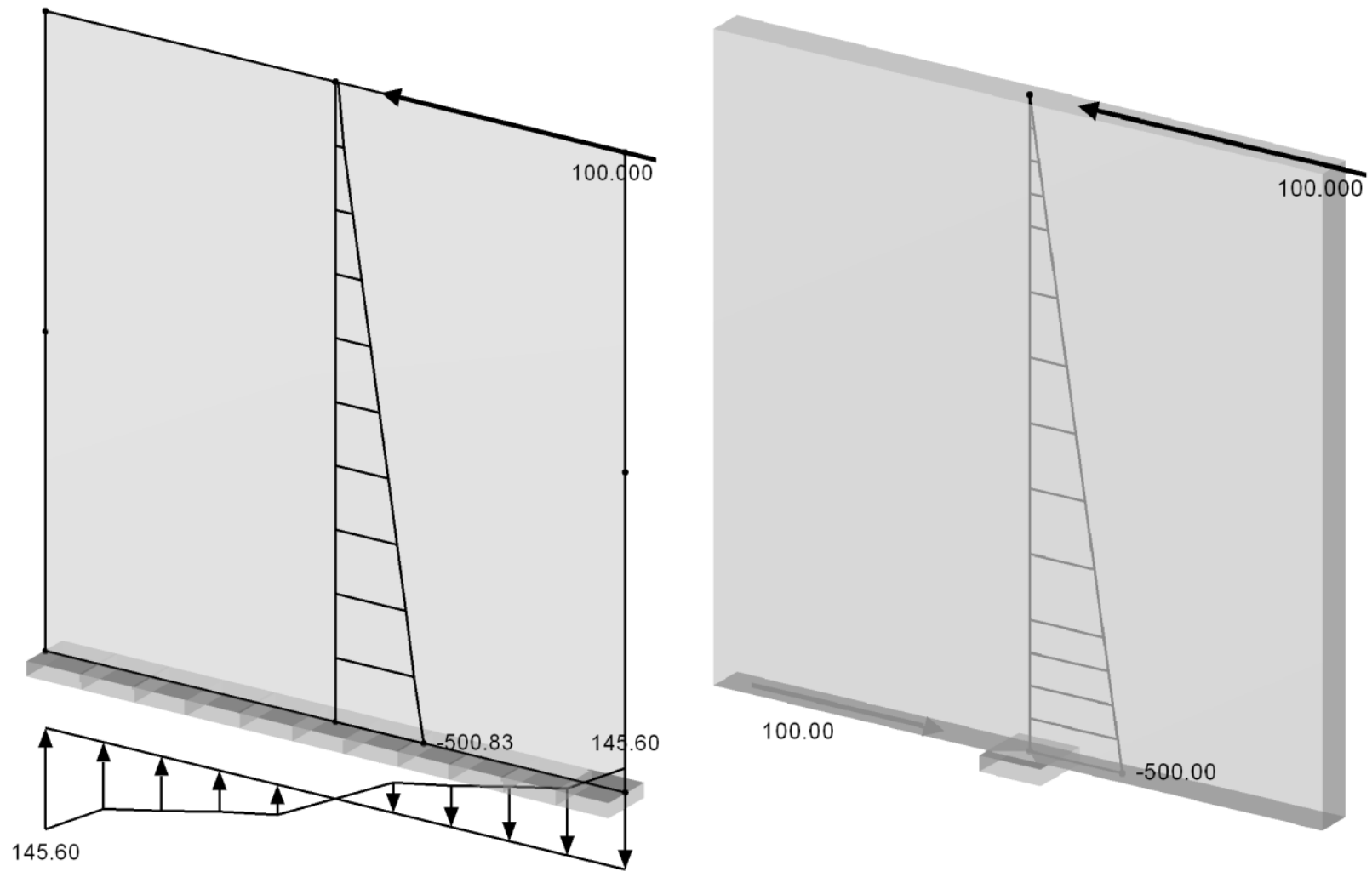

Figure 12 Illustration of a wall modelled by a surface (left) and member (right)

The wall which is modelled by a surface is defined by four points and supported by a line support. To illustrate the distribution of the cutting forces along the wall, a result beam must be installed. A result beam has no cross section, it only illustrates the cutting forces within a defined volume around the result beam for the surface in which it is integrated.

The wall which is modelled by a member is defined by two points and supported by one nodal support. No result beam is required to illustrate the moment, shear or normal force distribution along the wall.

Both possibilities to model a wall have advantages. The definition of the member only needs two points and a cross section. Changes of the cross section are implemented quickly and easily. 
Furthermore, the course of the forces within the member and its deformation are easy to understand. On the other hand, the member does not convert the moment at the foot of the wall into a stress distribution. Since the calculation for the reinforcement requires a tensile force, the moment must be converted into a stress first.

The surface converts the resulting moment into a vertical line load at the foot of the wall. Moreover, it distributes the vertical line load along the length of the wall. However, the surface requires more expense to define and changes in cross section are not implemented easily. Furthermore, the course of the forces within the wall and its deformation are more difficult to understand.

A further comparison of the two walls connects them by a horizontal roof which is suspended to a horizontal line force. In the following model, which is illustrated in figure 13 , both investigated walls will be connected by a surface of an area by $10 \times 10 \mathrm{~m}$. The horizontal line load is $20 \mathrm{kN} / \mathrm{m}$.

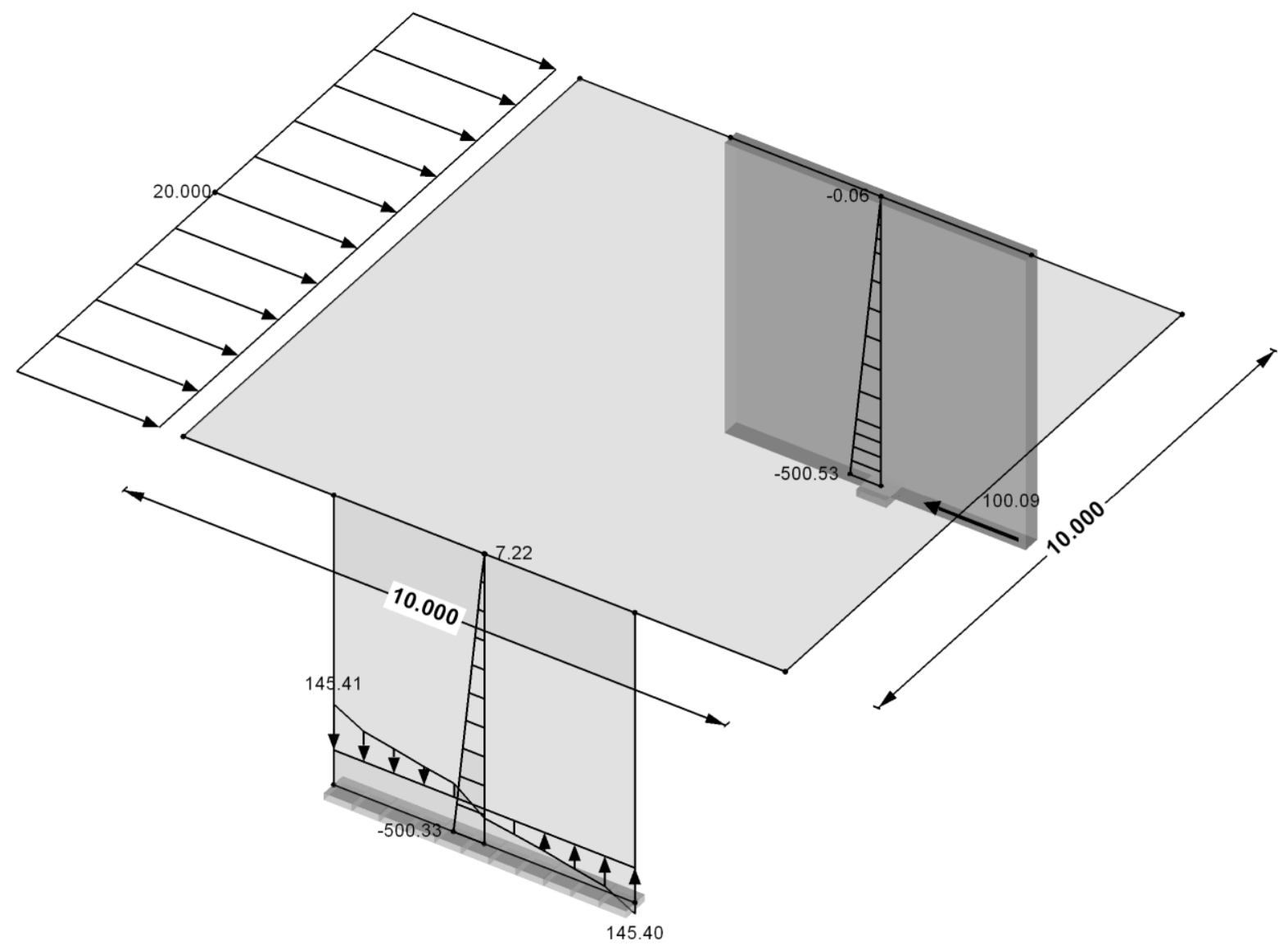

Figure 13 Model for investigation of absorption behaviour of investigated walls 
The result of the investigation shows, that both walls absorb the same amount of the horizontal line load. Since both walls absorb the half of the line load, the resulting moment distribution along the walls match the moment distribution of the walls of figure 12. This means that both ways of modeling a wall have the same stiffness. The only difference that stands out, is that the moment distribution of the wall, which is modelled by a surface, has a change of sign on the top. This is due to constraining forces.

Considering the results from the two investigations above, the way of modelling the walls of the investigated building for the spatial model, are performed by modelling a member. This is due to the easy and quick possibility to implement a wall and to change location or cross section. Furthermore, the course of the cutting forces is easier to understand which helps in finding possible mistakes. In the following, a possibility to convert the moment at the foot of the wall into a line load that can be used to determine the required reinforcement will be introduced.

\subsubsection{Determination of required vertical reinforcement}

To determine the required vertical reinforcement for earthquake resistance, the resulting moment must be converted into a stress distribution. Therefore, the system is illustrated in figure 14 below and then calculated underneath. The total tensile or compressive force is multiplied with the lever arm between and then compared with moment $M$. This calculation assumes a noncracked concrete.

[M: Stress]

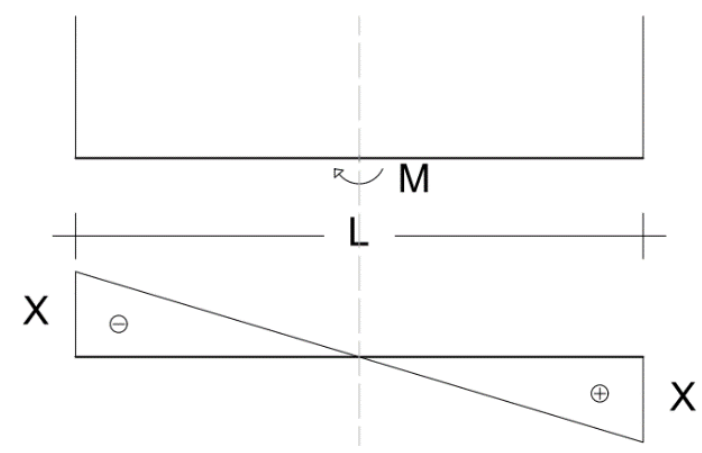

Figure 14 System for conversion of moment into stress distribution

$$
M=2 \cdot((L / 2 \cdot X \cdot 1 / 2) \cdot 2 / 3 \cdot L / 2)=\frac{L^{2} \cdot X}{6}
$$




$$
X=\frac{6 \cdot M}{L^{2}}
$$

Now that the moment is converted into a stress, the superposition with the vertical force due to vertical loading can be performed to reduce the resulting reinforcement since a vertical compressive force reduces the tensile stress resulting of the moment. It will be assumed that the vertical load is distributed equally along the wall. The static system and shear distribution due to the moment and vertical loading is illustrated in figure 15 below.

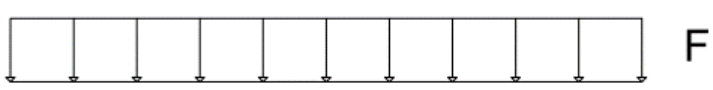

[M: Stress]

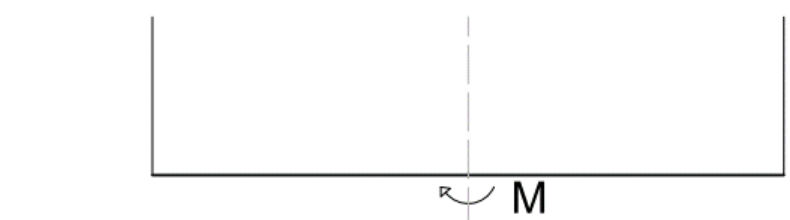

[F: Stress]

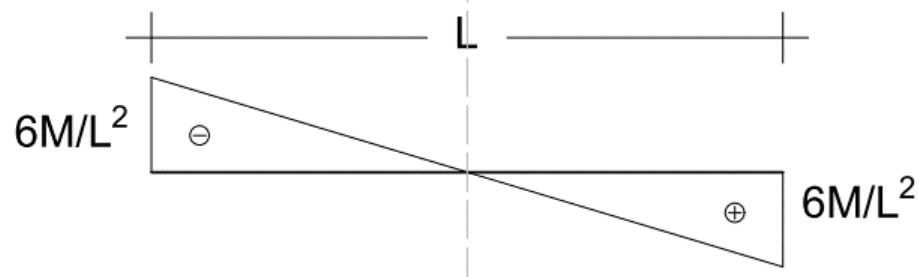

[M+F: Stress]

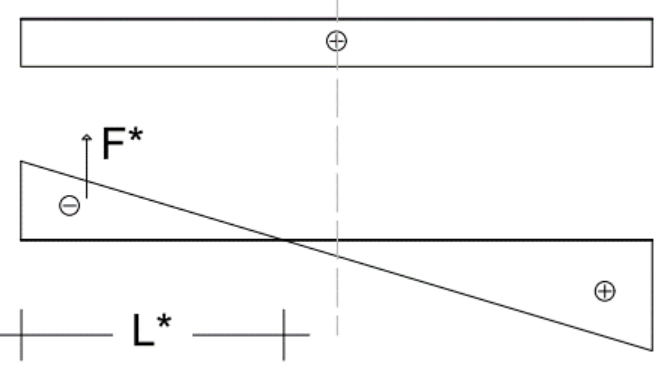

$\mathrm{F} / \mathrm{L}$

Figure 15 Static system and shear distribution due to vertical and earthquake loading

The length $L^{*}$ of the negative stress can be calculated following the formula below.

$$
L^{*}=\frac{\frac{6 \cdot M}{L^{2}}-\frac{F}{L}}{\frac{6 \cdot M}{L^{2}}} \cdot L \cdot \frac{1}{2}
$$

Since the distribution of the stress is trapezoidal, an even distribution of the reinforcement would be wrong. In this case, the reinforcement would be oversized in sections closer to the middle of the wall but more importantly in sections closer to the end of the wall, the reinforcement would 
not be enough for the occurring tensile force. Therefore, the reinforcement needs to be distributed according to the stress. This results in more reinforcement on both ends of the wall. To account for the effect described above, the distribution of the reinforcement will be divided into 10 sections with the same length. In every section the resulting tensile force will be calculated to determine the vertical reinforcement in this section. Figure 16 below illustrates the 10 subdivisions.

$[\mathrm{M}+\mathrm{F}:$ Stress $]$

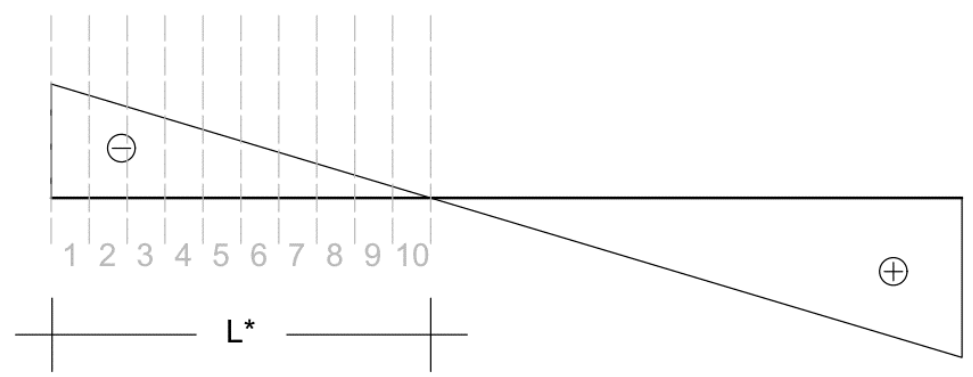

Figure 16 Subdivisions to determine the required vertical reinforcement

To determine the required vertical reinforcement for each subdivision of the wall, the area $A_{i}$ of the vertical line force for each section needs to be calculated. The area is not only the area, but also the vertical tensile force that needs to be absorbed by the vertical reinforcement. Therefore, the amount of required reinforcement can be determined by the following formula.

$$
a_{s, v, i}=\frac{A_{i}}{f_{y d}}
$$

The result is the required amount of vertical reinforcement for each subdivision. Even though figure 16 shows the tensile force only on one side of the wall, the vertical reinforcement will be installed symmetrically on both ends of the wall since the moment that leads to a tensile force can change in sign.

\subsubsection{Example for determination of vertical reinforcement}

To illustrate an example of the determination of the vertical reinforcement, the wall used in chapter 3.3.1 will be used. The wall has a height of $5 \mathrm{~m}$, a length of $5 \mathrm{~m}$ and a width of $0,30 \mathrm{~m}$. The resulting moment at the foot of the wall is $500 \mathrm{kNm}$. 
First, the maximum stress according to figure 14 due to the moment will be calculated. The calculation is illustrated below.

$$
\begin{gathered}
X=\frac{6 \cdot M}{L^{2}} \\
X=\frac{6 \cdot 500[k N m]}{5[m]^{2}} \\
X=120[k N / m]
\end{gathered}
$$

The result of $X$ of $120 \mathrm{kN} / \mathrm{m}$ is comparable to the stress distribution of figure 12 for the wall that is modelled by a surface.

After the distribution of the stress is determined, two walls will now be investigated. Wall A will

\begin{tabular}{|c|c|c|c|c|}
\hline & \multicolumn{2}{|c|}{ Wall A } & \multicolumn{2}{|c|}{ Wall B } \\
\hline Moment $[\mathrm{kNm}]$ & \multicolumn{2}{|c|}{500} & \multicolumn{2}{|c|}{500} \\
\hline Vertical force $\quad[k N]$ & \multicolumn{2}{|c|}{0} & \multicolumn{2}{|c|}{100} \\
\hline M: Stress $[\mathrm{kN} / \mathrm{m}]$ & \multicolumn{2}{|c|}{120} & \multicolumn{2}{|c|}{120} \\
\hline F: Stress $[\mathrm{kN} / \mathrm{m}]$ & \multicolumn{2}{|c|}{0} & \multicolumn{2}{|c|}{20} \\
\hline M+F: Stress $[\mathrm{kN} / \mathrm{m}]$ & -120 & +120 & -100 & +140 \\
\hline $\mathrm{L}^{*} \quad[\mathrm{~m}]$ & \multicolumn{2}{|c|}{2,50} & \multicolumn{2}{|c|}{2,10} \\
\hline
\end{tabular}
only be exposed to a moment and Wall B to a moment and a vertical line force. The required vertical reinforcement will then be calculated.

Table 28 Calculation of $L^{*}$ for example of vertical reinforcement

Now that all factors are known, the required vertical reinforcement can be determined for ten subsections of $L^{*}$ as shown below. The used design value of yield strength of steel is $435 \mathrm{~N} / \mathrm{mm}^{2}$.

\begin{tabular}{c|cccccccccc|c} 
& $\mathbf{L}_{\mathbf{1}}$ & $\mathbf{L}_{\mathbf{2}}$ & $\mathbf{L}_{\mathbf{3}}$ & $\mathbf{L}_{\mathbf{4}}$ & $\mathbf{L}_{5}$ & $\mathbf{L}_{6}$ & $\mathbf{L}_{\mathbf{7}}$ & $\mathbf{L}_{8}$ & $\mathbf{L}_{9}$ & $\mathbf{L}_{\mathbf{1 0}}$ & $\mathbf{L}_{\text {tot }}$ \\
\hline Wall A $\left[\mathrm{cm}^{2}\right]$ & 0,70 & 0,60 & 0,50 & 0,40 & 0,40 & 0,30 & 0,20 & 0,20 & 0,10 & 0,0 & 3,40 \\
\hline Wall B $\left[\mathrm{cm}^{2}\right]$ & 0,50 & 0,40 & 0,40 & 0,30 & 0,30 & 0,20 & 0,20 & 0,10 & 0,10 & 0,0 & 2,40 \\
\hline
\end{tabular}

Table 29 Required vertical reinforcement for Wall A and Wall B of example for vertical reinforcement

The distribution of the required vertical reinforcement show that the vertical force has influence on the amount of required reinforcement. Wall $A$ requires $40 \%$ more vertical reinforcement than wall B. Moreover, the example shows that the stress distribution is a simplification that can be used to determine the vertical reinforcement for non-cracked concrete. 


\subsubsection{Modelling of tilted pillars}

A tilted pillar can be modelled by two points which are connected by a member. Therefore, only the cross section, start and end point of the pillar need to be known. The feature of a tilted pillar is to absorb horizontal forces.

Before the pillar can be modelled, the engineer needs to determine whether the pillar carries normal forces, shear forces and moments or only normal forces along the direction of the pillar. If the pillar is modelled as a beam, the pillar can absorb normal forces, shear forces and moments. If the pillar is modelled as a truss, it only carries normal forces along the member. A comparison of a pillar modelled as a beam and second pillar modelled as a truss suspended to a vertical force of $100 \mathrm{kN}$ is illustrated in figure 17 below. The angle of the tilted pillar for this investigation is $11,31^{\circ}$. The resulting cutting forces are summarized in table 30.
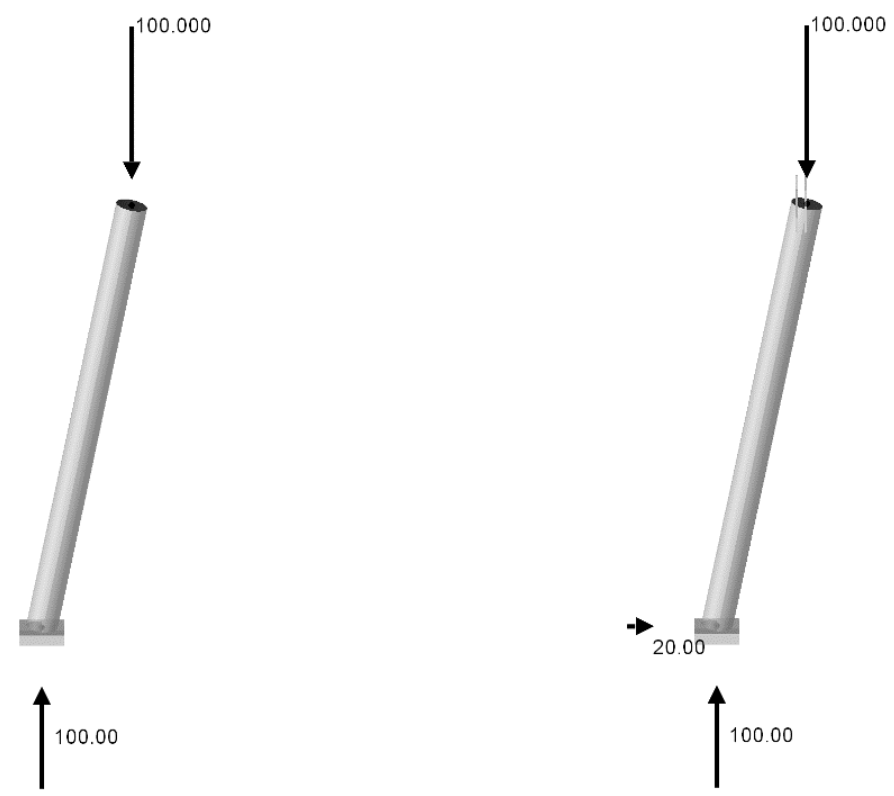

Figure 17 Static system for tilted pillars suspended to a vertical force modelled as a beam (left) and as a truss (right)

\begin{tabular}{r|cc} 
& Beam & Truss \\
\hline Normal force $[k N]$ & 98,06 & 101,98 \\
\hline Shear force $[k N]$ & 19,61 & 0,00 \\
\hline Moment (bottom) $[k N m]$ & 100,00 & 0,00 \\
\hline
\end{tabular}

Table 30 Resulting cutting forces along pillars illustrated figure 17 
Moreover, the two pillars of figure 17 will be investigated under the load of a horizontal force of $100 \mathrm{kN}$. The static system is illustrated in figure 18 below. The resulting cutting forces are summarized in table 31 underneath.
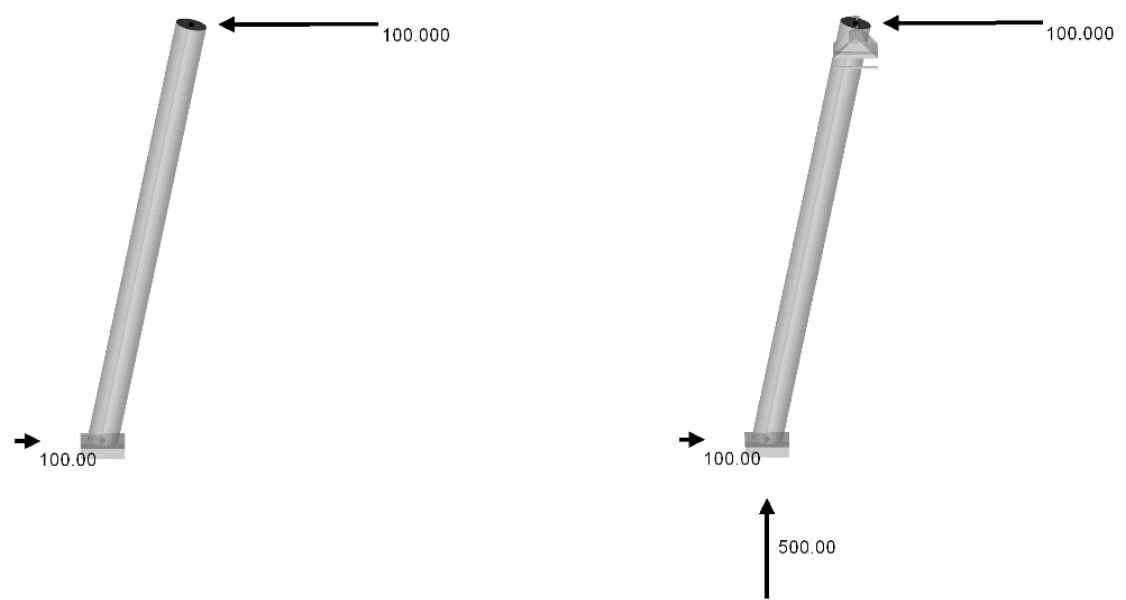

Figure 18 Static system for tilted pillars suspended to a horizontal force modelled as a beam (left) and as a truss (right)

\begin{tabular}{r|cc} 
& Beam & Truss \\
\hline Normal force $[k N]$ & 19,61 & 509,90 \\
\hline Shear force $[k N]$ & 98,06 & 0,00 \\
\hline Moment (bottom) $[k N m]$ & 500,00 & 0,00 \\
\hline
\end{tabular}

Table 31 Resulting cutting forces along pillars illustrated in figure 18

The investigation of the two possibilities to model a tilted pillar show the differences. A tilted pillar modelled by a truss only carries a normal force. This normal force can be way bigger due to a horizontal loading since the pillar can not absorb the horizontal force as a shear force. Moreover, the vertical loading generates a vertical force at the foot of the pillar which needs to be absorbed by a roof or a foundation. However, no moment or shear force is generated by any loading.

The other possibility to model the tilted pillar by a beam does not generate a large normal force due to the horizontal loading but it generates moment, normal and shear forces along the pillar due to any loading. Since the amount of required vertical reinforcement depends mostly on the moment, the chosen member for modelling the tilted pillars will be the truss. Another advantage of the truss is that the forwarding of forces is easier to understand. 


\subsubsection{Final model of investigated building}

Now that most of the features of the investigated building and their possibilities to implement them into a model have been explained, the final model can be installed using the finite element software RFEM5 by Dlubal.

First, the bracing walls will be modelled as a beam with real outer dimensions since RFEM5 already accounts for the shear deformation which is described in chapter 2.3. Afterwards, the pillars will be modelled as trusses so that only a force in the direction of the pillar will be carried. Now that all vertical elements of a floor are installed, the horizontal downstand beams will be modelled as beams with an eccentricity thereby the top edge of the downstand beam is on the same height as the lower edge of the ceiling. Then, a ceiling of the floor will be modelled as a surface. Since the ceiling has openings for escalators or stairs, those openings are modelled as a recess. The last step is to add the loadings listed in table 16 on each floor.

All these steps need to be performed for each floor to finish the total model of the investigated building. The complete model without loading is illustrated in figure 19 below.

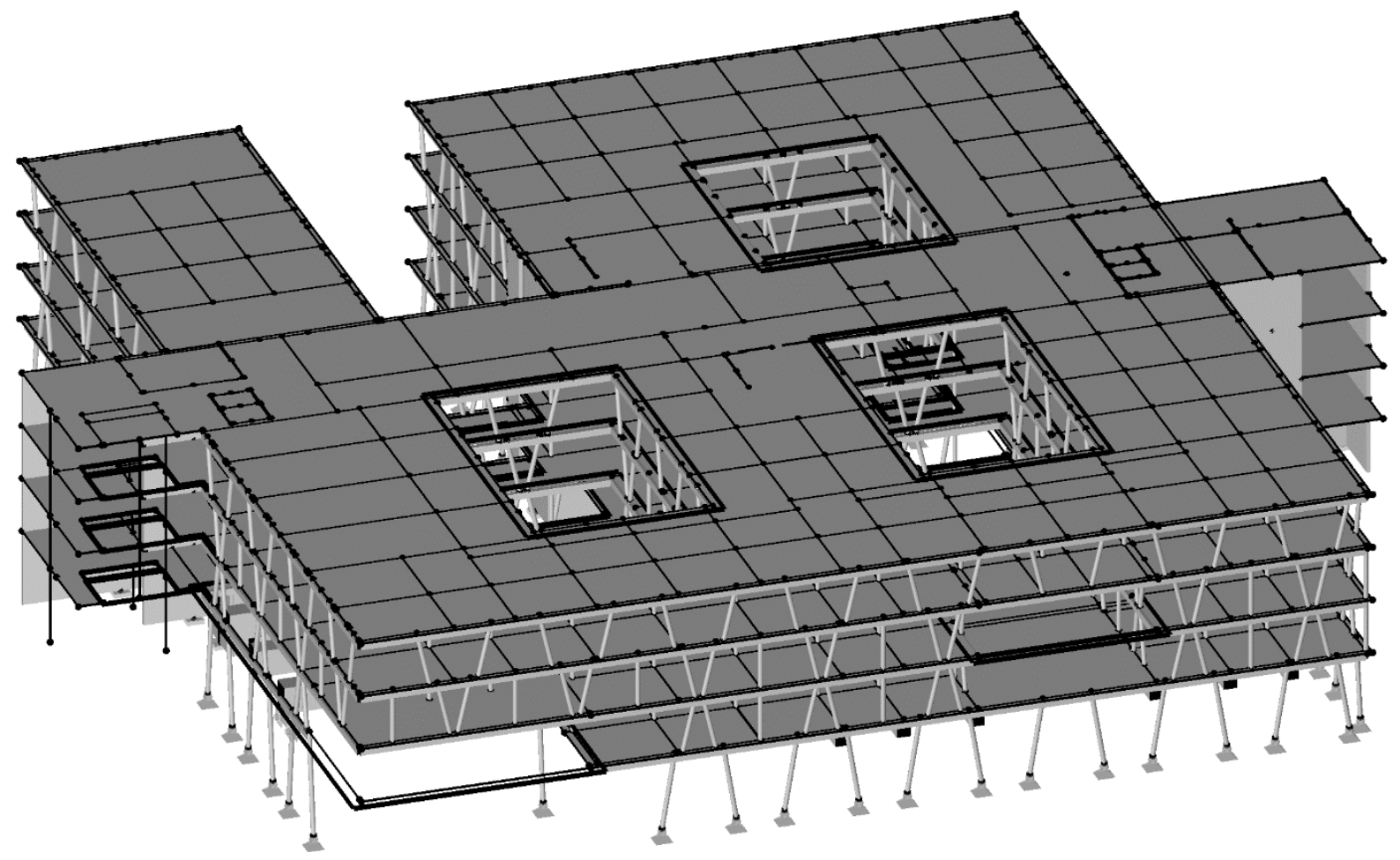

Figure 19 Illustration of RFEM5 model of the investigated building 
After the final model of the investigated is implemented, the earthquake resistance forces can now be generated using the add-on module DYNAM Pro.

\subsection{SEISMIC ANALYSIS OF INVESTIGATED BUILDING}

To calculate the earthquake resistance for the investigated building, the static software RFEM5 by Dlubal offers the add-on module DYNAM Pro which performs seismic analysis using the multimodal response spectrum analysis and generating the equivalent static loads.

First, the input parameters need to be defined. The way of calculating the earthquake resistance is chosen by the response spectrum analysis with the generation of equivalent loads by using mass combinations.

To generate the mass combinations, the mass cases need to be defined first. In the case of the investigated building, there are only permanent and variable loading. Both will be put into a mass case. These mass cases define what loading will be used to establish the equivalent loads of the earthquake. The total masses of permanent and variable loading are summarized and converted into a vertical force in table 32 below.

\begin{tabular}{r|cc} 
& Total mass $[\mathrm{kg}]$ & Vertical force $[\mathrm{kN}]$ \\
\hline Permanent loading & $21.226 .191,40$ & $208.157,90$ \\
\hline Variable loading & $7.621 .983,87$ & $74.746,14$
\end{tabular}

Table 32 Total masses and vertical forces for mass cases of investigated building

After the mass cases are defined, the mass combination and its parameters must be determined according to EC8-1 3.2.4 as shown below.

$$
\sum G_{k, j}+\sum \psi_{E, i} \cdot Q_{k, i}
$$

The parameter $\psi_{\mathrm{E}, \mathrm{i}}$ is explained in chapter 1.3.1, formula 1.2. In case of the investigated building, $\psi_{\mathrm{E}, \mathrm{i}}$ is chosen to be 0,30 for all floors. The reduction of $\psi_{\mathrm{E}, \mathrm{i}}$ by $\varphi$ for all floors except the roof will be neglected to constitute a conservative solution since if a larger mass is chosen, larger equivalent loads will be used for the earthquake resistance calculation.

Next, the natural vibration cases need to be determined. Therefore, the directions will be chosen in which the model will vibrate. For the investigated building, only the $X$ and $Y$ direction are 
chosen. A vibration in Z direction is neglected to avoid large deformations of the surfaces in the vertical direction since the earthquake resistance calculation within this master's project is about the bracing elements.

To determine the equivalent loads, a response spectrum must be determined. Since this master's project is based on the concept of the National Annex of EC 8-1 in Germany, a table with values must be imported into the add-on module since the concept of the NA is not implemented into the module yet. Therefore, the elastic design response spectrum of figure 7 is used according to the concept of the NA NDP to 3.2.2.1.(4) and 3.2.2.2(2)P for vibrations in $\mathrm{X}$ and $\mathrm{Y}$ direction.

A table with all values that are inserted into the add-on module DYNAM Pro to generate the elastic response design spectrum of figure 7 is illustrated in Appendix R.

Next, the modal response combination rule needs to be chosen. On one hand, there is the square root of sum of squares (SRSS) rule which follows the equation below.

$$
R_{S R S S}=\sqrt{R_{1}^{2}+R_{2}^{2}+\ldots+R_{p}^{2}}
$$

In this formula, $R_{1}, R_{2}$ and $R_{p}$ represents each a result of a modal from $p$ modes of the structure. The combination of them all is the result $\mathrm{R}_{\mathrm{SRSS}}$. This combination rule is only allowed for systems where adjacent natural periods meet the following condition:

$$
\frac{T_{i}}{T_{j}}<0,9
$$

On the other hand, there is the Complete Quadratic Combination (CQC) rule which must be applied for all other systems according to EC8-1 4.3.3.3.2 (3)P. The CQC rule is defined by the following equation:

$$
R_{C Q C}=\sqrt{\sum_{i=1}^{p} \sum_{j=1}^{p} R_{i} \varepsilon_{i j} R_{j}}
$$

Where the correlation coefficient $\varepsilon$ is described by the following equation below:

$$
\varepsilon_{i j}=\frac{8 \cdot \sqrt{D_{i} D_{j}}\left(D_{i}+D_{j}\right) \cdot r^{3 / 2}}{\left(1-r^{2}\right)^{2}+4 D_{j} D_{i} r\left(1+r^{2}\right)+4\left(D_{i}^{2}+D_{j}^{2}\right) \cdot r^{2}} \quad \text { with } r=\frac{\omega_{j}}{\omega_{i}}
$$


Since the condition above is not met for the investigated building, the CQC rule must be applied. Therefore, a damping value of 5\% according to EC 8-1 figure 3.2 and figure 3.3 is considered for the calculation of the equivalent loads.

Finally, the mode shapes of the investigated building must be determined. Therefore, it is required according to EC 8-1: 4.3.3.3.1 (3) that the sum of the modal masses equal at least $90 \%$ of the total mass of the structure. The table of the mode shapes including frequency, period, acceleration and effective modal mass factor for $\mathrm{X}, \mathrm{Y}$ and $\mathrm{Z}$ direction of each mode shape is shown in table 33 below.

\begin{tabular}{|c|c|c|c|c|c|c|}
\hline \multirow{2}{*}{ Mode No. } & \multirow{2}{*}{ To Generate } & \multirow{2}{*}{ Period T [s] } & \multirow{2}{*}{$\begin{array}{c}\text { Acceleration } \\
\mathrm{S}_{\mathrm{a}}\left[\mathrm{m} / \mathrm{s}^{2}\right]\end{array}$} & \multicolumn{3}{|c|}{ Effective Modal Mass Factor } \\
\hline & & & & $F_{\operatorname{mex}}[\mathbf{k g}]$ & $F_{\mathrm{meY}}[\mathrm{kg}]$ & $F_{\mathrm{mez}}[\mathrm{kg}]$ \\
\hline 1 & $x$ & 0.649 & 1.229 & 0.011 & 0.361 & 0.000 \\
\hline 2 & $x$ & 0.449 & 1.587 & 0.723 & 0.045 & 0.000 \\
\hline 3 & $X$ & 0.369 & 1.587 & 0.049 & 0.343 & 0.000 \\
\hline 4 & - & 0.284 & 1.587 & 0.010 & 0.005 & 0.000 \\
\hline 5 & $x$ & 0.242 & 1.587 & 0.017 & 0.019 & 0.000 \\
\hline 6 & $\mathrm{x}$ & 0.221 & 1.587 & 0.018 & 0.007 & 0.000 \\
\hline 7 & $\mathrm{X}$ & 0.208 & 1.587 & 0.031 & 0.001 & 0.000 \\
\hline 8 & $\mathrm{X}$ & 0.200 & 1.587 & 0.041 & 0.024 & 0.000 \\
\hline 9 & - & 0.185 & 1.587 & 0.003 & 0.001 & 0.000 \\
\hline 10 & $x$ & 0.183 & 1.587 & 0.017 & 0.000 & 0.000 \\
\hline 11 & - & 0.173 & 1.587 & 0.002 & 0.007 & 0.000 \\
\hline 12 & $x$ & 0.168 & 1.587 & 0.000 & 0.017 & 0.000 \\
\hline 13 & - & 0.162 & 1.587 & 0.001 & 0.010 & 0.000 \\
\hline 14 & - & 0.157 & 1.587 & 0.000 & 0.000 & 0.000 \\
\hline 15 & - & 0.154 & 1.587 & 0.003 & 0.000 & 0.000 \\
\hline 16 & $x$ & 0.146 & 1.587 & 0.001 & 0.119 & 0.000 \\
\hline 17 & - & 0.143 & 1.587 & 0.000 & 0.003 & 0.000 \\
\hline 18 & - & 0.126 & 1.587 & 0.001 & 0.001 & 0.000 \\
\hline 19 & - & 0.124 & 1.587 & 0.001 & 0.004 & 0.000 \\
\hline 20 & - & 0.123 & 1.587 & 0.000 & 0.000 & 0.000 \\
\hline$M_{\text {eff,i }} / \Sigma M$ & & & & 0.908 & 0.936 & 0.000 \\
\hline
\end{tabular}

Table 33 Period, acceleration and effective modal mass factor for each mode shape

As shown in table 33, ten of the 20 mode shapes are taken into account since the other ten mode shapes are deselected because the corresponding $M_{\text {eff, } i} / \sum M$ is smaller than 0,01 . However, the 
mode shapes that are generated meet the required sum of modal masses of $90 \%$ of the total mass. Furthermore, table 33 shows that only one mode shape number 1 is not within the plateau section of the elastic response design spectrum.

With these mode shapes and settings described in this chapter, the add-on module DYNAM Pro for RFEM5 can calculate the cutting forces along all members or surfaces of the investigated building. To compare the pre-dimensioning approach to the results of this dimensioning, only the shear and moment distribution along the bracing walls will be compared. Therefore, the results of the shear and moment distribution will be illustrated in the following chapter.

\subsection{RESULTING MOMENT DISTRIBUTION ON BRACING WALLS}

After the calculation is finished, RFEM5 can illustrate all cutting forces of each member or surface. According to EC 8-1: 4.3.3.5.1 (3), the following two combination of the horizontal components of the seismic action can be used:

(1) $E_{E d x} "+" 0,30 E_{E d y}$

(2) $0,30 E_{E d x} "+" E_{E d y}$

Within these two combinations, $E_{E d x}$ and $E_{E d y}$ represent the action effects due to the application of the seismic action along the chosen horizontal axis $X$ or $Y$ of the structure and "+" implies "to be combined with" (EC 8-1: 4.3.3.5.1 (3)).

Therefore, the two combinations will be used to determine the maximum cutting forces along the bracing walls. As an example, figure 20 illustrates the shear distribution along wall 102. 


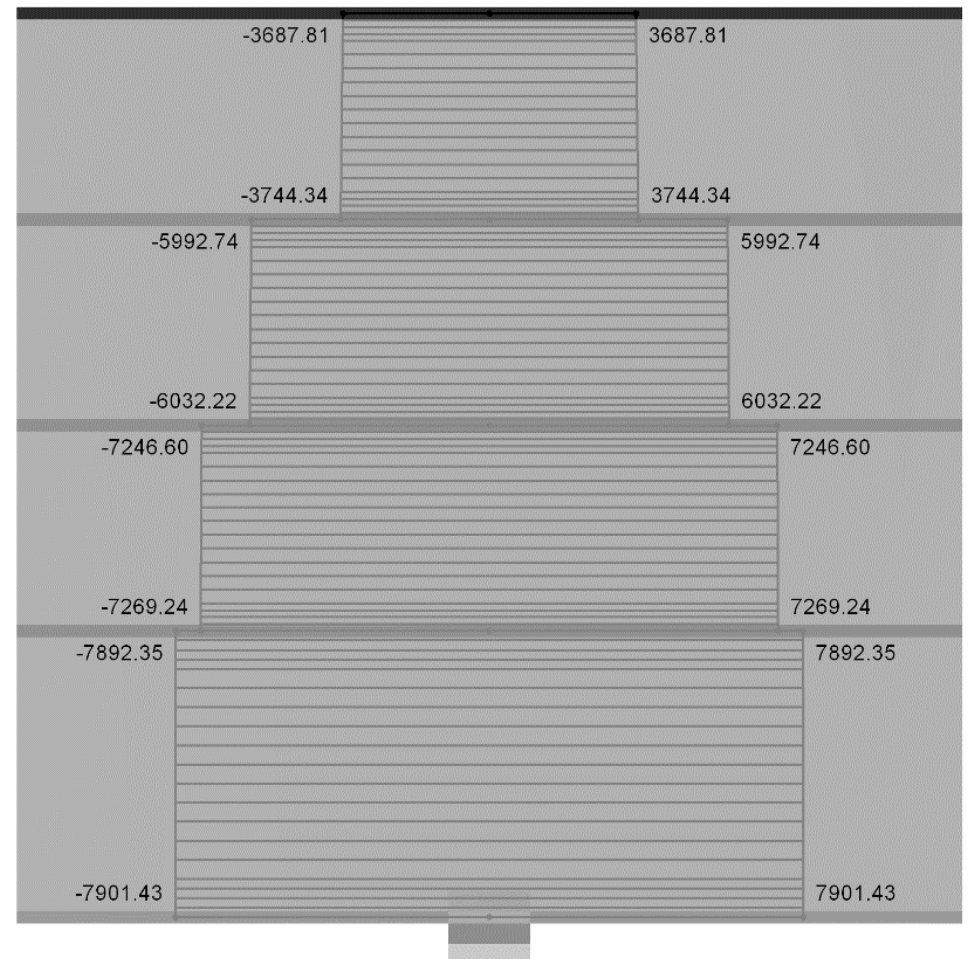

Figure 20 Shear distribution along wall 102 according to RFEM5

Furthermore, figure 21 illustrates the moment distribution according to the results of the RFEM5 calculation along wall 102.

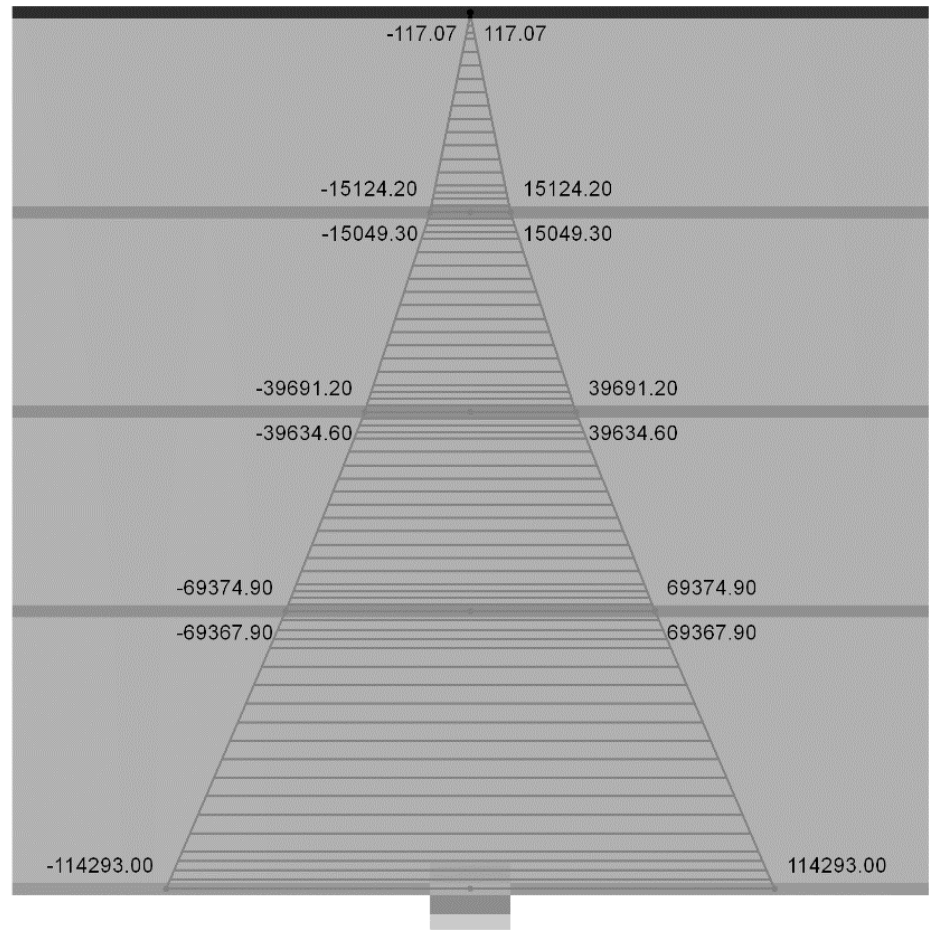

Figure 21 Moment distribution along wall 102 according to RFEM5 
Figure 23 illustrates the amount of the horizontal force that is being absorbed by the wall in each floor. To determine the value of the absorbed force of each bracing wall, the differences of the two shear forces above and below each ceiling must be calculated. With these horizontal forces, the moment distribution of figure 21 can be explained. A MDOF system with the absorbed horizontal forces of figure 20 is shown in figure 22 below.
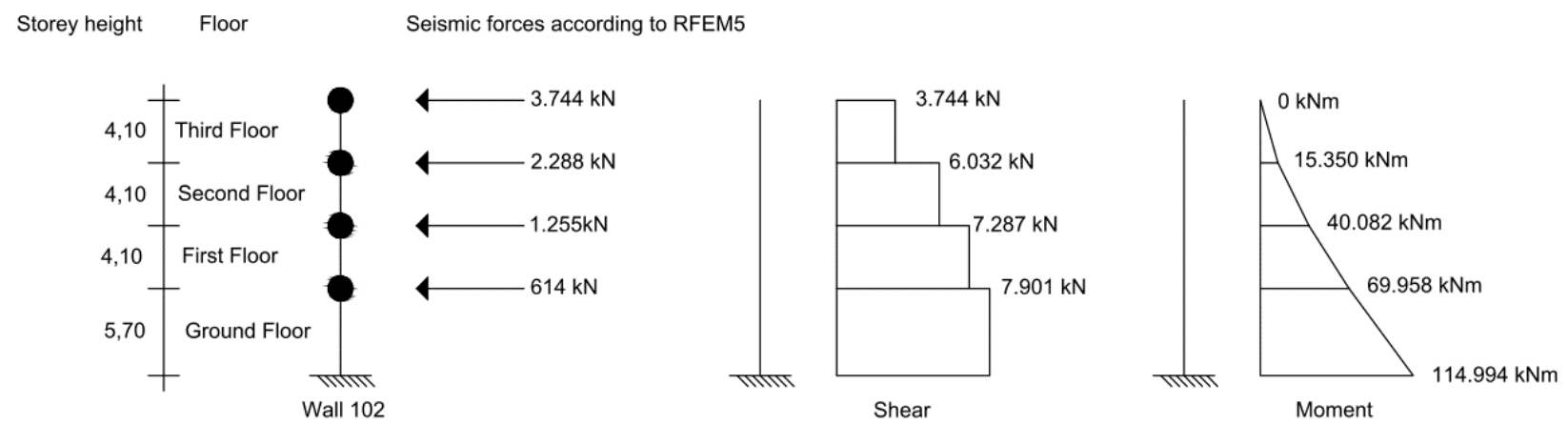

Figure 22 Moment distribution according to horizontal forces of figure 20

This comparison shows that the moment distribution is the result to seismic horizontal forces in each floor. In the following table 34, the maximum shear distribution along each bracing wall is summarized. The complete shear force distribution due to the two combinations described in the beginning of this chapter are illustrated in Appendices $\mathrm{S}$ and $\mathrm{T}$.

\begin{tabular}{|c|c|c|c|c|c|c|c|c|c|}
\hline \multirow{2}{*}{$\begin{array}{r}\text { Bracing } \\
\text { element }\end{array}$} & \multicolumn{4}{|c|}{ Walls in $\mathrm{X}$ direction: $\mathrm{V}$ [kN] } & \multirow{2}{*}{$\begin{array}{r}\text { Bracing } \\
\text { element }\end{array}$} & \multicolumn{4}{|c|}{ Walls in Y direction: $\mathrm{V}$ [kN] } \\
\hline & Floor 0 & Floor 1 & Floor 2 & Floor 3 & & Floor 0 & Floor 1 & Floor 2 & Floor 3 \\
\hline 102 & 7.901 & 7.247 & 6.032 & 3.744 & 107 & 2.730 & 1.931 & 1.171 & 574 \\
\hline 104 & 2.418 & 1.943 & 1.278 & 546 & 109 & 1.796 & 1.270 & 643 & 322 \\
\hline 110 & 269 & 153 & 67 & 42 & 111 & 1.676 & 1.200 & 618 & 312 \\
\hline 112 & 232 & 168 & 75 & 41 & 201 & 306 & 193 & 103 & 49 \\
\hline 114 & 270 & 181 & 88 & 52 & 203 & 1.515 & 998 & 617 & 297 \\
\hline 202 & 1.797 & 1.185 & 790 & 450 & 205 & 1.614 & 1.212 & 871 & 594 \\
\hline 302 & 2.407 & 1.897 & 1.342 & 697 & 301 & 1.704 & 924 & 644 & 350 \\
\hline 402 & 836 & 396 & 289 & 67 & 303 & 1.472 & 887 & 579 & 342 \\
\hline 404 & 353 & 149 & 125 & 32 & 401 & 5.374 & 4.793 & 3.950 & 2.707 \\
\hline 406 & 2.375 & 1.847 & 1.281 & 557 & 403 & 701 & 368 & 223 & 132 \\
\hline 408 & 1.883 & 1.415 & 948 & 391 & 405 & 997 & 689 & 506 & 152 \\
\hline 410 & 263 & 98 & 82 & 29 & 407 & 2.778 & 2.245 & 1.615 & 716 \\
\hline 412 & 369 & 105 & 99 & 46 & 409 & 2.910 & 2.610 & 2.053 & 1.154 \\
\hline 414 & 7.189 & 6.717 & 5.772 & 3.525 & - & - & - & - & - \\
\hline
\end{tabular}

Table 34 Maximum shear force distribution of each bracing wall according to Appendices $S$ and $T$ 
Furthermore, table 35 illustrates the maximum moment distribution along each bracing wall according to Appendices $\mathrm{U}$ and $\mathrm{V}$.

\begin{tabular}{|c|c|c|c|c|c|c|c|c|c|}
\hline \multirow{2}{*}{$\begin{array}{l}\text { Bracing } \\
\text { element }\end{array}$} & \multicolumn{4}{|c|}{ Walls in X direction: $M$ [kNm] } & \multirow{2}{*}{$\begin{array}{l}\text { Bracing } \\
\text { element }\end{array}$} & \multicolumn{4}{|c|}{ Walls in $\mathrm{Y}$ direction: $\mathrm{M}$ [kNm] } \\
\hline & Floor 0 & Floor 1 & Floor 2 & Floor 3 & & Floor 0 & Floor 1 & Floor 2 & Floor 3 \\
\hline 102 & 114.293 & 69.375 & 39.691 & 15.124 & 107 & 29.230 & 14.310 & 6.817 & 2.279 \\
\hline 104 & 28.384 & 14.872 & 7.129 & 2.106 & 109 & 18.300 & 8.438 & 3.667 & 1.214 \\
\hline 110 & 2.275 & 821 & 300 & 109 & 111 & 17.371 & 8.175 & 3.574 & 1.188 \\
\hline 112 & 2.007 & 799 & 276 & 123 & 201 & 2.119 & 673 & 398 & 187 \\
\hline 114 & 2.425 & 1.093 & 376 & 193 & 203 & 15.459 & 7.381 & 3.563 & 1.188 \\
\hline 202 & 19.018 & 9.289 & 4.683 & 1.727 & 205 & 19.586 & 10.725 & 5.910 & 2.392 \\
\hline 302 & 24.961 & 11.825 & 4.824 & 1.082 & 301 & 16.093 & 7.242 & 3.904 & 1.416 \\
\hline 402 & 6.820 & 2.551 & 1.085 & 247 & 303 & 14.126 & 6.539 & 3.537 & 1.335 \\
\hline 404 & 2.818 & 937 & 389 & 163 & 401 & 77.052 & 46.981 & 27.412 & 11.182 \\
\hline 406 & 27.731 & 14.556 & 7.188 & 2.131 & 403 & 5.643 & 2.080 & 736 & 547 \\
\hline 408 & 21.218 & 10.773 & 5.161 & 1.459 & 405 & 7.662 & 2.887 & 1.382 & 678 \\
\hline 410 & 2.050 & 645 & 284 & 64 & 407 & 33.948 & 18.628 & 9.556 & 2.993 \\
\hline 412 & 2.796 & 808 & 433 & 107 & 409 & 40.550 & 24.078 & 13.298 & 4.823 \\
\hline 414 & 105.813 & 65.116 & 37.717 & 14.235 & - & - & - & - & - \\
\hline
\end{tabular}

Table 35 Maximum moment distribution of each bracing wall according to Appendices $U$ and $V$

Knowing the maximum moment distribution along each bracing wall, the required reinforcement can be determined as described in chapter 3.3.2 to calculate the investigated building for earthquake resistance.

Figure 23 below illustrates the deformed spatial model due to the combination of $E_{E d x}$ " $+0,30$ $E_{E d y}$. The illustration of the deformation shows that the investigated building tends to turn. This process can result in torsion forces which needs to be considered when it comes to the comparison of the simplified approach to the dimensioning calculation using the spatial model. 

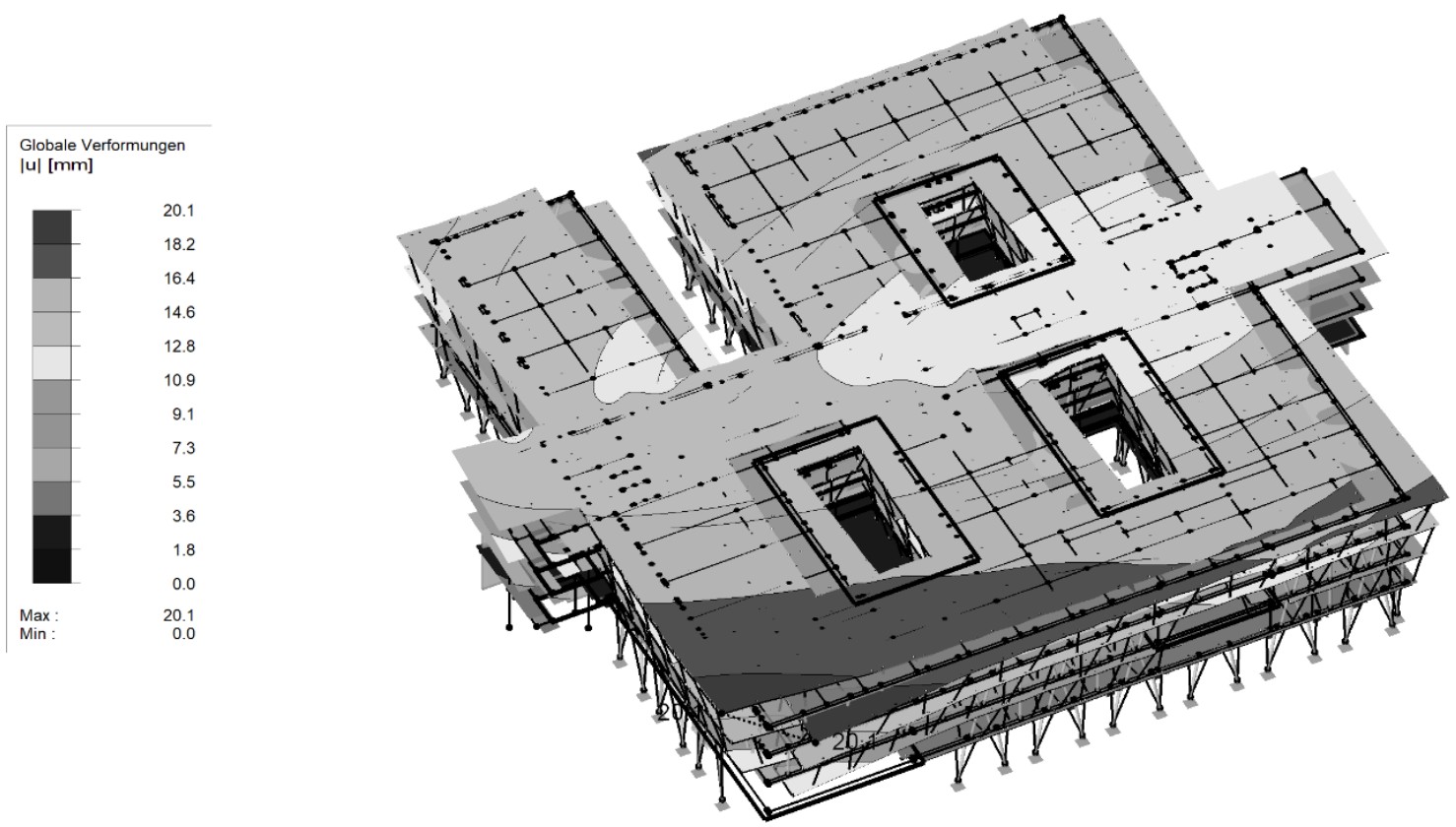

Figure 23 Deformed spatial model due to $E_{E d x}$ "+" 0,30 EEdy

Figure 24 shows the deformed spatial model due to the combination of $0,30 E_{E d x}$ "+" $E_{E d y}$. The spatial model also tends to turn for this combination since circular lines are visible in figure 24 .
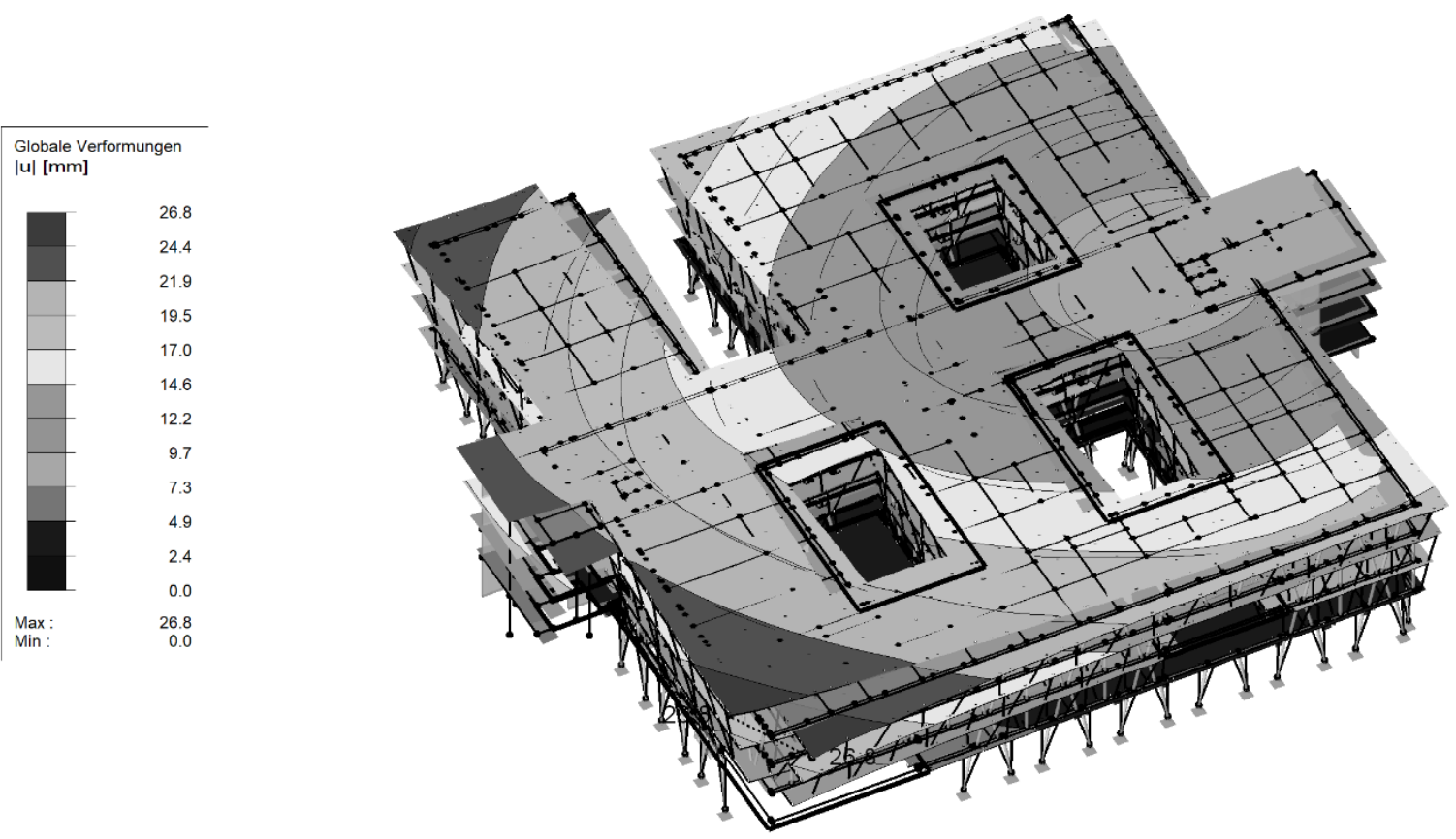

Figure 24 Deformed spatial model due to 0,30 $E_{E d x}$ "+" $E_{E d y}$

Knowing the shear and moment distribution as well as the deformation of the investigated building, the comparison to the approach can be conducted in the following chapter. 


\section{COMPARISION BETWEEN PREDIMENSIONING AND DIMENSIONING}

The investigated building has regularity in elevation but no regularity in plan. Therefore, the calculation for earthquake resistance must be performed using a spatial model according to EC81 table 4.1. Since the approach of predimension the investigated building for earthquake resistance, which is carried out in chapter 2, neglects table 4.1 of EC8-1, a comparison will be conducted to investigate the differences of the approach with the actual calculation for earthquake resistance according to EC 8-1.

\subsection{COMPARISION OF MOMENT DISTIRBUTION ALONG BRACING WALLS}

To compare the simplified approach and the actual calculation for earthquake resistance of the investigated building, the moment distribution along each bracing wall will be examined. Therefore, the moment of each floor of the approach will be divided by the related moment calculated using a spatial model. The result is a factor that determines how close the predimensioning approach is to the actual calculation for earthquake resistance.

Table 36 illustrates the moment distribution along each bracing wall of the approach from chapter 2.

\begin{tabular}{|c|c|c|c|c|c|c|c|c|c|}
\hline \multirow{2}{*}{$\begin{array}{r}\text { Bracing } \\
\text { element }\end{array}$} & \multicolumn{4}{|c|}{ Walls in $\mathrm{X}$ direction: $\mathrm{M}$ [kNm] } & \multirow{2}{*}{$\begin{array}{r}\text { Bracing } \\
\text { element }\end{array}$} & \multicolumn{4}{|c|}{ Walls in $Y$ direction: $M$ [kNm] } \\
\hline & Floor 0 & Floor 1 & Floor 2 & Floor 3 & & Floor 0 & Floor 1 & Floor 2 & Floor 3 \\
\hline 102 & 90.741 & 52.648 & 28.889 & 10.504 & 107 & 23.487 & 13.764 & 7.562 & 2.756 \\
\hline 104 & 35.846 & 20.966 & 11.504 & 4.183 & 109 & 16.234 & 9.542 & 5.243 & 1.912 \\
\hline 110 & 4.939 & 2.923 & 1.603 & 582 & 111 & 16.234 & 9.542 & 5.243 & 1.912 \\
\hline 112 & 4.295 & 2.543 & 1.395 & 507 & 201 & 3.455 & 2.045 & 1.123 & 409 \\
\hline 114 & 4.939 & 2.923 & 1.603 & 582 & 203 & 19.687 & 11.555 & 6.350 & 2.316 \\
\hline 202 & 26.129 & 15.325 & 8.409 & 3.059 & 205 & 25.650 & 15.022 & 8.255 & 3.010 \\
\hline 302 & 29.776 & 17.445 & 9.572 & 3.481 & 301 & 22.132 & 12.978 & 7.132 & 26.01 \\
\hline 402 & 11.301 & 6.666 & 3.657 & 1.329 & 303 & 22.132 & 12.978 & 7.132 & 2.601 \\
\hline 404 & 5.618 & 3.323 & 1.822 & 662 & 401 & 78.634 & 45.579 & 25.045 & 9.131 \\
\hline 406 & 34.032 & 19.914 & 10.927 & 3.974 & 403 & 13.050 & 7.681 & 4.221 & 1.538 \\
\hline 408 & 28.613 & 16.769 & 9.203 & 3.348 & 405 & 15.434 & 9.075 & 4.986 & 1.818 \\
\hline 410 & 4.295 & 2.543 & 1.395 & 507 & 407 & 47.687 & 27.765 & 15.256 & 5.561 \\
\hline 412 & 5.618 & 3.323 & 1.822 & 662 & 409 & 54.541 & 31.714 & 17.425 & 6.353 \\
\hline 414 & 77.706 & 45.136 & 24.767 & 9.007 & - & - & - & - & - \\
\hline
\end{tabular}

Table 36 Moment distribution along each bracing wall according to the approach of predimension (same as table 27) 
Table 37 shows the moment distribution along each bracing wall of the actual calculation from chapter 3 using a spatial model.

\begin{tabular}{r|cccc|r|cccc}
$\begin{array}{r}\text { Bracing } \\
\text { element }\end{array}$ & \multicolumn{3}{|c|}{ Walls in X direction: $\mathbf{M}_{\text {RFEM }}[\mathbf{k N m}]$} & \multicolumn{3}{|c|}{ Bracing } & \multicolumn{3}{c}{ Walls in Y direction: $\mathbf{M}_{\text {RFEM }}$ [kNm] } \\
\hline $\mathbf{1 0 2}$ & 114.293 & 69.375 & 39.691 & 15.124 & $\mathbf{1 0 7}$ & 29.230 & 14.310 & 6.817 & 2.279 \\
\hline $\mathbf{1 0 4}$ & 28.384 & 14.872 & 7.129 & 2.106 & $\mathbf{1 0 9}$ & 18.300 & 8.438 & 3.667 & 1.214 \\
\hline $\mathbf{1 1 0}$ & 2.275 & 821 & 300 & 109 & $\mathbf{1 1 1}$ & 17.371 & 8.175 & 3.574 & 1.188 \\
\hline $\mathbf{1 1 2}$ & 2.007 & 799 & 276 & 123 & $\mathbf{2 0 1}$ & 2.119 & 673 & 398 & 187 \\
\hline $\mathbf{1 1 4}$ & 2.425 & 1.093 & 376 & 193 & $\mathbf{2 0 3}$ & 15.459 & 7.381 & 3.563 & 1.188 \\
\hline $\mathbf{2 0 2}$ & 19.018 & 9.289 & 4.683 & 1.727 & $\mathbf{2 0 5}$ & 19.586 & 10.725 & 5.910 & 2.392 \\
\hline $\mathbf{3 0 2}$ & 24.961 & 11.825 & 4.824 & 1.082 & $\mathbf{3 0 1}$ & 16.093 & 7.242 & 3.904 & 1.416 \\
\hline $\mathbf{4 0 2}$ & 6.820 & 2.551 & 1.085 & 247 & $\mathbf{3 0 3}$ & 14.126 & 6.539 & 3.537 & 1.335 \\
\hline $\mathbf{4 0 4}$ & 2.818 & 937 & 389 & 163 & $\mathbf{4 0 1}$ & 77.052 & 46.981 & 27.412 & 11.182 \\
\hline $\mathbf{4 0 6}$ & 27.731 & 14.556 & 7.188 & 2.131 & $\mathbf{4 0 3}$ & 5.643 & 2.080 & 736 & 547 \\
\hline $\mathbf{4 0 8}$ & 21.218 & 10.773 & 5.161 & 1.459 & $\mathbf{4 0 5}$ & 7.662 & 2.887 & 1.382 & 678 \\
\hline $\mathbf{4 1 0}$ & 2.050 & 645 & 284 & 64 & $\mathbf{4 0 7}$ & 33.948 & 18.628 & 9.556 & 2.993 \\
\hline $\mathbf{4 1 2}$ & 2.796 & 808 & 433 & 107 & $\mathbf{4 0 9}$ & 40.550 & 24.078 & 13.298 & 4.823 \\
\hline $\mathbf{4 1 4}$ & 105.813 & 65.116 & 37.717 & 14.235 & - & - & - & - & - \\
\hline
\end{tabular}

Table 37 Moment distribution along each bracing wall using a spatial model (same as table 33)

The following table 38 illustrates the factors for all bracing walls in each floor.

\begin{tabular}{|c|c|c|c|c|c|c|c|c|c|}
\hline \multirow{2}{*}{$\begin{array}{l}\text { Bracing } \\
\text { element }\end{array}$} & \multicolumn{4}{|c|}{ Factor: $\mathbf{M}_{\text {App }} / \mathbf{M}_{\mathrm{RFEM}}$} & \multirow{2}{*}{$\begin{array}{r}\text { Bracing } \\
\text { element }\end{array}$} & \multicolumn{4}{|c|}{ Factor: $\mathrm{M}_{\mathrm{App}} / \mathrm{M}_{\mathrm{RFEM}}$} \\
\hline & Floor 0 & Floor 1 & Floor 2 & Floor 3 & & Floor 0 & Floor 1 & Floor 2 & Floor 3 \\
\hline 102 & 0,79 & 0,76 & 0,73 & 0,69 & 107 & 0,80 & 0,96 & 1,11 & 1,21 \\
\hline 104 & 1,26 & 1,41 & 1,61 & 1,99 & 109 & 0,89 & 1,13 & 1,43 & 1,57 \\
\hline 110 & 2,17 & 3,56 & 5,34 & 5,33 & 111 & 0,93 & 1,17 & 1,47 & 1,61 \\
\hline 112 & 2,14 & 3,18 & 5,05 & 4,11 & 201 & 1,63 & 3,04 & 2,82 & 2,19 \\
\hline 114 & 2,04 & 2,67 & 4,26 & 3,02 & 203 & 1,27 & 1,57 & 1,78 & 1,95 \\
\hline 202 & 1,37 & 1,65 & 1,80 & 1,77 & 205 & 1,31 & 1,40 & 1,40 & 1,26 \\
\hline 302 & 1,19 & 1,48 & 4,98 & 3,22 & 301 & 1,38 & 1,79 & 1,83 & 1,84 \\
\hline 402 & 1,66 & 2,61 & 3,37 & 5,37 & 303 & 1,57 & 1,98 & 2,02 & 1,95 \\
\hline 404 & 1,99 & 3,55 & 4,68 & 4,05 & 401 & 1,02 & 0,97 & 0,91 & 0,82 \\
\hline 406 & 1,23 & 1,37 & 1,52 & 1,86 & 403 & 2,31 & 3,69 & 5,74 & 2,81 \\
\hline 408 & 1,35 & 1,56 & 1,78 & 2,29 & 405 & 2,01 & 3,14 & 3,61 & 2,68 \\
\hline 410 & 2,10 & 3,95 & 4,91 & 7,93 & 407 & 1,40 & 1,49 & 1,60 & 1,86 \\
\hline 412 & 2,01 & 4,11 & 4,21 & 6,17 & 409 & 1,35 & 1,32 & 1,31 & 1,32 \\
\hline 414 & 0,73 & 0,69 & 0,66 & 0,63 & - & - & - & - & - \\
\hline$\phi \Delta$ & 0,64 & 1,40 & 2,08 & 2,56 & $\varnothing$ & 0,43 & 0,83 & 1,09 & 0,80 \\
\hline
\end{tabular}

Table 38 Comparison factors of approach to actual calculation for earthquake resistance 
The results of table 38 show that there are differences between the approach of predimensioning and the dimensioning calculation of the investigated building for earthquake resistance.

The average delta factor in table 38 is determined by calculating the average difference between each factor and the value 1 of each floor. This factor shows the average deviation of the approach to the dimensioning calculation for earthquake resistance on each floor. It stands out, that the walls in $\mathrm{X}$ direction have a larger average deviation than the walls in $\mathrm{Y}$ direction. Moreover, the average deviation increases for each floor compared to the floor below for walls in $\mathrm{X}$ direction. This is not the case for the walls in $Y$ direction.

Basically, all walls with larger factors than four, which means that the moment according to the approach is more than four times the related moment according to the dimensioning calculation, are short bracing walls. Moreover, the bracing walls with high factors are only in X direction. Since short walls only absorb a smaller proportion of the horizontal forces in each floor, a high factor does not imply a high difference of the moment according to the approach to the dimensioning calculation. Therefore, the differences between the moment distribution according to the approach to the moment distribution according to the dimensioning calculation will be illustrated in table 39 below.

\begin{tabular}{|c|c|c|c|c|c|c|c|c|c|}
\hline \multirow{2}{*}{$\begin{array}{r}\text { Bracing } \\
\text { element }\end{array}$} & \multicolumn{4}{|c|}{$M_{\text {App }}-M_{\text {RFEM }}[k N m]: X$ direction } & \multirow{2}{*}{$\begin{array}{r}\text { Bracing } \\
\text { element }\end{array}$} & \multicolumn{4}{|c|}{$M_{\text {App }}-M_{\text {RFEM }}[k N m]: Y$ direction } \\
\hline & Floor 0 & Floor 1 & Floor 2 & Floor 3 & & Floor 0 & Floor 1 & Floor 2 & Floor 3 \\
\hline 102 & -23.541 & -16.722 & -10.801 & -4.619 & 107 & -5.743 & -546 & 746 & 477 \\
\hline 104 & 7.461 & 6.094 & 4.375 & 2.078 & 109 & -2.066 & 1.104 & 1.576 & 697 \\
\hline 110 & 2.664 & 2.102 & 1.302 & 473 & 111 & -1.136 & 1.367 & 1.669 & 723 \\
\hline 112 & 2.289 & 1.744 & 1.119 & 383 & 201 & 1.336 & 1.372 & 725 & 222 \\
\hline 114 & 2.515 & 1.829 & 1.227 & 390 & 203 & 4.228 & 4.175 & 2.787 & 1.128 \\
\hline 202 & 7.111 & 6.036 & 3.726 & 1.331 & 205 & 6.065 & 4.297 & 2.345 & 618 \\
\hline 302 & 4.815 & 5.620 & 4.748 & 2.399 & 301 & 6.039 & 5.736 & 3.228 & 1.185 \\
\hline 402 & 4.481 & 4.114 & 2.572 & 1.082 & 303 & 8.006 & 6.438 & 3.595 & 1.266 \\
\hline 404 & 2.800 & 2.386 & 1.433 & 499 & 401 & 1.581 & -1.403 & -2.366 & -2.050 \\
\hline 406 & 6.301 & 5.359 & 3.740 & 1.843 & 403 & 7.407 & 5.601 & 3.485 & 991 \\
\hline 408 & 7.395 & 5.997 & 4.041 & 1.889 & 405 & 7.772 & 6.188 & 3.604 & 1.140 \\
\hline 410 & 2.246 & 1.898 & 1.111 & 443 & 407 & 13.739 & 9.136 & 5.700 & 2.569 \\
\hline 412 & 2.822 & 2.514 & 1.389 & 555 & 409 & 13.991 & 7.637 & 4.127 & 1.529 \\
\hline 414 & -28.107 & -19.979 & -12.950 & -5.228 & - & - & - & - & - \\
\hline
\end{tabular}

Table 39 Differences between approach and dimensioning calculation 
The results of the differences of table 39 show that the larger differences are for longer walls. The walls with a high factor do not have a large difference in their values of the moments. Comparing the moment values of the differences of the two calculations in table 39 with the length of the wall, a connection can be made since the larger differences occur for longer walls. Therefore, the differences of table 39 will be divided by the length of the wall in table 40 below.

\begin{tabular}{|c|c|c|c|c|c|c|c|c|c|}
\hline \multirow{2}{*}{$\begin{array}{r}\text { Bracing } \\
\text { element }\end{array}$} & \multicolumn{4}{|c|}{$\left(M_{\text {App }}-M_{\text {RFEM }}\right) / L_{w}[k N m / m]$} & \multirow{2}{*}{$\begin{array}{l}\text { Bracing } \\
\text { element }\end{array}$} & \multicolumn{4}{|c|}{$\left(M_{\text {App }}-M_{\text {RFEM }}\right) / L_{w}[k N m / m]$} \\
\hline & Floor 0 & Floor 1 & Floor 2 & Floor 3 & & Floor 0 & Floor 1 & Floor 2 & Floor 3 \\
\hline 102 & -1.632 & -1.159 & -749 & -320 & 107 & -989 & -94 & 128 & 82 \\
\hline 104 & 1.017 & 831 & 597 & 283 & 109 & -356 & 231 & 329 & 146 \\
\hline 110 & 955 & 753 & 467 & 170 & 111 & -196 & 286 & 349 & 151 \\
\hline 112 & 867 & 661 & 424 & 145 & 201 & 230 & 560 & 296 & 91 \\
\hline 114 & 901 & 656 & 440 & 140 & 203 & 728 & 791 & 528 & 214 \\
\hline 202 & 1.171 & 994 & 613 & 219 & 205 & 1.044 & 704 & 384 & 101 \\
\hline 302 & 735 & 858 & 725 & 366 & 301 & 1.040 & 1.021 & 574 & 211 \\
\hline 402 & 1.129 & 1.036 & 648 & 272 & 303 & 1.378 & 1.146 & 640 & 225 \\
\hline 404 & 953 & 811 & 487 & 170 & 401 & 272 & -107 & -181 & -157 \\
\hline 406 & 887 & 755 & 527 & 260 & 403 & 1.275 & 1.303 & 810 & 230 \\
\hline 408 & 1.155 & 937 & 631 & 295 & 405 & 1.338 & 1.327 & 773 & 244 \\
\hline 410 & 851 & 719 & 421 & 168 & 407 & 2.366 & 1.015 & 633 & 285 \\
\hline 412 & 960 & 855 & 473 & 189 & 409 & 2.409 & 771 & 417 & 154 \\
\hline 414 & -2.211 & -1.572 & -1.019 & -411 & - & - & - & - & - \\
\hline
\end{tabular}

Table 40 Difference of the moments per $m$ wall length

Table 40 illustrates the connection between the length of each wall to the difference of the moments according to the values of the differences of the two calculations. All values of table 40 for walls in X direction have a similar scale except for the longest two walls, wall 102 and wall 414. In Y direction however, the values of table 38 differ more. Wall 111, 201 and 401 already have a moment distribution according to the approach that comes close to the dimensioning calculation.

It needs to be mentioned, that the comparisons of the approach and the dimensioning calculation in table 38 to 40 show, that the approach does not constitute a conservative solution to dimension the investigated building for earthquake resistance. This is because some values of the moment distribution according to the approach are smaller than the related values of the moment distribution according to the dimension calculation using RFEM5. 
To investigate where the differences of the approach to the dimensioning calculation for earthquake resistance come from, a further spatial model will be created to examine if RFEM distributes the horizontal forces of an earthquake like the approach.

\subsection{DISTRIBUTION OF A HORIZONTAL FORCE ON BRACING ELEMENTS ON SPATIAL MODEL}

To investigate the distribution of a horizontal force on the bracing elements, a further spatial model will be installed. First, this model will only contain the ground floor. The model will be exposed to a single load of $1.000 \mathrm{kN}$ in $\mathrm{X}$ or $\mathrm{Y}$ direction in the shear center.

The goal of this investigation is to figure out if the finite element software RFEM5 distributes a single load the same way as assumed for the approach of predimensioning the investigated building. If there are differences in the distribution of a horizontal force on the bracing elements, it could explain the differences in the result of the comparison of the approach of predimensioning and the dimensioning calculation.

Figure 25 below, illustrates the spatial model of the ground floor with a single load in the shear center of $1.000 \mathrm{kN}$. The shear forces of the bracing walls are listed in table 341 underneath. It needs to be mentioned, that the surface that constitutes the ceiling is modelled with a factored stiffness of 100 to avoid the effect that the single load can not spread on the total area of the surface. In this case, only walls close to the single load would absorb the horizontal single load.

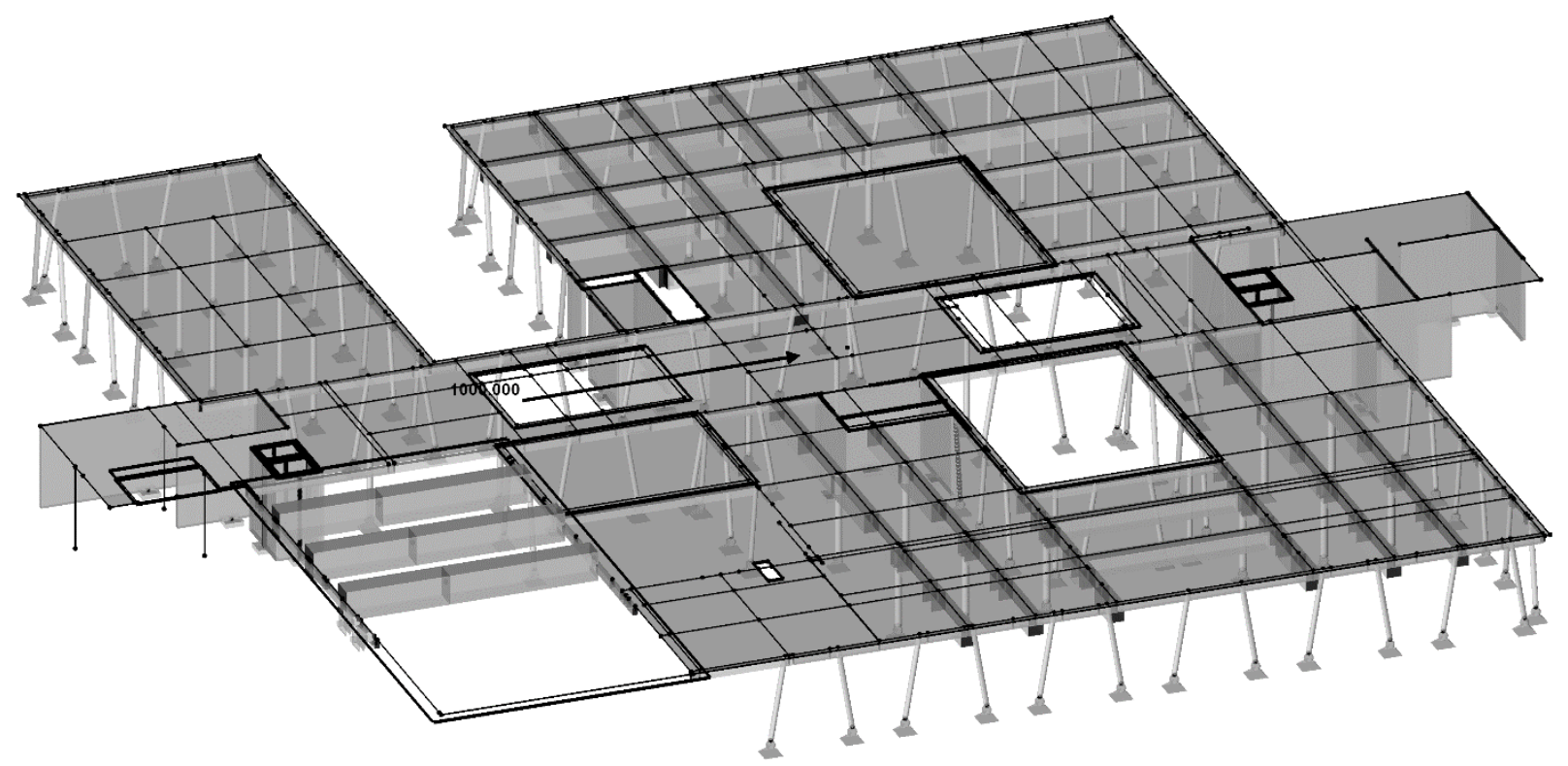

Figure 25 Illustration of spatial model of ground floor suspended to a single load of $1.000 \mathrm{kN}$ 


\begin{tabular}{r|cc|r|cc}
$\begin{array}{r}\text { Bracing } \\
\text { element }\end{array}$ & Proportion of horizontal force [\%] & Bracing & \multicolumn{2}{|c}{ Proportion of horizontal force [\%] } \\
Spatial Model & Approach & element & Spatial Model & Approach \\
\hline $\mathbf{1 0 2}$ & $\mathbf{2 7 , 2 0}$ & $\mathbf{2 7 , 0 7}$ & $\mathbf{1 0 7}$ & 5,76 & 5,88 \\
\hline $\mathbf{1 0 4}$ & 9,30 & 9,23 & $\mathbf{1 0 9}$ & 3,72 & 3,83 \\
\hline $\mathbf{1 1 0}$ & 0,97 & 0,97 & $\mathbf{1 1 1}$ & 3,73 & 3,83 \\
\hline $\mathbf{1 1 2}$ & 0,84 & 0,84 & $\mathbf{2 0 1}$ & 0,69 & 0,69 \\
\hline $\mathbf{1 1 4}$ & 0,98 & 0,97 & $\mathbf{2 0 3}$ & 4,79 & 4,79 \\
\hline $\mathbf{2 0 2}$ & 6,36 & 6,36 & $\mathbf{2 0 5}$ & 6,54 & 6,52 \\
\hline $\mathbf{3 0 2}$ & 7,57 & 7,41 & $\mathbf{3 0 1}$ & 5,51 & 5,49 \\
\hline $\mathbf{4 0 2}$ & 2,41 & 2,42 & $\mathbf{3 0 3}$ & 5,54 & 5,49 \\
\hline $\mathbf{4 0 4}$ & 1,11 & 1,12 & $\mathbf{4 0 1}$ & 24,96 & 2,11 \\
\hline $\mathbf{4 0 6}$ & 8,76 & 8,68 & $\mathbf{4 0 3}$ & 3,02 & 3,61 \\
\hline $\mathbf{4 0 8}$ & 7,12 & 7,08 & $\mathbf{4 0 5}$ & 3,73 & 13,54 \\
\hline $\mathbf{4 1 0}$ & 0,84 & 0,84 & $\mathbf{4 0 7}$ & 13,94 & 15,84 \\
\hline $\mathbf{4 1 2}$ & 1,12 & 1,12 & $\mathbf{4 0 9}$ & 16,30 & - \\
\hline $\mathbf{4 1 4}$ & 23,41 & 22,73 & - & - & 3,39 \\
\hline Pillars & 2,01 & 3,17 & Pillars & 1,77 & \\
\hline
\end{tabular}

Table 41 Comparison of absorption of a horizontal force of each bracing element of spatial model and approach

Table 41 shows the proportion that each bracing element absorbs of the horizontal force. Furthermore table 41 compares the proportion with the proportion calculated for the approach in chapter 2. It becomes apparent that the software and the approach distributes the horizontal force similar on the bracing elements. Therefore, the differences of the predimensioning approach to the dimensioning calculation can not be explained by a different distribution of the horizontal forces on the bracing elements.

Since the spatial model of the ground floor only considers one floor, a further model will be created including all floors. The model is the same model as used for the dimensioning calculation for earthquake resistance illustrated in figure 19. But all floors will be exposed to a horizontal force of $1.000 \mathrm{kN}$ in their shear center.

This model will be created to understand the distribution and forwarding of the horizontal forces into the bracing elements. The resulting shear distribution along each bracing wall will be compared to the shear distribution of the approach of predimensioning according to table 25 . Therefore, bracing wall 102 and its shear distribution according to the approach (right side of figure 24) and to the spatial model (left side of figure 24) will be illustrated below. 

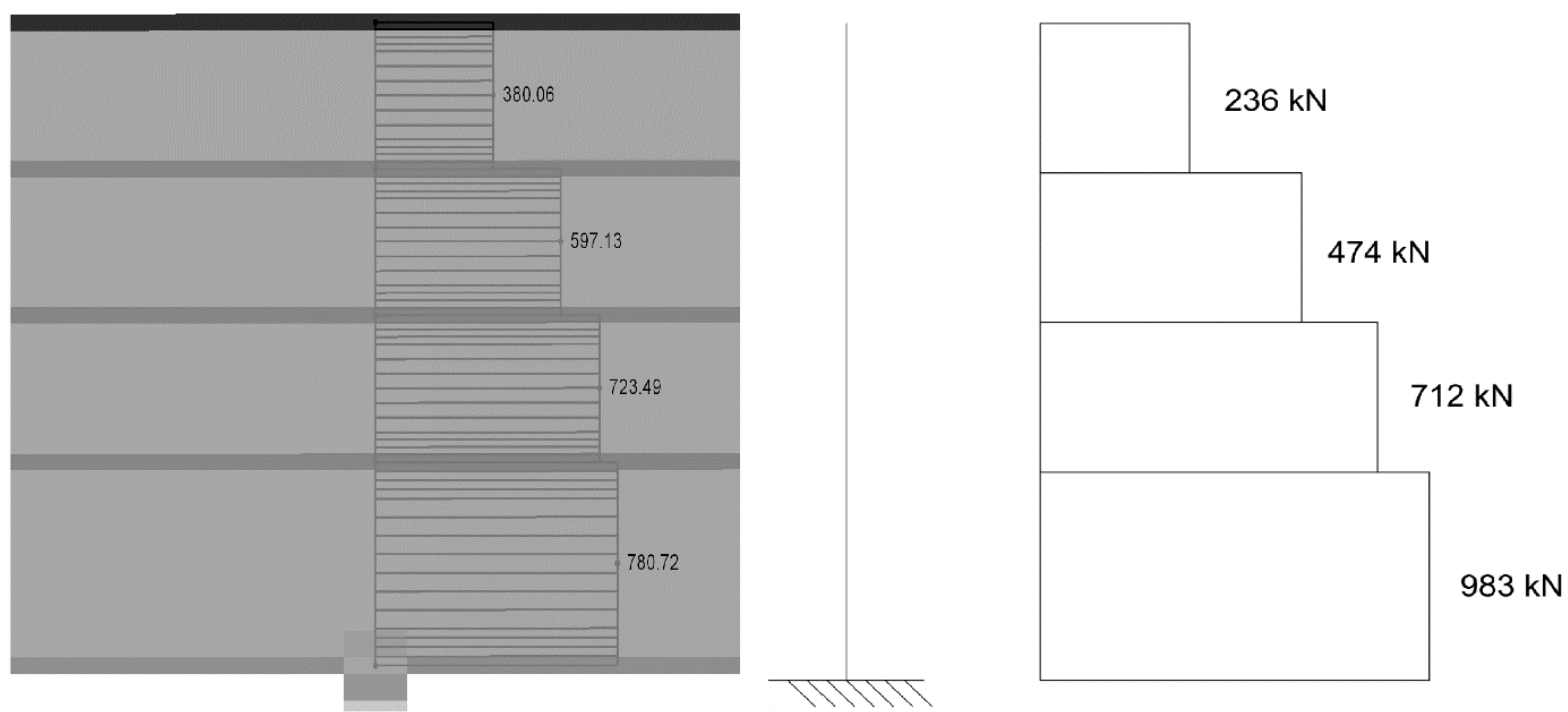

Figure 26 Shear distribution according to a horizontal force of $1.000 \mathrm{kN}$ in each floor of spatial model and approach

Figure 26 demonstrates that the shear force distribution according to the spatial model is different to the shear force distribution according to the approach. If the bracing walls function as a cantilever, the proportions of the horizontal force that is being absorbed in each floor by the bracing walls can be calculated. The value of the absorbed horizontal force in each floor is the difference between the shear force of the floor below and the shear force above. The proportion is then calculated by dividing the value of the absorbed shear force by $1.000 \mathrm{kN}$ which is the horizontal force in each floor and then multiplied by 100 to get the proportion.

Table 42 shows the proportions that are assumed to be absorbed by bracing wall 102 according to the spatial model and to the approach.

\begin{tabular}{r|cccc} 
& Ground floor & First floor & Second floor & Third floor \\
\hline Spatial model & $5,72 \%$ & $12,64 \%$ & $21,71 \%$ & $38,00 \%$ \\
\hline Approach & $27,07 \%$ & $23,84 \%$ & $23,76 \%$ & $23,63 \%$
\end{tabular}

Table 42 Comparison of spatial model and approach for wall 102

The comparison shows that there are differences between the approach and the spatial model calculation. More than one third of the horizontal force is being absorbed by wall 102 on the top floor, however only six per cent of the horizontal force in the ground floor is being absorbed of the same wall. Since the approach assumes that the bracing walls function like a cantilever, this assumption will now be investigated. 
Therefore, the spatial model of the investigated building will only be exposed to a horizontal force of $1.000 \mathrm{kN}$ in the shear center of the ground floor. If the bracing walls work like a cantilever, no cutting forces can be expected along the bracing walls in the upper floors.

Figure 27 below illustrates the shear distribution along wall 102 of the spatial model and of the expected shear distribution according to the approach due to a horizontal force in $\mathrm{X}$ direction of $1.000 \mathrm{kN}$ in the shear center of the ground floor.
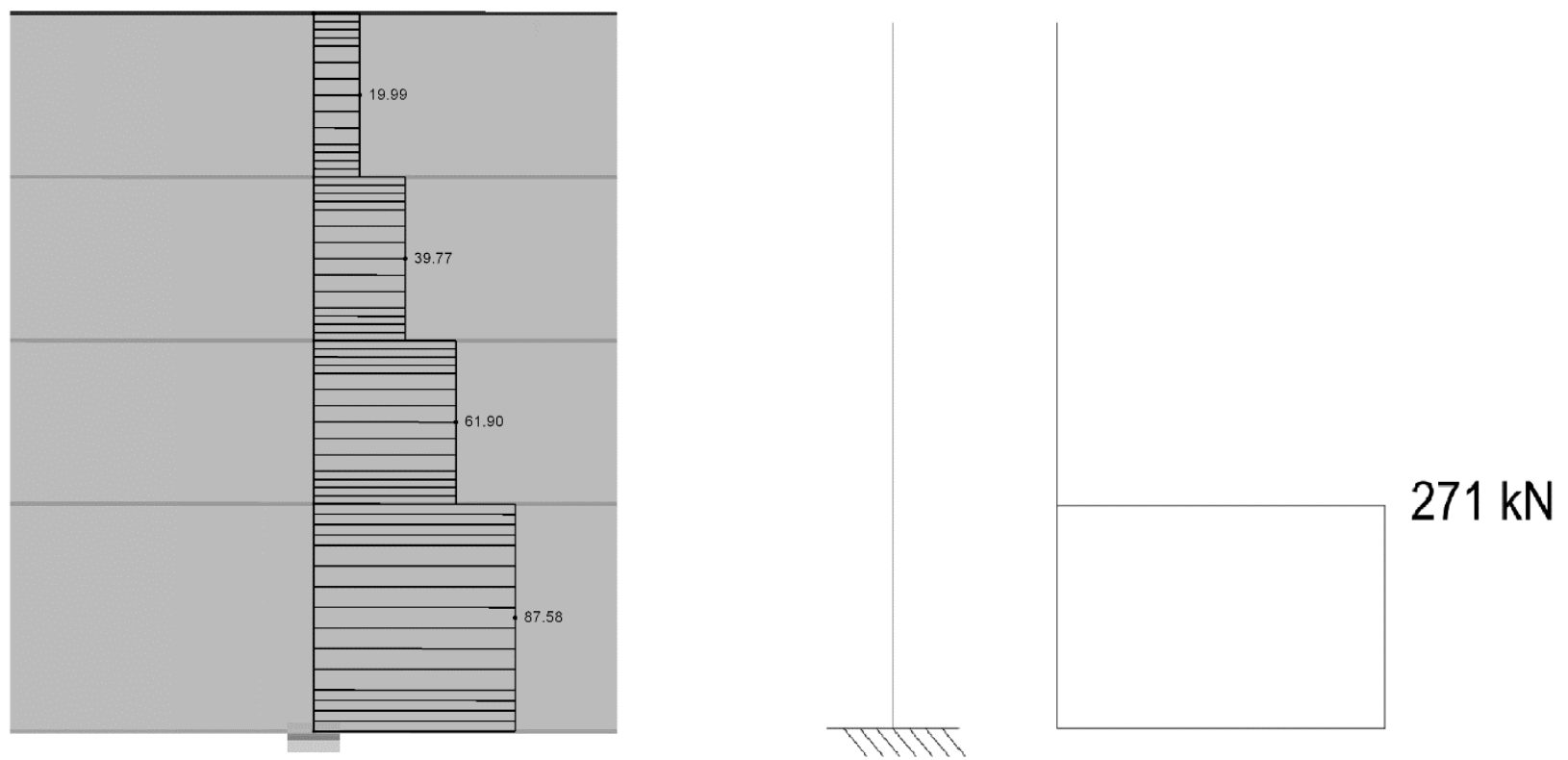

Figure 27 Comparison of shear distribution along wall 102

If the bracing walls would function like a cantilever the shear distribution along each bracing wall would look like the right shear distribution in figure 25. Furthermore, if the distribution of the horizontal force on the bracing elements would work as assumed for the approach, the value of the shear force for wall 102 on the ground floor would be like the right side of figure 25 . However, the shear force distribution of wall 102 according to RFEM5 is illustrated on the left side of figure 25 and neither the shape of the shear force distribution or the value at the ground floor are like the expected shear force distribution. That means, that the forwarding of forces is not easily predictable for spatial models for multiple reasons.

First, a spatial model accounts for deformation which means that a deformation of a model can result in cutting forces due to constraining forces. This is very likely to be the case for the investigation of the spatial model which is exposed to a horizontal force in the shear center of the 
ground floor. The horizontal force leads to a deformation of the building and since each bracing wall deforms differently, tensile or compressive forces are the result in the ceilings above. These horizontal forces within each floor needs to be absorbed by the bracing elements. By these additional horizontal force in each floor, the shear distribution on the left side of figure 25 can be explained.

Since any spatial model accounts for constraining forces, a comparison of a spatial model with a regular calculation always has differences. The comparison of the approach and the dimensioning calculation shows that the basics of the two ways to calculate for earthquake resistance are comparable. But when it comes to compare a spatial model with a regular calculation, the regular calculation always has different results due to the singularity of the calculation. This singularity of the approach to predimension the investigated building for earthquake resistance explains the differences to the dimensioning calculation using a spatial model.

\subsection{CONCLUSION}

After comparing the results of the simplified approach and the dimensioning calculation of the investigated building for earthquake resistance, the approach turns out not to be a good conservative solution.

The approach aimed to be an estimation for earthquake resistance without using a complex spatial model and finite element software. The comparison of the moment at the foot of each bracing wall shows that the values are on the same scale. However, the moment distribution along each wall differs more on the upper floors. This is due to the consideration of constraining forces of the dimensioning calculation using finite element software.

Moreover, the comparison shows that the difference of the value of the moment per meter is on

the same scale for most bracing walls. However, the dimensioning calculation of the finite element software determines a higher value of the moment distribution for some bracing walls than the simplified approach. Therefore, the approach can not be considered to be a good simplification. Even if a further investigation would determine a factor that accounts for the difference between the approach and the dimensioning calculation, a conservative solution must result in higher values of the moment distribution than the actual dimensioning. Since this is not 
the case for two walls in $\mathrm{X}$ direction and three walls in $\mathrm{Y}$ direction, the approach can not be used as a conservative solution.

Furthermore, it is noticeable that long walls in $\mathrm{X}$ direction result in a lower value of the moment distribution compared to the dimensioning calculation but short walls in a higher value. This is due to the proportion that is being absorbed by each bracing wall of the horizontal forces in each floor. It can be said, that long walls need to absorb a bigger proportion of the horizontal force in each floor and short walls a smaller proportion. This could also lead to a possible valid conservative solution since the moment distribution of the longer walls could then be larger than actual dimensioning calculation. Since the calculation of the replacement moment of inertia is the base for the calculation of the proportion that is being absorbed of a horizontal force in each floor by each bracing element, the determination of the replacement moment of inertia must be further investigated.

If the approach can be adjusted so no moment distribution of each bracing wall is lower than the dimensioning calculation using finite element software, the approach can be a valid conservative simplification. However, the approach described and investigated in this master's project can not be used as a simplification to determine the moment distribution of each bracing wall of the investigated building.

Finally, it can be said that the comparison of a planar approach with a spatial model has differences due to the singularity of the planar model. The planar model does not account for any torsion forces or constraining forces. However, a spatial model has a more complex and accurate effectiveness and therefore table 4.1 in EC 8-1 has its eligibility so that a building with no regularity in plan or elevation must be calculated for earthquake resistance using a spatial model. 
APPENDICES 


\section{Appendix A Current floor plan of ground floor}

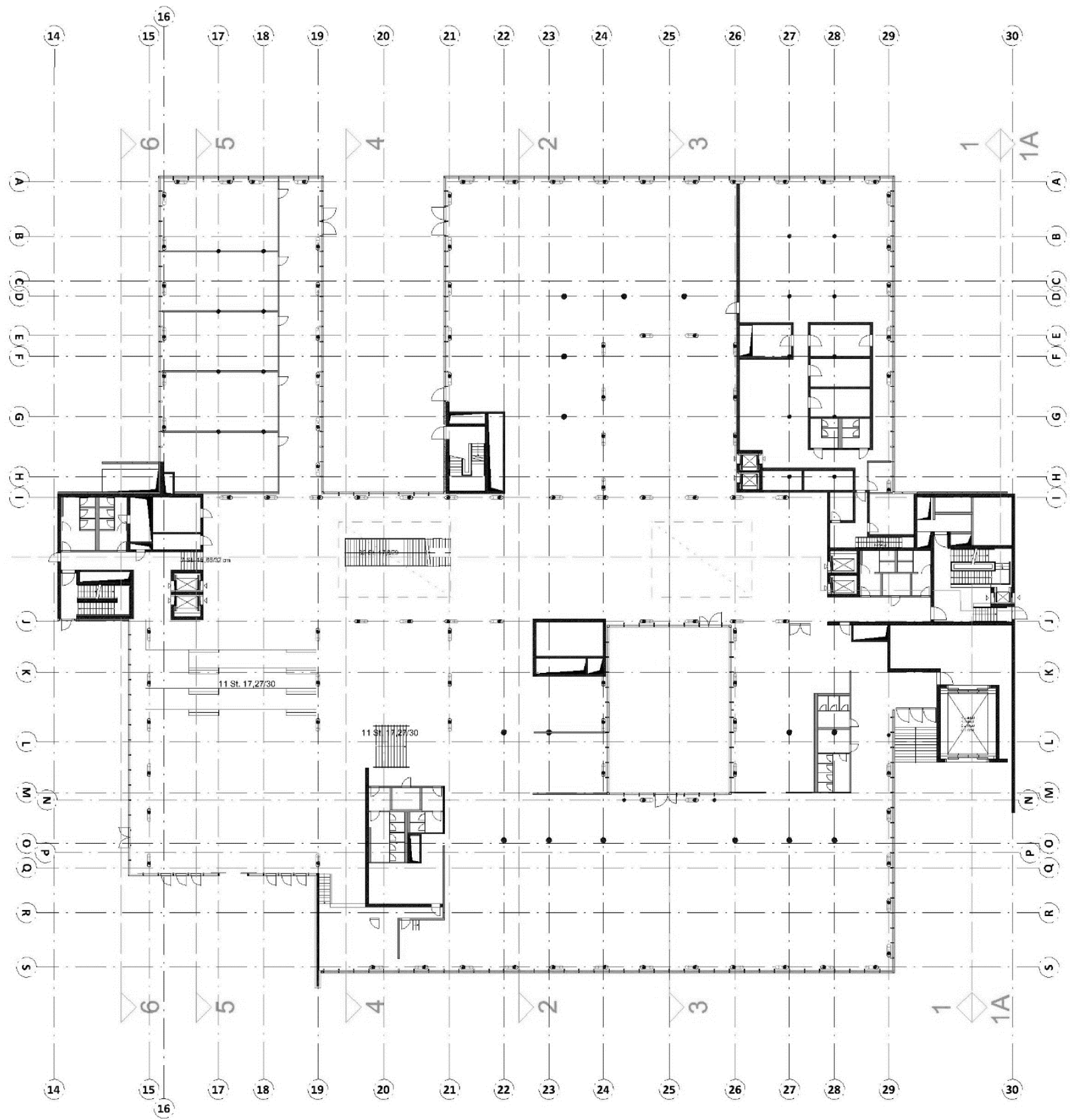


Appendix B Current floor plan of first floor

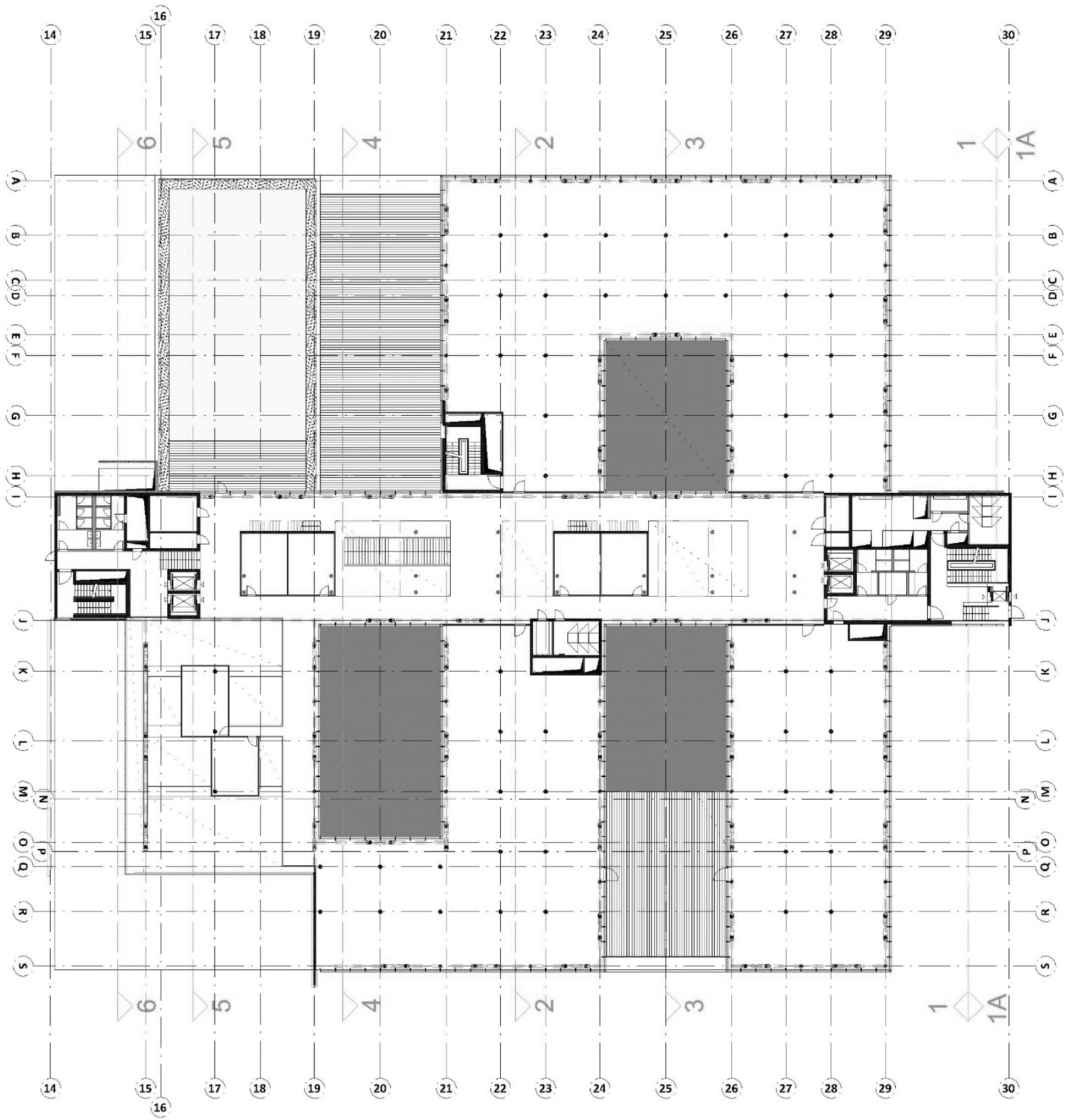


Appendix C Current floor plan of second floor

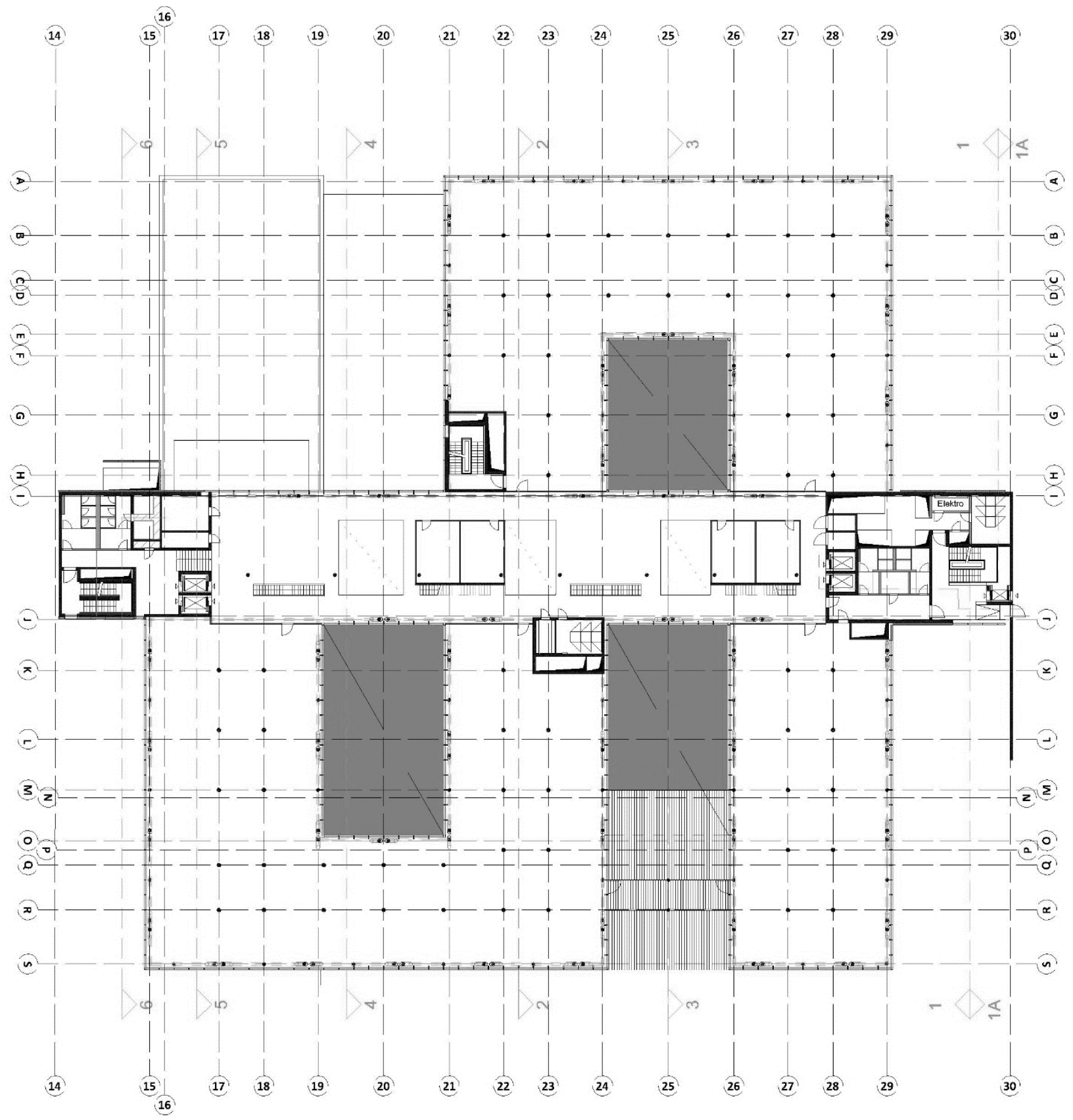


Appendix D Current floor plan of third floor

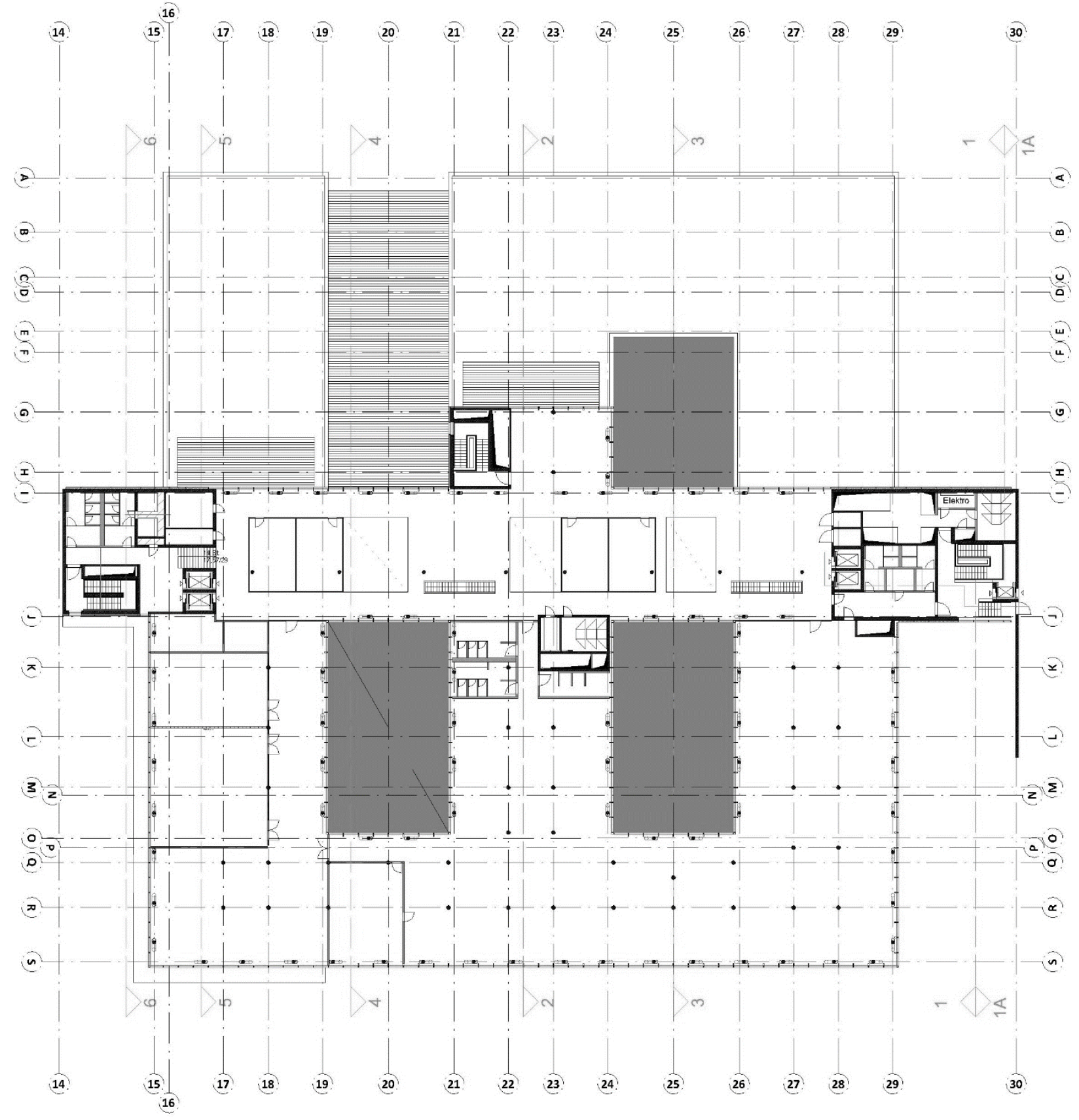


Appendix E Floor plan of ground floor including all openings [m]

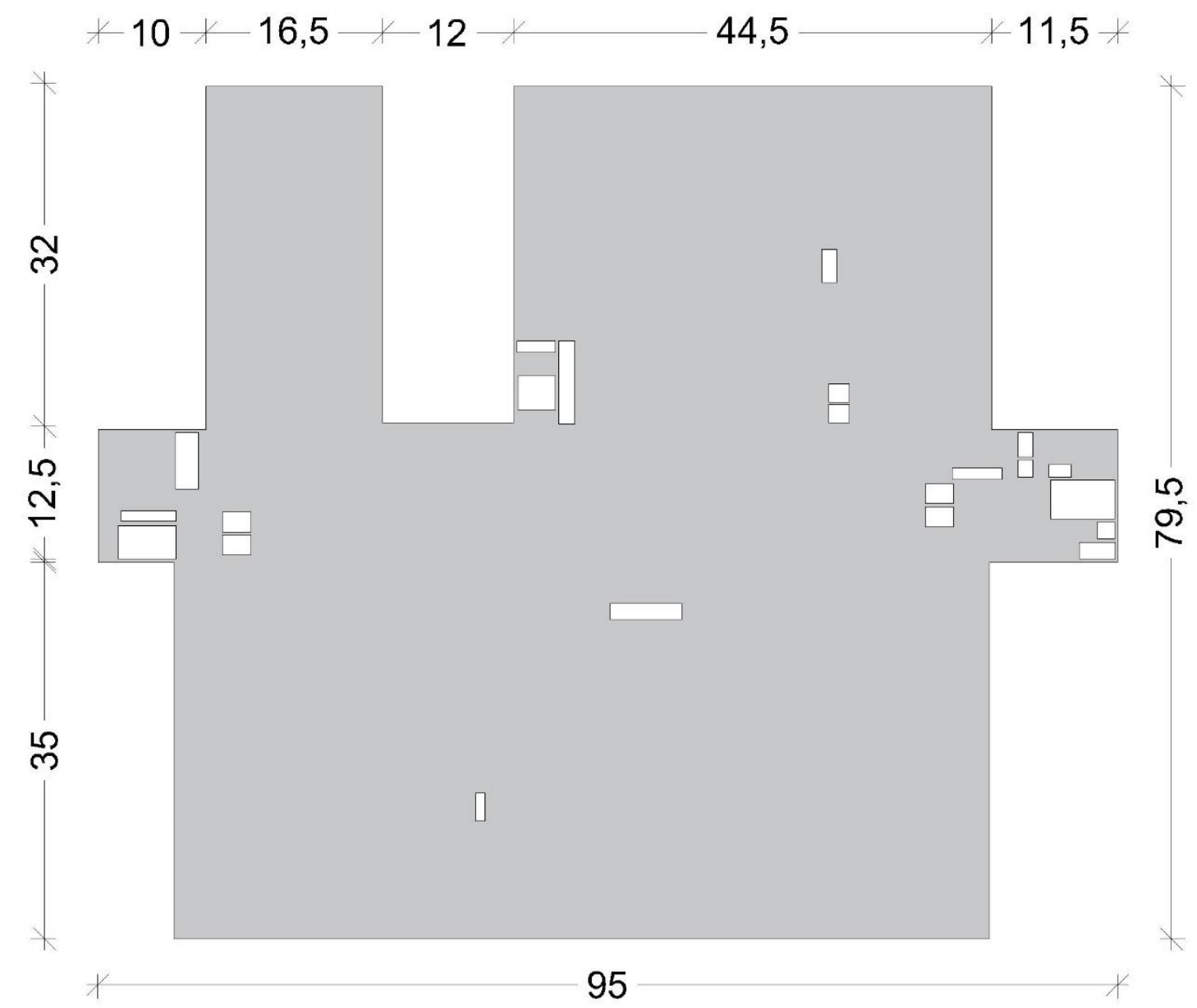


Appendix F Floor plan of first floor including all openings [m]

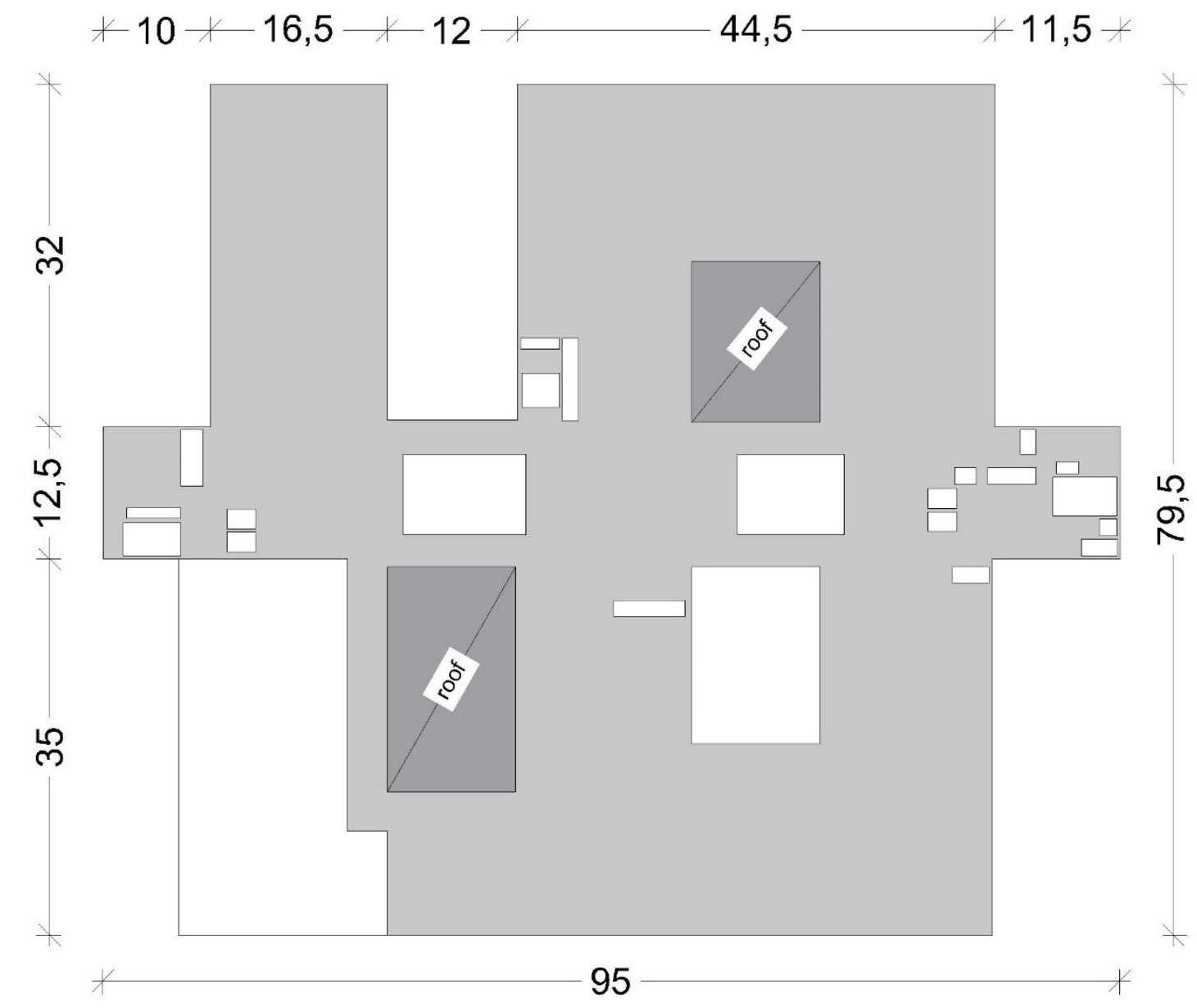


Appendix G Floor plan of second floor including all openings [m]

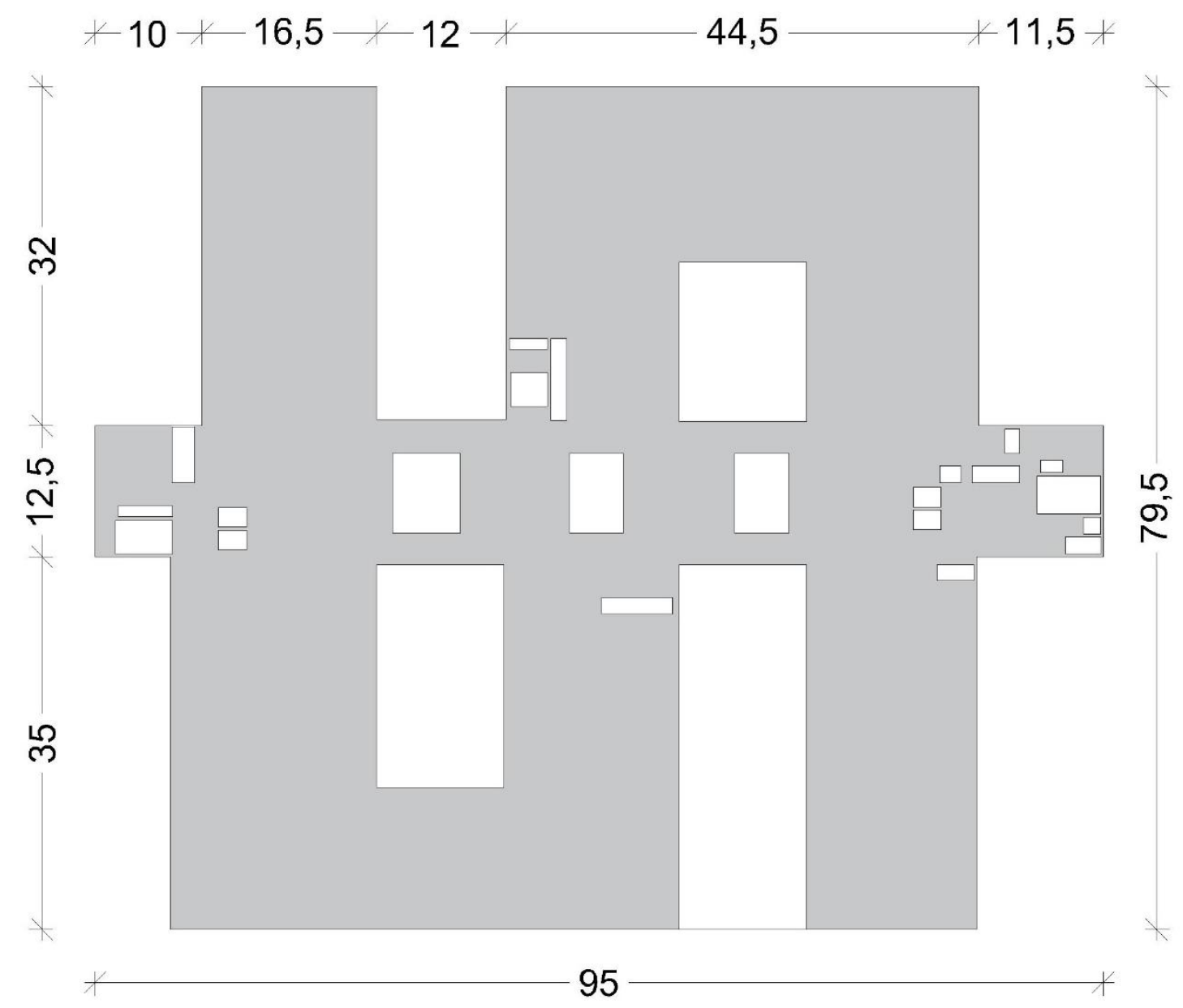


Appendix $\boldsymbol{H}$ Floor plan of third floor including all openings [m]

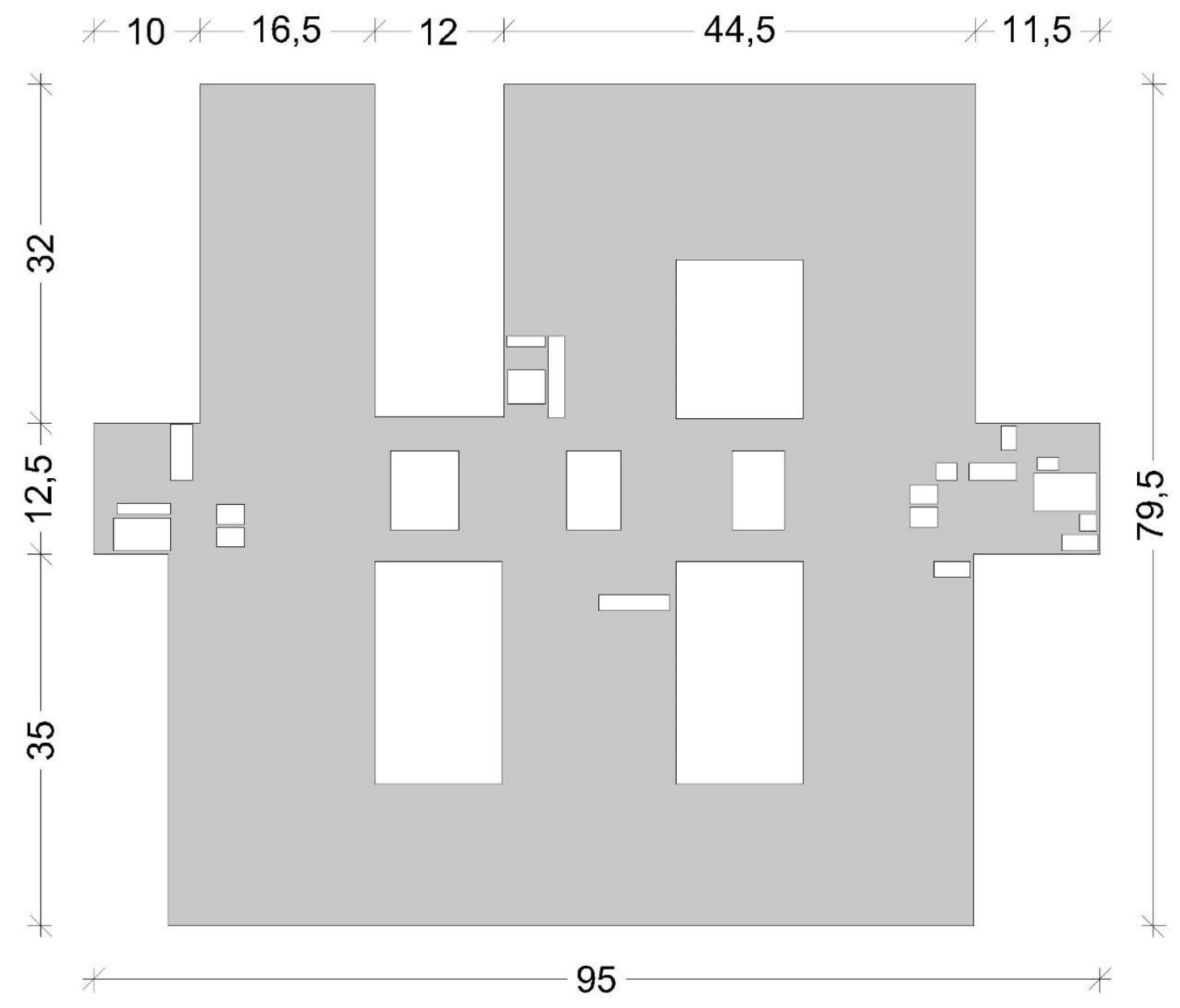


Appendix I Floor plan of rooftop including all openings [m]

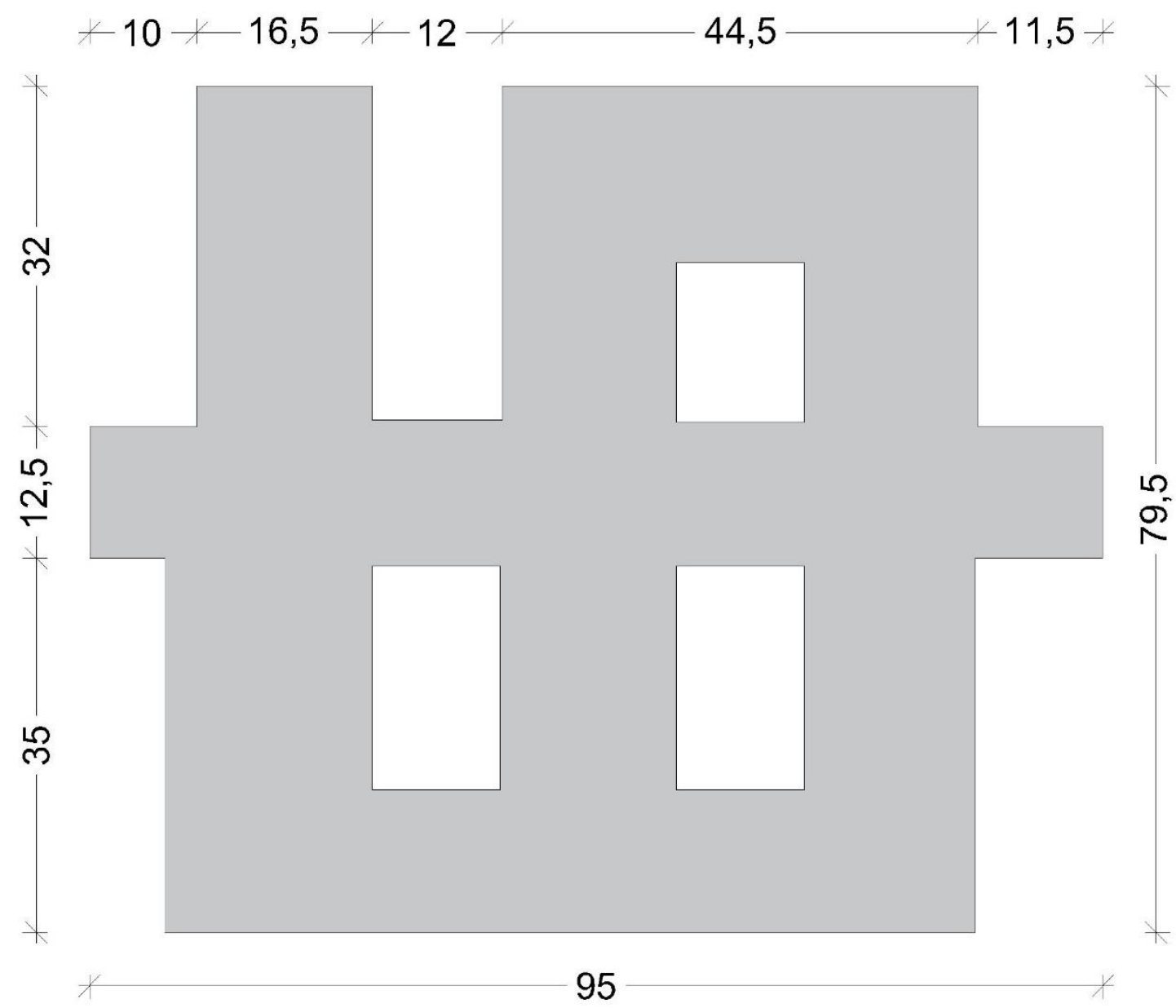


Appendix J Visualisation of all Axis and Cuts in investigated building

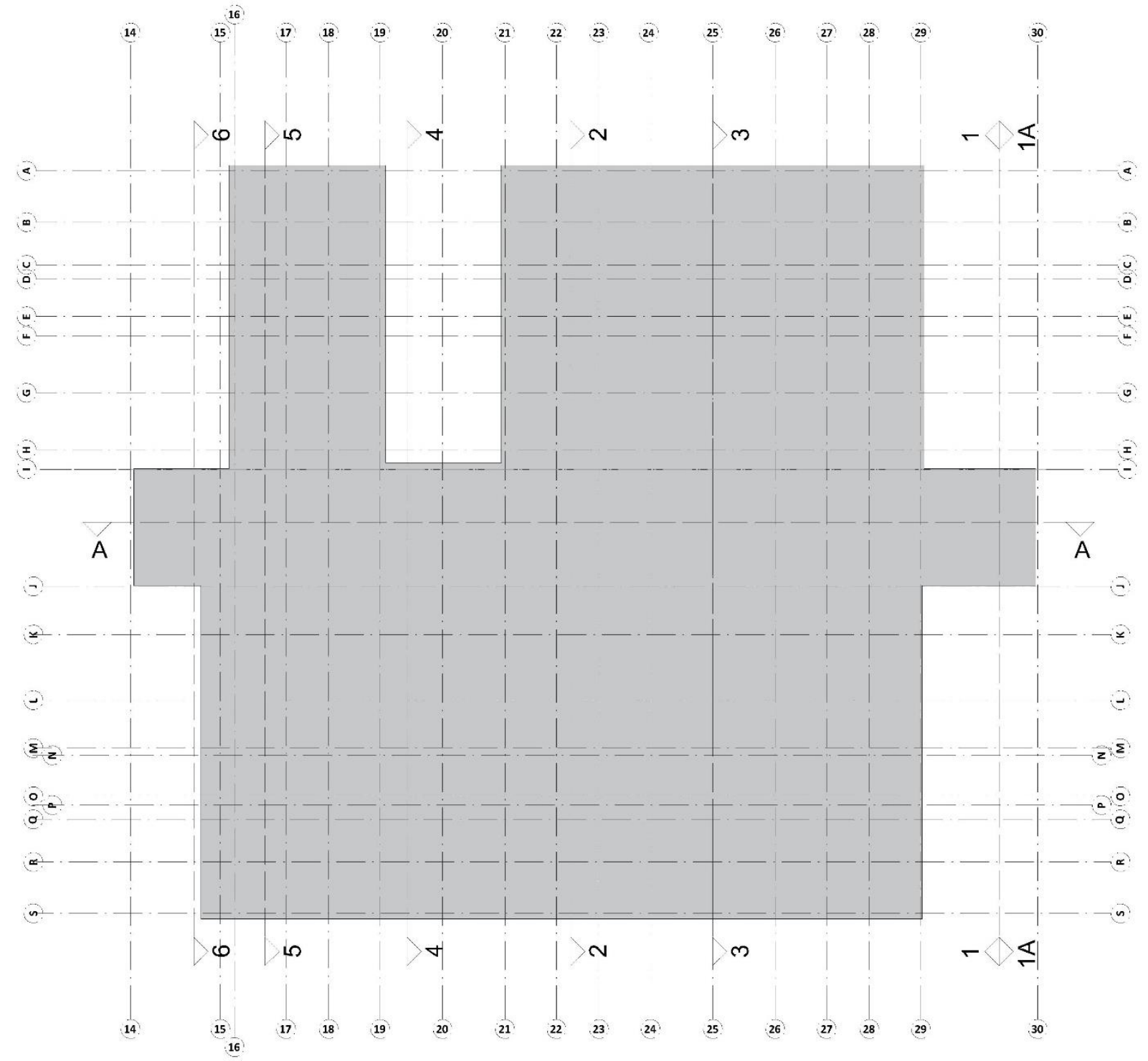


Appendix K Illustration of Cores and distribution of embracing walls

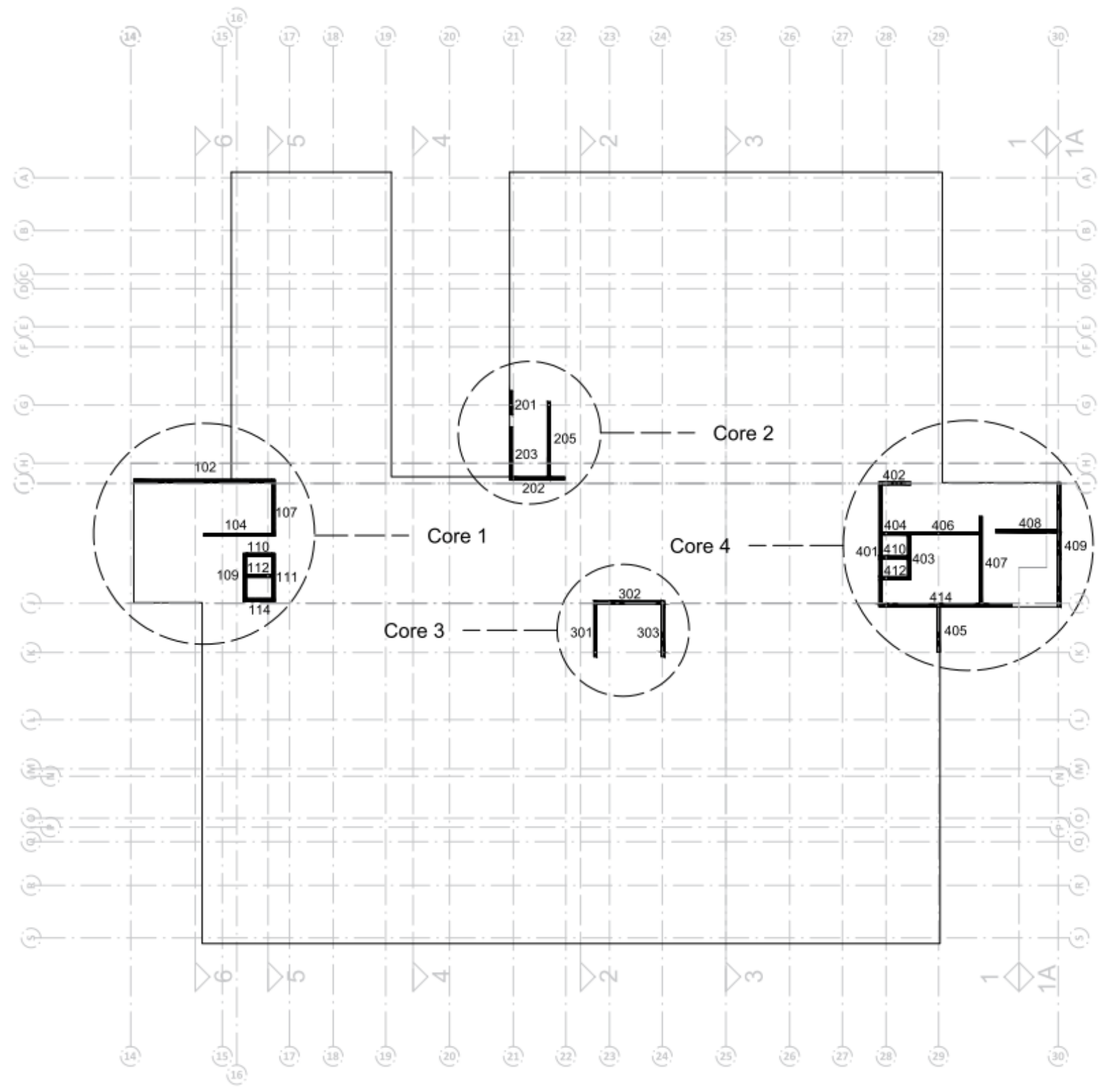


Appendix L Calculation of the replacement moment of inertia for bracing walls on ground floor

Walls in $\mathrm{X}$ direction

\begin{tabular}{r|cccccc}
\hline Wall & Width b $[\mathbf{m}]$ & Length $\mathbf{L}[\mathbf{m}]$ & Area $\mathbf{A}\left[\mathbf{m}^{\mathbf{2}}\right]$ & $\mathbf{I}\left[\mathbf{m}^{\mathbf{4}}\right]$ & $\mathbf{I}_{\mathbf{r}}\left[\mathbf{m}^{\mathbf{4}}\right]$ & $\mathbf{I}_{\mathbf{r}} \mathbf{I}$ \\
\hline $\mathbf{1 0 2}$ & 0,30 & 14,43 & 4,33 & 75,102 & 12,817 & 0,17 \\
\hline $\mathbf{1 0 4}$ & 0,30 & 7,33 & 2,20 & 9,858 & 4,371 & 0,44 \\
\hline $\mathbf{1 1 0}$ & 0,30 & 2,79 & 0,84 & 0,543 & 0,459 & 0,85 \\
\hline $\mathbf{1 1 2}$ & 0,30 & 2,64 & 0,79 & 0,460 & 0,396 & 0,86 \\
\hline $\mathbf{1 1 4}$ & 0,30 & 2,79 & 0,84 & 0,543 & 0,459 & 0,85 \\
\hline $\mathbf{2 0 2}$ & 0,30 & 6,08 & 1,82 & 5,605 & 3,011 & 0,54 \\
\hline $\mathbf{3 0 2}$ & 0,30 & 6,55 & 1,97 & 7,025 & 3,510 & 0,50 \\
\hline $\mathbf{4 0 2}$ & 0,30 & 3,97 & 1,19 & 1,564 & 1,144 & 0,73 \\
\hline $\mathbf{4 0 4}$ & 0,30 & 2,94 & 0,88 & 0,635 & 0,529 & 0,83 \\
\hline $\mathbf{4 0 6}$ & 0,30 & 7,10 & 2,13 & 8,948 & 4,111 & 0,46 \\
\hline $\mathbf{4 0 8}$ & 0,30 & 6,40 & 1,92 & 6,554 & 3,350 & 0,51 \\
\hline $\mathbf{4 1 0}$ & 0,30 & 2,64 & 0,79 & 0,460 & 0,396 & 0,86 \\
\hline $\mathbf{4 1 2}$ & 0,30 & 2,94 & 0,88 & 0,635 & 0,529 & 0,83 \\
\hline $\mathbf{4 1 4}$ & 0,30 & 12,71 & 3,81 & 51,355 & 10,762 & 0,21 \\
\hline $\mathbf{\Sigma}$ & & & $\mathbf{1 6 9 , 2 9}$ & $\mathbf{4 5 , 8 5}$ & \\
\hline
\end{tabular}

Walls in $\mathrm{Y}$ direction

\begin{tabular}{r|cccccc}
\hline Wall & Width b $[\mathbf{m}]$ & Length $\mathbf{L}[\mathbf{m}]$ & Area $\mathbf{A}\left[\mathbf{m}^{\mathbf{2}}\right]$ & $\mathbf{I}\left[\mathbf{m}^{4}\right]$ & $\mathbf{I}_{\mathbf{r}}\left[\mathbf{m}^{4}\right]$ & $\mathbf{I}_{\mathbf{r}} / \mathbf{I}$ \\
\hline $\mathbf{1 0 7}$ & 0,30 & 5,81 & 1,74 & 4,898 & 2,740 & 0,56 \\
\hline $\mathbf{1 0 9}$ & 0,30 & 4,78 & 1,44 & 2,737 & 1,784 & 0,65 \\
\hline $\mathbf{1 1 1}$ & 0,30 & 4,78 & 1,44 & 2,737 & 1,784 & 0,65 \\
\hline $\mathbf{2 0 1}$ & 0,30 & 2,45 & 0,74 & 0,368 & 0,322 & 0,88 \\
\hline $\mathbf{2 0 3}$ & 0,30 & 5,28 & 1,58 & 3,680 & 2,229 & 0,61 \\
\hline $\mathbf{2 0 5}$ & 0,30 & 6,10 & 1,83 & 5,675 & 3,037 & 0,54 \\
\hline $\mathbf{3 0 1}$ & 0,30 & 5,62 & 1,69 & 4,438 & 2,554 & 0,58 \\
\hline $\mathbf{3 0 3}$ & 0,30 & 5,62 & 1,69 & 4,438 & 2,554 & 0,58 \\
\hline $\mathbf{4 0 1}$ & 0,30 & 13,10 & 3,93 & 56,202 & 11,228 & 0,20 \\
\hline $\mathbf{4 0 3}$ & 0,30 & 4,30 & 1,29 & 1,988 & 1,388 & 0,70 \\
\hline $\mathbf{4 0 5}$ & 0,30 & 4,67 & 1,40 & 2,538 & 1,683 & 0,66 \\
\hline $\mathbf{4 0 7}$ & 0,30 & 9,00 & 2,70 & 18,225 & 6,305 & 0,35 \\
\hline $\mathbf{4 0 9}$ & 0,30 & 9,90 & 2,97 & 24,257 & 7,378 & 0,30 \\
\hline $\boldsymbol{\Sigma}$ & & & & $\mathbf{1 3 2 , 1 8}$ & $\mathbf{4 4 , 9 9}$ & \\
\hline & & & & &
\end{tabular}


Appendix M Calculation of the replacement moment of inertia for bracing walls on upper floors

Walls in $\mathrm{X}$ direction

\begin{tabular}{r|cccccc}
\hline Wall & Width b [m] & Length L [m] & Area A $\left[\mathbf{m}^{\mathbf{2}}\right]$ & $\mathbf{I}\left[\mathbf{m}^{4}\right]$ & $\mathbf{I}_{\mathbf{r}}\left[\mathbf{m}^{4}\right]$ & $\mathbf{I}_{\mathbf{r}} / \mathbf{I}$ \\
\hline $\mathbf{1 0 2}$ & 0,30 & 14,43 & 4,33 & 75,102 & 7,227 & 0,10 \\
\hline $\mathbf{1 0 4}$ & 0,30 & 7,33 & 2,20 & 9,858 & 2,878 & 0,29 \\
\hline $\mathbf{1 1 0}$ & 0,30 & 2,79 & 0,84 & 0,543 & 0,402 & 0,74 \\
\hline $\mathbf{1 1 2}$ & 0,30 & 2,64 & 0,79 & 0,460 & 0,350 & 0,76 \\
\hline $\mathbf{1 1 4}$ & 0,30 & 2,79 & 0,84 & 0,543 & 0,402 & 0,74 \\
\hline $\mathbf{2 0 2}$ & 0,30 & 6,08 & 1,82 & 5,605 & 2,103 & 0,38 \\
\hline $\mathbf{3 0 2}$ & 0,30 & 6,55 & 1,97 & 7,025 & 2,393 & 0,34 \\
\hline $\mathbf{4 0 2}$ & 0,30 & 3,97 & 1,19 & 1,564 & 0,914 & 0,58 \\
\hline $\mathbf{4 0 4}$ & 0,30 & 2,94 & 0,88 & 0,635 & 0,457 & 0,72 \\
\hline $\mathbf{4 0 6}$ & 0,30 & 7,10 & 2,13 & 8,948 & 2,733 & 0,31 \\
\hline $\mathbf{4 0 8}$ & 0,30 & 6,40 & 1,92 & 6,554 & 2,301 & 0,35 \\
\hline $\mathbf{4 1 0}$ & 0,30 & 2,64 & 0,79 & 0,460 & 0,350 & 0,76 \\
\hline $\mathbf{4 1 2}$ & 0,30 & 2,94 & 0,88 & 0,635 & 0,457 & 0,72 \\
\hline $\mathbf{4 1 4}$ & 0,30 & 12,71 & 3,81 & 51,355 & 6,195 & 0,12 \\
\hline \hline $\boldsymbol{r}$ & & & $\mathbf{1 6 9 , 2 9}$ & $\mathbf{2 9 , 1 6}$ & \\
\hline \hline
\end{tabular}

Walls in $Y$ direction

\begin{tabular}{|c|c|c|c|c|c|c|}
\hline Wall & Width b [m] & Length L [m] & Area $A\left[\mathrm{~m}^{2}\right]$ & $\mathrm{I}\left[\mathrm{m}^{4}\right]$ & $I_{r}\left[m^{4}\right]$ & $I_{r} / I$ \\
\hline 107 & 0,30 & 5,81 & 1,74 & 4,898 & 1,942 & 0,40 \\
\hline 109 & 0,30 & 4,78 & 1,44 & 2,737 & 1,347 & 0,49 \\
\hline 111 & 0,30 & 4,78 & 1,44 & 2,737 & 1,347 & 0,49 \\
\hline 201 & 0,30 & 2,45 & 0,74 & 0,368 & 0,289 & 0,79 \\
\hline 203 & 0,30 & 5,28 & 1,58 & 3,680 & 1,630 & 0,44 \\
\hline 205 & 0,30 & 6,10 & 1,83 & 5,675 & 2,118 & 0,37 \\
\hline 301 & 0,30 & 5,62 & 1,69 & 4,438 & 1,830 & 0,41 \\
\hline 303 & 0,30 & 5,62 & 1,69 & 4,438 & 1,830 & 0,41 \\
\hline 401 & 0,30 & 13,10 & 3,93 & 56,202 & 6,429 & 0,11 \\
\hline 403 & 0,30 & 4,30 & 1,29 & 1,988 & 1,084 & 0,55 \\
\hline 405 & 0,30 & 4,67 & 1,40 & 2,538 & 1,281 & 0,50 \\
\hline 407 & 0,30 & 9,00 & 2,70 & 18,225 & 3,916 & 0,21 \\
\hline 409 & 0,30 & 9,90 & 2,97 & 24,257 & 4,474 & 0,18 \\
\hline$\Sigma$ & & & & 132,18 & 29,52 & \\
\hline
\end{tabular}


Appendix N Distribution of a horizontal force on bracing elements on ground floor

\begin{tabular}{|c|c|c|c|c|c|}
\hline \multicolumn{3}{|c|}{ Walls in $\mathrm{X}$ direction } & \multicolumn{3}{|c|}{ Walls in $Y$ direction } \\
\hline Bracing element & $\mathrm{I}_{\mathrm{e}}\left[\mathrm{m}^{4}\right]$ & $\mathrm{I}_{e} / \mathrm{I}_{\mathrm{t}}[\%]$ & Bracing element & $\mathrm{I}_{\mathrm{e}}\left[\mathrm{m}^{4}\right]$ & $\mathrm{I}_{\mathrm{e}} / \mathrm{I}_{\mathrm{t}}[\%$ \\
\hline 102 & 12,82 & 27,07 & 107 & 2,74 & 5,88 \\
\hline 104 & 4,37 & 9,23 & 109 & 1,78 & 3,83 \\
\hline 110 & 0,46 & 0,97 & 111 & 1,78 & 3,83 \\
\hline 112 & 0,40 & 0,84 & 201 & 0,32 & 0,69 \\
\hline 114 & 0,46 & 0,97 & 203 & 2,23 & 4,79 \\
\hline 202 & 3,01 & 6,36 & 205 & 3,04 & 6,52 \\
\hline 302 & 3,51 & 7,41 & 301 & 2,55 & 5,49 \\
\hline 402 & 1,14 & 2,42 & 303 & 2,55 & 5,49 \\
\hline 404 & 0,53 & 1,12 & 401 & 11,23 & 24,11 \\
\hline 406 & 4,11 & 8,68 & 403 & 1,39 & 2,98 \\
\hline 408 & 3,35 & 7,08 & 405 & 1,68 & 3,61 \\
\hline 410 & 0,40 & 0,84 & 407 & 6,30 & 13,54 \\
\hline 412 & 0,53 & 1,12 & 409 & 7,38 & 15,84 \\
\hline 414 & 10,76 & 22,73 & - & - & - \\
\hline Pillars & 1,50 & 3,17 & Pillars & 1,58 & 3,39 \\
\hline Total & 47,34 & 100,00 & Total & 46,57 & 100,00 \\
\hline
\end{tabular}

Appendix $\mathrm{O}$ Distribution of a horizontal force on bracing elements on first floor

\begin{tabular}{|c|c|c|c|c|c|}
\hline \multicolumn{3}{|c|}{ Walls in $\mathrm{X}$ direction } & \multicolumn{3}{|c|}{ Walls in $Y$ direction } \\
\hline Bracing element & $\mathrm{I}_{\mathrm{e}}\left[\mathrm{m}^{4}\right]$ & $\mathrm{I}_{e} / \mathrm{I}_{\mathrm{t}}[\%]$ & Bracing element & $\mathrm{I}_{\mathrm{e}}\left[\mathrm{m}^{4}\right]$ & $\mathrm{I}_{\mathrm{e}} / \mathrm{I}_{\mathrm{t}}[\%]$ \\
\hline 102 & 7,23 & 23,84 & 107 & 1,94 & 6,19 \\
\hline 104 & 2,88 & 9,49 & 109 & 1,35 & 4,29 \\
\hline 110 & 0,40 & 1,33 & 111 & 1,35 & 4,29 \\
\hline 112 & 0,35 & 1,15 & 201 & 0,29 & 0,92 \\
\hline 114 & 0,40 & 1,33 & 203 & 1,63 & 5,19 \\
\hline 202 & 2,10 & 6,94 & 205 & 2,12 & 6,75 \\
\hline 302 & 2,39 & 7,90 & 301 & 1,83 & 5,83 \\
\hline 402 & 0,91 & 3,02 & 303 & 1,83 & 5,83 \\
\hline 404 & 0,46 & 1,51 & 401 & 6,43 & 20,48 \\
\hline 406 & 2,73 & 9,02 & 403 & 1,08 & 3,45 \\
\hline 408 & 2,30 & 7,59 & 405 & 1,28 & 4,08 \\
\hline 410 & 0,35 & 1,15 & 407 & 3,92 & 12,48 \\
\hline 412 & 0,46 & 1,51 & 409 & 4,49 & 14,26 \\
\hline 414 & 6,19 & 20,44 & - & - & - \\
\hline Pillars & 1,15 & 3,79 & Pillars & 1,87 & 5,96 \\
\hline Total & 30,31 & 100,00 & Total & 31,39 & 100,00 \\
\hline
\end{tabular}


Appendix P Distribution of a horizontal force on bracing elements on second floor

\begin{tabular}{r|cc|r|rc}
\multicolumn{3}{c|}{ Walls in X direction } & \multicolumn{3}{c}{ Walls in $Y$ direction } \\
Bracing element & $I_{\mathrm{e}}\left[\mathbf{m}^{4}\right]$ & $\mathrm{I}_{\mathrm{e}} / \mathrm{I}_{\mathrm{t}}[\%]$ & Bracing element & $\mathrm{l}_{\mathrm{e}}\left[\mathbf{m}^{4}\right]$ & $\mathrm{I}_{\mathrm{e}} / \mathrm{I}_{\mathrm{t}}[\%]$ \\
\hline $\mathbf{1 0 2}$ & 7,23 & $\mathbf{2 3 , 7 6}$ & $\mathbf{1 0 7}$ & 1,94 & 6,18 \\
\hline $\mathbf{1 0 4}$ & 2,88 & 9,46 & $\mathbf{1 0 9}$ & 1,35 & 4,28 \\
\hline $\mathbf{1 1 0}$ & 0,40 & 1,32 & $\mathbf{1 1 1}$ & 1,35 & 4,28 \\
\hline $\mathbf{1 1 2}$ & 0,35 & 1,15 & $\mathbf{2 0 1}$ & 0,29 & 0,92 \\
\hline $\mathbf{1 1 4}$ & 0,40 & 1,32 & $\mathbf{2 0 3}$ & 1,63 & 5,18 \\
\hline $\mathbf{2 0 2}$ & 2,10 & 6,91 & $\mathbf{2 0 5}$ & 2,12 & 6,74 \\
\hline $\mathbf{3 0 2}$ & 2,39 & 7,87 & $\mathbf{3 0 1}$ & 1,83 & 5,82 \\
\hline $\mathbf{4 0 2}$ & 0,91 & 3,01 & $\mathbf{3 0 3}$ & 1,83 & 5,82 \\
\hline $\mathbf{4 0 4}$ & 0,46 & 1,50 & $\mathbf{4 0 1}$ & 6,43 & 20,45 \\
\hline $\mathbf{4 0 6}$ & 2,73 & 8,98 & $\mathbf{4 0 3}$ & 1,08 & 3,45 \\
\hline $\mathbf{4 0 8}$ & 2,30 & 7,56 & $\mathbf{4 0 5}$ & 1,28 & 4,07 \\
\hline $\mathbf{4 1 0}$ & 0,35 & 1,15 & $\mathbf{4 0 7}$ & 3,92 & 12,46 \\
\hline $\mathbf{4 1 2}$ & 0,46 & 1,50 & $\mathbf{4 0 9}$ & 4,49 & 14,23 \\
\hline $\mathbf{4 1 4}$ & 6,19 & $\mathbf{2 0 , 3 6}$ & - & - & - \\
\hline Pillars & 1,26 & 4,14 & Pillars & 1,92 & 6,11 \\
\hline Total & $\mathbf{3 0 , 4 2}$ & $\mathbf{1 0 0 , 0 0}$ & Total & $\mathbf{3 1 , 4 4}$ & $\mathbf{1 0 0 , 0 0}$ \\
\hline & & & & & \\
\hline \hline
\end{tabular}

Appendix Q Distribution of a horizontal force on bracing elements on third floor

\begin{tabular}{|c|c|c|c|c|c|}
\hline \multicolumn{3}{|c|}{ Walls in $\mathrm{X}$ direction } & \multicolumn{3}{|c|}{ Walls in $\mathrm{Y}$ direction } \\
\hline Bracing element & $\mathrm{I}_{\mathrm{e}}\left[\mathrm{m}^{4}\right]$ & $\mathrm{I}_{\mathrm{e}} / \mathrm{I}_{\mathrm{t}}[\%]$ & Bracing element & $\mathrm{I}_{\mathrm{e}}\left[\mathrm{m}^{4}\right]$ & $\mathrm{I}_{\mathrm{e}} / \mathrm{I}_{\mathrm{t}}[\%]$ \\
\hline 102 & 7,23 & 23,63 & 107 & 1,94 & 6,20 \\
\hline 104 & 2,88 & 9,41 & 109 & 1,35 & 4,30 \\
\hline 110 & 0,40 & 1,31 & 111 & 1,35 & 4,30 \\
\hline 112 & 0,35 & 1,14 & 201 & 0,29 & 0,92 \\
\hline 114 & 0,40 & 1,31 & 203 & 1,63 & 5,21 \\
\hline 202 & 2,10 & 6,88 & 205 & 2,12 & 6,77 \\
\hline 302 & 2,39 & 7,83 & 301 & 1,83 & 5,85 \\
\hline 402 & 0,91 & 2,99 & 303 & 1,83 & 5,85 \\
\hline 404 & 0,46 & 1,49 & 401 & 6,43 & 20,54 \\
\hline 406 & 2,73 & 8,94 & 403 & 1,08 & 3,46 \\
\hline 408 & 2,30 & 7,53 & 405 & 1,28 & 4,09 \\
\hline 410 & 0,35 & 1,14 & 407 & 3,92 & 12,51 \\
\hline 412 & 0,46 & 1,49 & 409 & 4,49 & 14,29 \\
\hline 414 & 6,19 & 20,26 & - & - & - \\
\hline Pillars & 1,42 & 4,64 & Pillars & 1,79 & 5,72 \\
\hline Total & 30,58 & 100,00 & Total & 31,31 & 100,00 \\
\hline
\end{tabular}


Appendix $\boldsymbol{R}$ Values of the elastic design response spectrum of figure 7

\begin{tabular}{|c|c|c|}
\hline $\begin{array}{l}\text { Control } \\
\text { Section }\end{array}$ & $\begin{array}{c}\text { Period T } \\
\text { [s] }\end{array}$ & $\begin{array}{c}\text { Spectral acceleration } \\
{\left[\mathrm{m} / \mathrm{s}^{2}\right]}\end{array}$ \\
\hline$T_{0}$ & 0,00 & 0,635 \\
\hline $\mathbf{T}_{\mathrm{A}}$ & 0,01 & 0,635 \\
\hline$T_{B}$ & 0,10 & 1,587 \\
\hline$T_{C}$ & 0,50 & 1,587 \\
\hline- & 0,60 & 1,323 \\
\hline- & 0,70 & 1,134 \\
\hline- & 0,80 & 0,992 \\
\hline - & 0,90 & 0,882 \\
\hline - & 1,00 & 0,794 \\
\hline- & 1,10 & 0,721 \\
\hline- & 1,20 & 0,661 \\
\hline- & 1,30 & 0,610 \\
\hline- & 1,40 & 0,567 \\
\hline- & 1,50 & 0,529 \\
\hline- & 1,60 & 0,496 \\
\hline- & 1,70 & 0,467 \\
\hline- & 1,80 & 0,441 \\
\hline- & 1,90 & 0,418 \\
\hline$T_{D}$ & 2,00 & 0,397 \\
\hline- & 2,10 & 0,360 \\
\hline- & 2,20 & 0,328 \\
\hline - & 2,30 & 0,300 \\
\hline - & 2,40 & 0,276 \\
\hline- & 2,50 & 0,254 \\
\hline - & 2,60 & 0,235 \\
\hline- & 2,70 & 0,218 \\
\hline - & 2,80 & 0,202 \\
\hline- & 2,90 & 0,189 \\
\hline- & 3,00 & 0,176 \\
\hline - & 3,10 & 0,165 \\
\hline - & 3,20 & 0,155 \\
\hline - & 3,30 & 0,146 \\
\hline - & 3,40 & 0,137 \\
\hline- & 3,50 & 0,130 \\
\hline - & 3,60 & 0,122 \\
\hline
\end{tabular}

Control Period T Spectral acceleration Section

[s] $\quad\left[\mathrm{m} / \mathrm{s}^{2}\right]$

\begin{tabular}{|c|c|c|}
\hline- & 3,70 & 0,116 \\
\hline- & 3,80 & 0,110 \\
\hline - & 3,90 & 0,104 \\
\hline- & 4,00 & 0,099 \\
\hline - & 4,10 & 0,094 \\
\hline- & 4,20 & 0,090 \\
\hline - & 4,30 & 0,086 \\
\hline- & 4,40 & 0,082 \\
\hline - & 4,50 & 0,078 \\
\hline - & 4,60 & 0,075 \\
\hline - & 4,70 & 0,072 \\
\hline- & 4,80 & 0,069 \\
\hline- & 4,90 & 0,066 \\
\hline- & 5,00 & 0,063 \\
\hline- & 5,10 & 0,061 \\
\hline- & 5,20 & 0,059 \\
\hline - & 5,30 & 0,056 \\
\hline- & 5,40 & 0,054 \\
\hline - & 5,50 & 0,052 \\
\hline - & 5,60 & 0,051 \\
\hline- & 5,70 & 0,049 \\
\hline- & 5,80 & 0,047 \\
\hline - & 5,90 & 0,046 \\
\hline- & 6,00 & 0,044 \\
\hline - & 6,10 & 0,043 \\
\hline - & 6,20 & 0,041 \\
\hline - & 6,30 & 0,040 \\
\hline - & 6,40 & 0,039 \\
\hline- & 6,50 & 0,038 \\
\hline - & 6,60 & 0,036 \\
\hline- & 6,70 & 0,035 \\
\hline - & 6,80 & 0,034 \\
\hline - & 6,90 & 0,033 \\
\hline - & 7,00 & 0,032 \\
\hline
\end{tabular}


Appendix S Shear force distribution along each bracing wall for combination $100 \% X$ and $30 \% Y$

Shear force distribution according to $E_{E d x}$ "+" 0,30 $E_{E d y}$

\begin{tabular}{|c|c|c|c|c|c|c|c|c|c|}
\hline \multirow{2}{*}{$\begin{array}{r}\text { Bracing } \\
\text { element }\end{array}$} & \multicolumn{4}{|c|}{ Walls in $\mathrm{X}$ direction: $\mathrm{V}$ [kN] } & \multirow{2}{*}{$\begin{array}{r}\text { Bracing } \\
\text { element }\end{array}$} & \multicolumn{4}{|c|}{ Walls in $\mathrm{Y}$ direction: $\mathrm{V}$ [kN] } \\
\hline & Floor 0 & Floor 1 & Floor 2 & Floor 3 & & Floor 0 & Floor 1 & Floor 2 & Floor 3 \\
\hline 102 & 7.901 & 7.247 & 6.032 & 3.744 & 107 & 1.343 & 902 & 596 & 336 \\
\hline 104 & 2.418 & 1.943 & 1.278 & 546 & 109 & 892 & 601 & 354 & 216 \\
\hline 110 & 269 & 153 & 67 & 42 & 111 & 823 & 553 & 322 & 219 \\
\hline 112 & 232 & 168 & 75 & 41 & 201 & 257 & 78 & 78 & 50 \\
\hline 114 & 270 & 181 & 88 & 52 & 203 & 1.006 & 613 & 367 & 203 \\
\hline 202 & 1.797 & 1.185 & 790 & 450 & 205 & 978 & 707 & 495 & 422 \\
\hline 302 & 2.407 & 1.897 & 1.342 & 697 & 301 & 1.183 & 716 & 371 & 192 \\
\hline 402 & 836 & 396 & 289 & 67 & 303 & 1.117 & 726 & 333 & 214 \\
\hline 404 & 353 & 149 & 125 & 32 & 401 & 3.676 & 3.386 & 2.854 & 2.032 \\
\hline 406 & 2.375 & 1.847 & 1.281 & 557 & 403 & 453 & 275 & 189 & 86 \\
\hline 408 & 1.883 & 1.415 & 948 & 391 & 405 & 743 & 521 & 424 & 125 \\
\hline 410 & 263 & 98 & 82 & 29 & 407 & 1.800 & 1.479 & 1.102 & 496 \\
\hline 412 & 369 & 105 & 99 & 46 & 409 & 1.769 & 1.580 & 1.258 & 727 \\
\hline 414 & 7.189 & 6.717 & 5.772 & 3.525 & - & - & - & - & - \\
\hline
\end{tabular}

Appendix T Shear force distribution along each bracing wall for combination $30 \% X$ and $100 \% Y$

Shear force distribution according to $0,30 E_{E d x} "+" E_{\text {edy }}$

\begin{tabular}{r|cccc|r|cccc} 
Bracing & \multicolumn{6}{|c}{ Walls in X direction: V [kN] } & Bracing & \multicolumn{3}{c}{ Walls in Y direction: V [kN] } \\
element & Floor $\mathbf{0}$ & Floor 1 & Floor 2 & Floor 3 & element & Floor 0 & Floor 1 & Floor 2 & Floor 3 \\
\hline $\mathbf{1 0 2}$ & 4.811 & 4.289 & 3.460 & 2.061 & $\mathbf{1 0 7}$ & 2.730 & 1.931 & 1.171 & 574 \\
\hline $\mathbf{1 0 4}$ & 1.297 & 1.023 & 681 & 273 & $\mathbf{1 0 9}$ & 1.796 & 1.270 & 643 & 322 \\
\hline $\mathbf{1 1 0}$ & 143 & 86 & 34 & 22 & $\mathbf{1 1 1}$ & 1.676 & 1.200 & 618 & 312 \\
\hline $\mathbf{1 1 2}$ & 133 & 103 & 39 & 25 & $\mathbf{2 0 1}$ & 306 & 193 & 103 & 49 \\
\hline $\mathbf{1 1 4}$ & 190 & 179 & 48 & 45 & $\mathbf{2 0 3}$ & 1.515 & 998 & 617 & 297 \\
\hline $\mathbf{2 0 2}$ & 1.024 & 666 & 428 & 254 & $\mathbf{2 0 5}$ & 1.614 & 1.212 & 871 & 594 \\
\hline $\mathbf{3 0 2}$ & 1.375 & 1.113 & 744 & 429 & $\mathbf{3 0 1}$ & 1.704 & 924 & 644 & 350 \\
\hline $\mathbf{4 0 2}$ & 467 & 208 & 163 & 68 & $\mathbf{3 0 3}$ & 1.472 & 887 & 579 & 342 \\
\hline $\mathbf{4 0 4}$ & 185 & 77 & 63 & 39 & $\mathbf{4 0 1}$ & 5.374 & 4.793 & 3.950 & 2.707 \\
\hline $\mathbf{4 0 6}$ & 1.234 & 947 & 650 & 299 & $\mathbf{4 0 3}$ & 701 & 368 & 223 & 132 \\
\hline $\mathbf{4 0 8}$ & 975 & 724 & 478 & 205 & $\mathbf{4 0 5}$ & 997 & 689 & 506 & 152 \\
\hline $\mathbf{4 1 0}$ & 140 & 53 & 39 & 13 & $\mathbf{4 0 7}$ & 2.778 & 2.245 & 1.615 & 716 \\
\hline $\mathbf{4 1 2}$ & 202 & 63 & 49 & 24 & $\mathbf{4 0 9}$ & 2.910 & 2.610 & 2.053 & 1.154 \\
\hline $\mathbf{4 1 4}$ & 4.163 & 3.861 & 3.298 & 1.996 & & - & - & - & - \\
\hline & & & & & & & & & \\
\hline
\end{tabular}


Appendix U Moment distribution along each bracing wall for combination $100 \% X$ and $30 \% Y$

\begin{tabular}{|c|c|c|c|c|c|c|c|c|c|}
\hline \multicolumn{10}{|c|}{ Moment distribution according to $E_{E d x} "+" 0,30 E_{E d y}$} \\
\hline \multirow{2}{*}{$\begin{array}{r}\text { Bracing } \\
\text { element }\end{array}$} & \multicolumn{4}{|c|}{ Walls in $\mathrm{X}$ direction: $\mathrm{M}$ [kNm] } & \multirow{2}{*}{$\begin{array}{r}\text { Bracing } \\
\text { element }\end{array}$} & \multicolumn{4}{|c|}{ Walls in $\mathrm{Y}$ direction: $\mathrm{M}$ [kNm] } \\
\hline & Floor 0 & Floor 1 & Floor 2 & Floor 3 & & Floor 0 & Floor 1 & Floor 2 & Floor 3 \\
\hline 102 & 114.293 & 69.375 & 39.691 & 15124 & 107 & 13.623 & 6.900 & 3.550 & 1.300 \\
\hline 104 & 28.384 & 14.872 & 7.129 & 2106 & 109 & 8.500 & 3.928 & 2.116 & 807 \\
\hline 110 & 2.275 & 821 & 300 & 109 & 111 & 8.047 & 3.937 & 2.027 & 825 \\
\hline 112 & 2.007 & 799 & 276 & 123 & 201 & 1.481 & 507 & 252 & 215 \\
\hline 114 & 2.425 & 1.093 & 376 & 193 & 203 & 9.342 & 4.348 & 2.134 & 785 \\
\hline 202 & 19.018 & 9.289 & 4.683 & 1727 & 205 & 11.556 & 6.346 & 3.592 & 1.647 \\
\hline 302 & 24.961 & 11.825 & 4.824 & 1082 & 301 & 10.331 & 4.419 & 2.097 & 787 \\
\hline 402 & 6.820 & 2.551 & 1.085 & 247 & 303 & 9.992 & 4.313 & 2.091 & 834 \\
\hline 404 & 2.818 & 9.37 & 389 & 163 & 401 & 54.334 & 33.642 & 19.856 & 8.232 \\
\hline 406 & 27.731 & 14.556 & 7.188 & 2131 & 403 & 3.877 & 1.510 & 476 & 403 \\
\hline 408 & 21.218 & 10.773 & 5.161 & 1459 & 405 & 5.603 & 2.037 & 1.032 & 574 \\
\hline 410 & 2.050 & 645 & 284 & 64 & 407 & 22.271 & 12.339 & 6.380 & 1.959 \\
\hline 412 & 2.796 & 808 & 433 & 107 & 409 & 24.462 & 14.470 & 8.040 & 2.926 \\
\hline 414 & 10.5813 & 65.116 & 37.717 & 14235 & - & - & - & - & - \\
\hline
\end{tabular}

Appendix V Moment distribution along each bracing wall for combination $30 \% X$ and $100 \% Y$

\begin{tabular}{|c|c|c|c|c|c|c|c|c|c|}
\hline \multicolumn{10}{|c|}{ Moment distribution according to $0,30 E_{E d x}$ "+" $E_{e d y}$} \\
\hline \multirow{2}{*}{$\begin{array}{r}\text { Bracing } \\
\text { element }\end{array}$} & \multicolumn{4}{|c|}{ Walls in $\mathrm{X}$ direction: $\mathrm{M}[\mathrm{kNm}]$} & \multirow{2}{*}{$\begin{array}{r}\text { Bracing } \\
\text { element }\end{array}$} & \multicolumn{4}{|c|}{ Walls in $Y$ direction: $M$ [kNm] } \\
\hline & Floor 0 & Floor 1 & Floor 2 & Floor 3 & & Floor 0 & Floor 1 & Floor 2 & Floor 3 \\
\hline 102 & 67.451 & 40.186 & 22.634 & 8.458 & 107 & 29.230 & 14.310 & 6.817 & 2.279 \\
\hline 104 & 15.106 & 7.916 & 3.855 & 1.122 & 109 & 18.300 & 8.438 & 3.667 & 1.214 \\
\hline 110 & 1.213 & 462 & 191 & 83 & 111 & 17.371 & 8.175 & 3.574 & 1.188 \\
\hline 112 & 1.112 & 479 & 190 & 100 & 201 & 2.119 & 673 & 398 & 187 \\
\hline 114 & 1.465 & 711 & 277 & 170 & 203 & 15.459 & 7.381 & 3.563 & 1.188 \\
\hline 202 & 10.580 & 5.130 & 2.588 & 1.042 & 205 & 19.586 & 10.725 & 5.910 & 2.392 \\
\hline 302 & 14.387 & 6.902 & 2.905 & 816 & 301 & 16.093 & 7.242 & 3.904 & 1.416 \\
\hline 402 & 3.685 & 1.395 & 656 & 276 & 303 & 14.126 & 6.539 & 3.537 & 1.335 \\
\hline 404 & 1.458 & 489 & 226 & 166 & 401 & 77.052 & 46.981 & 27.412 & 11.182 \\
\hline 406 & 14.346 & 7.548 & 3.787 & 1.223 & 403 & 5.643 & 2.080 & 736 & 547 \\
\hline 408 & 10.953 & 5.577 & 2.716 & 839 & 405 & 7.662 & 2.887 & 1.382 & 678 \\
\hline 410 & 1.085 & 347 & 155 & 52 & 407 & 33.948 & 18.628 & 9.556 & 2.993 \\
\hline 412 & 1.528 & 447 & 250 & 82 & 409 & 40.550 & 24.078 & 13.298 & 4.823 \\
\hline 414 & 60.997 & 37.461 & 21.691 & 8.191 & - & - & - & - & - \\
\hline
\end{tabular}




\section{REFERENCES}

[1]. ALFRED STEINLE, HUBERT BACHMANN, MATHIAS TILLMANN (2016): Beton Kalender 2016, Bauen mit Betonfertigteilen im Hochbau. Wilhelm Ernst \& Sohn. 10772 Berlin.

[2]. BEUTH VERLAG GmbH (2019): Eurocode 8: Erdbeben. 10772 Berlin. Retrieved May 13, 2019 from: https://www.eurocode-online.de/de/eurocode-inhalte/eurocode-8

[3]. E DIN EN 1998-1/NA:2018-10, Nationaler Anhang - National festgelegte Parameter - Eurocode 8: Auslegung von Bauwerken gegen Erdbeben - Teil 1: Grundlagen, Erdbebeneinwirkungen und Regeln für Hochbau

[4]. GFZ HELMHOLTZ ZENTRUM POTSDAM (2018): Online Tool Spektralklassenkarte. 14467 Potsdam. Retrieved May 15, 2019 from: http://www-app5.gfz-potsdam.de/d-eqhaz16/index.html

[5]. F.P.MUELLER, E.KEINTZEL (1978): Erdbebensicherung von Hochbauten. Wilhelm Ernst \& Sohn. Berlin, München, Düsseldorf

[6]. BEUTH VERLAG GmbH (2019): Entstehung und Geschichte. 10772 Berlin. Retrieved July 25, 2019 from: https://www.eurocode-online.de/de/eurocode-informationen/entstehung-und-geschichte 